\title{
Substrate Nanotopography and Stiffness Modulation of Cell Behaviors for Disease Detection and Modeling
}

Lin Shi

Follow this and additional works at: https://researchrepository.wvu.edu/etd

\section{Recommended Citation}

Shi, Lin, "Substrate Nanotopography and Stiffness Modulation of Cell Behaviors for Disease Detection and Modeling" (2017). Graduate Theses, Dissertations, and Problem Reports. 6632.

https://researchrepository.wvu.edu/etd/6632

This Dissertation is protected by copyright and/or related rights. It has been brought to you by the The Research Repository @ WVU with permission from the rights-holder(s). You are free to use this Dissertation in any way that is permitted by the copyright and related rights legislation that applies to your use. For other uses you must obtain permission from the rights-holder(s) directly, unless additional rights are indicated by a Creative Commons license in the record and/ or on the work itself. This Dissertation has been accepted for inclusion in WVU Graduate Theses, Dissertations, and Problem Reports collection by an authorized administrator of The Research Repository @ WVU.

For more information, please contact researchrepository@mail.wvu.edu. 


\title{
Substrate Nanotopography and Stiffness Modulation of Cell Behaviors for Disease Detection and Modeling
}

\author{
Lin Shi \\ Dissertation submitted to the \\ Benjamin M. Statler College of Engineering and Mineral Resources \\ at West Virginia University
}

in partial fulfillment of the requirements for the degree of

Doctor of Philosophy in

the Chemical and Biomedical Engineering Department

Yong Yang, Ph.D., Committee Chairperson

Charter Stinespring, Ph.D.

Robin Hissam, Ph.D.

Karen Martin, Ph.D.

Yuxin Liu, Ph.D.

Department of Chemical and Biomedical Engineering

Morgantown, West Virginia

2017

Keywords: Stiffness, Nanotopography, Circulating tumor cells, Carbon nanotubes, Lung fibrosis

Copyright 2017 Lin Shi 


\section{ABSTRACT \\ Substrate Nanotopography and Stiffness Modulation of Cell Behaviors for Disease Detection and Modeling}

\section{Lin Shi}

In most living tissue, cells resident in a complex microenvironment where these cells interact with the extracellular matrix (ECM) and the neighboring cells. The interactions between cells and ECM could regulate the cell behavior. Similar to in vivo, in vitro models have been reported that cells have the ability to sense the nanotopography and stiffness of synthetic substrate and, the variation of substrate nanotopography configuration and stiffness could affect cell phenotype and function.

The first project focused on applying nanotopography to capture circulating tumor cells (CTCs) for early cancer detection. CTCs shed from primary tumors, transport through the bloodstream to distant sites, and cause $90 \%$ of cancer deaths. Although different techniques have been developed to isolate CTCs for cancer detection, diagnosis and treatment, the heterogeneity of expression of the target antigen and the significant size variance in CTCs limit clinical applications of antibody- and size-based isolation techniques. Cell adhesion using nanotopography has been suggested as a promising approach to isolate CTCs independent of surface marker expression or size of CTCs. However, the influence of nanotopography configuration (geometry and dimensions) on CTC capture efficiency has not been investigated. This study examined capture performance of several cancer cell lines of different types, surface marker expression and 
metastatic status on nanotopographies of various geometry and dimensions without antibody conjugation. Compared with flat surfaces and isotropic, discrete nanopillars, anisotropic nanogratings favored cancer cell adhesion, thus improving the capture efficiency. This study provides useful information to optimize nanotopography to further enhance CTC capture efficiency.

The second project focused on understanding the effects of substrate stiffness on fibrogenic responses of human lung fibroblasts to engineered nanomaterials. Most existing in vitro models focused on conducting the experiment using the rigid tissue culture polystyrene (TCPS) surfaces, which were much stiffer than the actual in vivo cell microenvironment. Thus, the behavior and nanomaterial responsiveness of cells could be largely changed due to the deviation of substrate stiffness when cultured on TCPS. Therefore, it is of the critical need to create physiologically relevant tissue models to mimic the in vivo environment by introducing stiffness cue. This study used the synthesized polyacrylamide (PAAm) hydrogel to represent the normal and fibrotic conditions of lung tissues to conduct in vitro models. The fibrogenic responses and mechanosensing of fibroblasts to carbon nanotubes (CNTs) at different stiffness conditions have been explored. This study provides understanding of the regulatory pathways and mediators of fibrogenic activities, which will potentially help identify therapeutic targets against fibrosis.

The incorporation of substrate nanotopography and stiffness could be further applied in three-dimensional culture model as the difference in dimensionality could also substantially change the cell behavior and function. Cells under in vivo conditions are embedded in multiple ECM components and experiencing different biophysical stimuli compared to those cultured on top of the two-dimensional substrate. Moreover, by introducing flow and shear stress into the in vivo system could largely replicate the in vivo condition, like the ultimate organ-on-a-chip 
microfluidic device. This study provides insight on building physiologically relevant in vitro model for disease detection and modeling and could be future applied in drug development and disease treatment. 


\section{Dedication}

To my parents, Limei Zhang and Shigang Shi

To my husband, Kai Wang and our son Alex M. Wang who is about to be born 


\section{Acknowledgement}

First and foremost, I would like to express my sincere gratitude and deepest appreciation to my advisor, Dr. Yong Yang, for his constant support, mentoring, instruction, patience and encouragement throughout my whole Ph.D. study. His inspiration always leads me to explore ways and solutions whenever issues and barriers occurred during my research. Not only did he broad my mind and perspective in the research field, but also teach me a lot of valuable lessons in real life. Without his continuous guidance, it would be impossible for me to finish my 4-year Ph.D. research and complete this dissertation. I am grateful that the valuable experience and abundant knowledge obtained from working with Dr. Yang have inspired me and directed me for my future career choice. I feel so lucky to have such a mentor in my life and I could not thank him enough for his help in every aspect.

I also would like to thank our lab's collaborator Dr. Yon Rojanasakul and Dr. Liying Wang Rojanasakul, whose generosity over the materials, equipment as well as the valuable advice that all made it possible for my research on the second project. Particularly, I would like to express my great thanks to Dr. Xiaoqing He, who took her precious time to teach me and guide me with the technique on western blotting, helping me master an essential skill for my current work and the potential future career.

I would also like to express my dear committee members, Dr. Charter Stinespring, Dr. Robbin Hissam, Dr. Yuxin Liu and Dr. Karen Martin, who are kind enough to take their precious time serving on my committee. I could not thank them enough for giving me all those great advice on my dissertation research proposal during my oral defense, which shed light on my upcoming 
research at that time. Special thanks to Dr. Stinespring and Dr. Hissam, who nicely gave me a lot of help and comfort on scheduling the time of my $\mathrm{Ph}$. D. final defense during the rough time.

For experimental and technical assistance, I would like to express my deepest gratitude to all the research scientists from Shared Research Facilities (SRF) in WVU engineering campus and Microscope Imaging Facility (MIF) in WVU health science campus. I thank Dr. Huiyuan Li for giving me the training for cell culture and all her assistance in the BioNano Research Facility (BNRF). Special thanks to Dr. Marcela Radigolo, for her excellent techniques on assisting me with the scanning electron microscopy (SEM) and her constant help and support in my personal life. Thanks to Dr. Kolin Brown, Dr. Weiqiang Ding and Harley Hart for training me with the equipment used in the cleanroom, for their friendly support on always scheduling the training promptly. Special thanks to Dr. Amanda Ammer and Dr. Karen Martin from MIF who consistently helped me with my microscopy skills, providing various technical training and troubleshooting on different microscopes and analytical software. It would be impossible for me to finish the imaging and analytical parts in this dissertation without their help, patience and exquisite techniques.

I would also like to especially thank Jim Hall, our department chemical hygiene officer (CHO), for his nice personality and continuous help with lab equipment, for his excellent handy skills that helped me make a lot of tools for the experiments. Moreover, I would like to express my gratitude to Linda Rogers and Monica Cebulak, our department secretaries, whose constant assistance on lab purchase, organizing department events and affairs, which made my Ph.D. life easier and more colorful.

My sincere thanks also go to all the current and former group members working in Dr. Yang's lab, especially to Allison Bruce, who taught me the skills of microfabrication, to Kai Wang, 
who constantly gave me great advice and shed light during my entire research work, to Ryan Mezan, who is excellent in imaging analysis and gave me great help with image processing.

My Ph.D. could not have been completed without the tremendous support of my parents, and also my friends from WVU. I would like to express my deepest thanks to Yuan Jiang, Ph.D. from Dr. Debangsu Bhattacharyya's group, who gave me numerous help since the first day I came to the United States. Last but not the least, I would like to thank my dear husband, Kai Wang, whose love and support kept me company throughout my whole Ph.D. career. 


\section{Table of Contents}

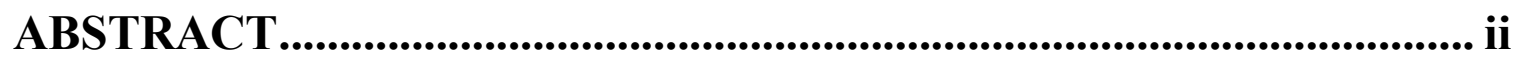

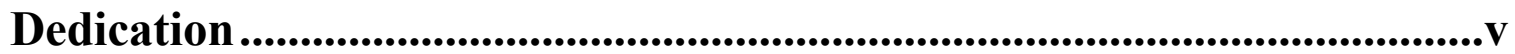

Acknowledgement .................................................................................................. vi

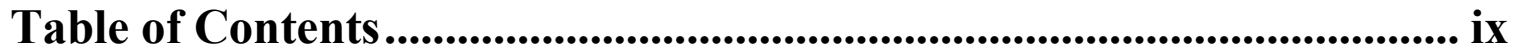

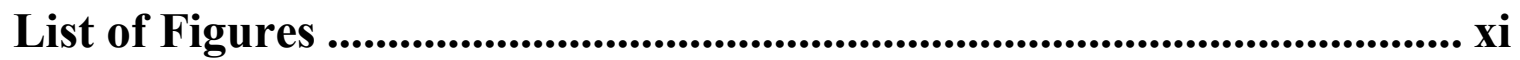

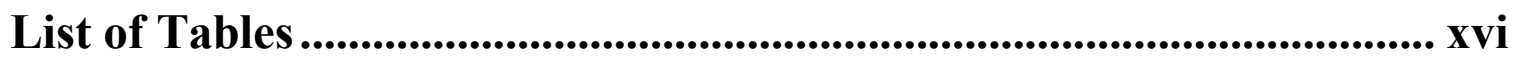

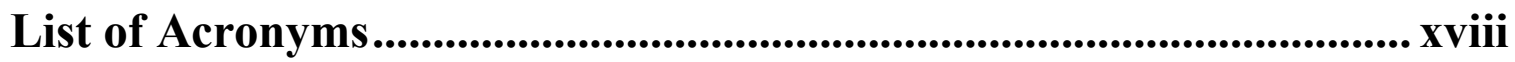

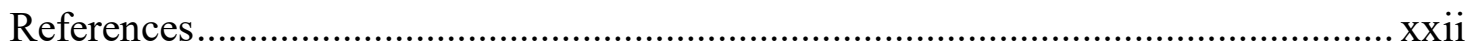

Chapter 1: Introduction ......................................................................................................1

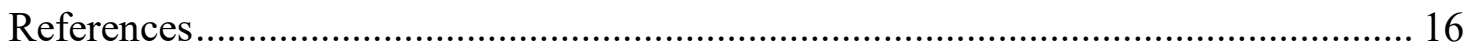

Chapter 2: Incorporating Nanotopography for Disease Detection Adhesion-based Circulating Tumor Cell Capture.......................................................28

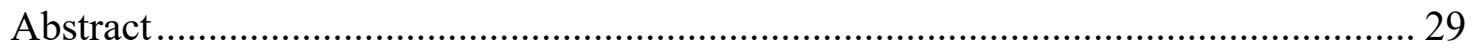

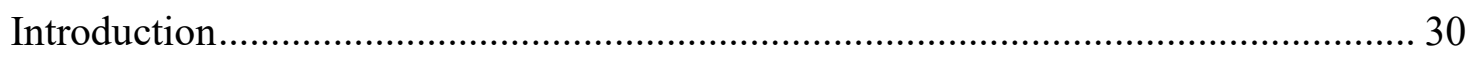

Materials and Methods.......................................................................................... 33

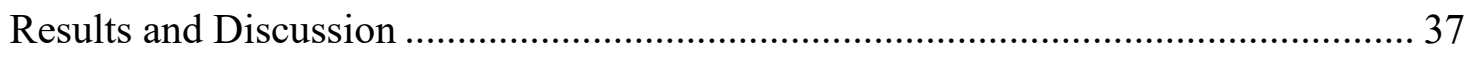

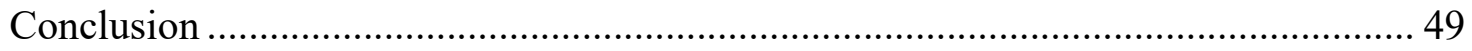

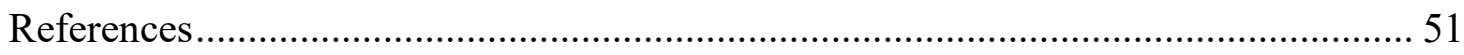




\section{Chapter 3: Incorporating Substrate Stiffness for Disease Modeling - In}

Vitro Model of Cell Sensing Nanomaterials................................................................59

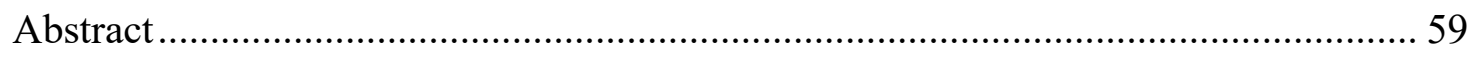

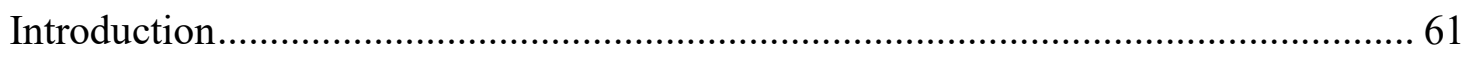

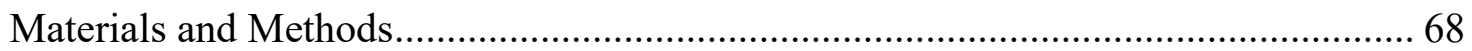

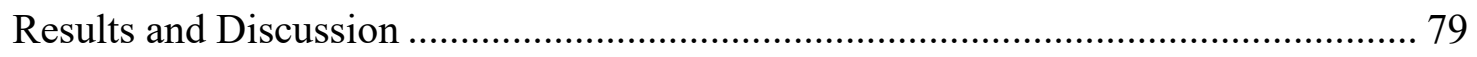

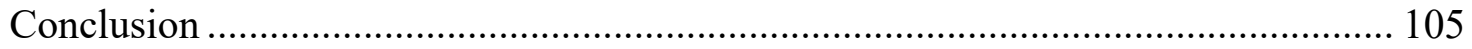

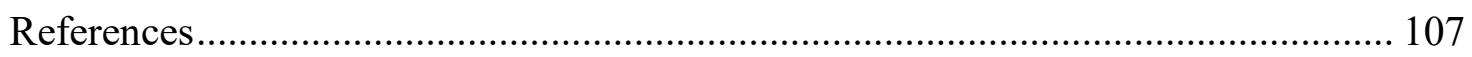

Chapter 4: Path Forward.............................................................................120

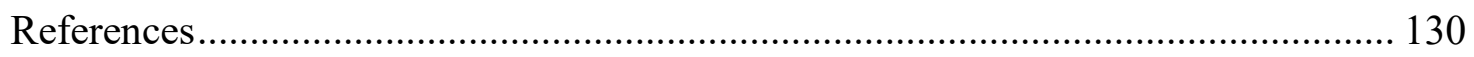




\section{List of Figures}

\section{Chapter 1: Introduction}

Figure 1-1: The biophysical cues that exist in typical human tissues. ${ }^{1}$

Figure 1-2: hMSCs differentiation directed by pre-culturing them on TCPS for different days. $^{2}$

Figure 1-3: Nanotopographical features exhibited in various tissues. ${ }^{3}$

Figure 1-4: Classification of nanotopograophies according to the shape. ${ }^{4}$ 


\section{Chapter 2: Incorporating Nanotopography for Disease Detection - Adhesion-based Circulating Tumor Cell Capture}

Figure 2-1: SEM micrographs of the PDMS nanotopographies and the flat substrate.

Figure 2-2: MCF7 cell capture on the nanotopographies.

Figure 2-3: (A) Fluorescent images of captured MCF7 cells on the nanotopographies and flat surfaces. (B) Cell area measurement of captured MCF7 cells on the nanotopographies and flat surfaces.

Figure 2-4: SEM micrographs of MCF7 cells adhered to the nanotopographies and flat surface.

Figure 2-5: Capture efficiency of MCF7, A549, MDA-MB-231 and HeLa cells after $4 \mathrm{~h}$ of incubation on the nanotopographies and flat surfaces.

Figure 2-6: SEM micrographs of (A) A549 and (B) HeLa cells on the nanotopographies and flat surfaces. 
Chapter 3: Incorporating Substrate Stiffness for Disease Modeling - In Vitro Model of Cell

\section{Sensing Nanomaterials}

Figure 3-1: Cell behaviors regulated by the variation of matrix mechanics. ${ }^{5}$

Figure 3-2: Cell contractility, motility and spreading influenced by the mechanical properties of the substrate. ${ }^{6}$

Figure 3-3: Effect of substrate stiffness on cell elongation and polarization. ${ }^{7}$

Figure 3-4: Schematic of the assembly of sandwich gels. ${ }^{8}$

Figure 3-5: Cell morphologies of NHLFs on different PAAm gel substrates (3 kPa, 100 $\mathrm{kPa}$ ) and TCPS.

Figure 3-6: Determination of MWCNTs dosage by cell proliferation assay on TCPS.

Figure 3-7: Dose-dependent collagen production of fibroblasts treated with MWCNTs. ${ }^{9}$

Figure 3-8: Immunofluorescent staining of F-actin, $\alpha$-SMA and nuclei of NHLFs on different substrates: $3 \mathrm{kPa}, 100 \mathrm{kPa}$ and TCPS.

Figure 3-9: MWCNTs effects on nuclei.

Figure 3-10: Cell proliferation of NHLFs on different PAAm gel substrates and TCPS control.

Figure 3-11: Collagen I expression of NHLFs treated with or without $0.2 \mu \mathrm{g} / \mathrm{cm}^{2}$ MWCNTs.

Figure 3-12: The influence of ROS generation of NHLFs on substrate stiffness in response to MWCNTs. 
Figure 3-13: Protein expression of NHLFs treated with or without $0.2 \mu \mathrm{g} / \mathrm{cm}^{2}$ MWCNTs.

Figure 3-14: Bright field images of cells treated with different dosages of Y27632.

Figure 3-15: Images of NHLFs cell morphologies treated with different dosages of Y27632.

Figure 3-16: Collagen I expression of NHLFs exposed to $0.2 \mu \mathrm{g} / \mathrm{cm}^{2}$ MWCNTs when treated with different dosages of Y27632 on TCPS.

Figure 3-17: Collagen I expression of NHLFs exposed to $0.2 \mu \mathrm{g} / \mathrm{cm}^{2} \mathrm{MWCNTs}$ and (5+ 5) $\mu \mathrm{M}$ Y27632 on $100 \mathrm{kPa}$ PAAm gel substrates.

Figure 3-18: Collagen I expression of NHLFs exposed to $0.2 \mu \mathrm{g} / \mathrm{cm}^{2} \mathrm{MWCNTs}$ and (5+ 5) $\mu \mathrm{M}$ Y27632 on $100 \mathrm{kPa}$ PDMS gel substrates. 


\section{Chapter 4: Path Forward}

Figure 4-1: RIE generated nanoroughened surface for cancer cell capture. ${ }^{10}$

Figure 4-2: Nanoroughened surfaces incorporated microfluidic device for cancer cell capture. $^{11}$

Figure 4-3: The difference between 2D culture (collagen-coated glass) and 3D culture (collagen gel) in regard to adhesion, polarity, spreading, matrix distribution and matrix stiffness. ${ }^{12}$

Figure 4-4: "Organ-on-a-chip" microfluidic devices that were fabricated to mimic tissue microenvironment for different disease models. ${ }^{13}$ 


\section{List of Tables}

\section{Chapter 1: Introduction}

Table 1-1: Different materials and their stiffness as in Young's modulus. 
Chapter 3: Incorporating Substrate Stiffness for Disease Modeling - In Vitro Model of Cell Sensing Nanomaterials

Table 3-1: Polyacrylamide Young's modulus table.

Table 3-2: The administrative dosage adding pattern for Y27632 treatment. 


\section{List of Acronyms}

\begin{tabular}{|c|c|}
\hline Abbreviation & Meaning \\
\hline 3-APTMS & (3-Aminopropyl)trimethoxysilan \\
\hline A549 & An adenocarcinomic basal epithelial cell line \\
\hline AFM & Atomic Force Microscope \\
\hline ALP & Alkaline Phosphatase \\
\hline ANOVA & Analysis of Variance \\
\hline APS & Ammonium Persulfate \\
\hline ATCC & American Type Culture Collection \\
\hline BCMN & Block Copolymer Micelle Nanolithography \\
\hline BSA & Bovine Serum Albumin \\
\hline CNTs & Carbon Nanotubes \\
\hline CPPs & Cell Penetrating Peptides \\
\hline CTCs & Circulating Tumor Cells \\
\hline DAPI & 4,6-diamidino-2-phenylindole \\
\hline DCFDA & Dichlorodihydrofluorescein Diacetate \\
\hline DI & Deionized \\
\hline DMEM & Dulbecco's Modified Eagle's Medium \\
\hline DMSO & Dimethyl Sulfoxide \\
\hline
\end{tabular}




\begin{tabular}{|c|c|}
\hline EBL & Electron Beam Lithography \\
\hline ECM & Extracellular Matrix \\
\hline ЕрСАМ & Epithelial Cell Adhesion Molecule \\
\hline EPCs & Endothelial Progenitor Cells \\
\hline FAs & Focal Adhesions \\
\hline FAK & Focal Adhesion Kinase \\
\hline F-actin & Filamentous Actin \\
\hline FBM & Fibroblast Basal Medium \\
\hline FBS & Fetal Bovine Serum \\
\hline HBSS & Hank's Balanced Salt Solution \\
\hline HeLa & A cervical cancer cell line \\
\hline HEPES & 4-(2-hydroxyethyl)-1-piperazineethanesulfonic acid \\
\hline HFFs & Human Foreskin Fibroblasts \\
\hline HMSCs & Human Mesenchymal Stem Cells \\
\hline IMCD & Inner Medullary Collecting Duct \\
\hline MCF7 & A luminal non-metastatic breast cancer cell line \\
\hline MDA-MB-231 & A basal aggressive metastatic breast cancer cell line \\
\hline MEM & Minimum Essential Media \\
\hline MSCs & Mesenchymal Stem Cells \\
\hline
\end{tabular}




\begin{tabular}{|c|c|}
\hline MWCNTs & Multi-Wall Carbon Nanotubes \\
\hline NGs & Nanogratings \\
\hline NHLF & Normal Human Lung Fibroblasts \\
\hline NHS & $\mathrm{N}$-hydroxysuccinimide \\
\hline NIH & National Institutes of Health \\
\hline NPs & Nanopillars \\
\hline OCN & Osteocalcin \\
\hline PBS & Phosphate Buffer Saline \\
\hline PDMS & Polydimethylsiloxane \\
\hline PEG & Poly(ethylene glycol) \\
\hline PFA & Paraformaldehyde \\
\hline pFAK & Phosphorylated Tyrosine-397 FAK \\
\hline PMMA & Poly(methylmethacrylate) \\
\hline PPAR $\gamma$ & Peroxisome Proliferator-activated Receptor Gamma \\
\hline PS & Polystyrene \\
\hline PVDF & Polyvinylidene Difluoride \\
\hline RIE & Reactive Ion Etching \\
\hline RIPA & Radioimmune Precipitation Assay \\
\hline ROCK & Rho-associated Protein Kinase \\
\hline
\end{tabular}




\begin{tabular}{|c|c|}
\hline ROI & Region of Interest \\
\hline ROS & Reactive Oxygen Species \\
\hline S.E.M. & Standard Error of Mean \\
\hline SDS-PAGE & Sodium Dodecyl Sulfate - Polyacrylamide Gel Electrophoresis \\
\hline SEM & Scanning Electron Microscope \\
\hline$\alpha-S M A$ & Alpha-Smooth Muscle Actin \\
\hline Sulfo-SANPAH & Sulfosuccinimidyl 6-(4'-azido-2'-nitrophenylamino)hexanoate \\
\hline TBST & 1X Tris-Buffered Saline With $0.1 \%$ Tween-20 \\
\hline TCPS & Tissue Culture Polystyrene \\
\hline TEMED & $\mathrm{N}, \mathrm{N}, \mathrm{N}^{\prime}, \mathrm{N}^{\prime}-$ Tetramethylethylenediamine \\
\hline VICs & Valvular Interstitial Cells \\
\hline Y27632 & $\begin{array}{l}\text { Trans-4-[(1R)-1-Aminoethyl]-N-4-pyridinylcyclohexanecarboxamide } \\
\text { Dihydrochloride }\end{array}$ \\
\hline
\end{tabular}




\section{References}

1. Yang, Y.; Wang, K.; Gu, X.; Leongc, K. W. Biophysical regulation of cell behavior - cross talk between substrate stiffness and nanotopography. Engineering 2017, 3 (1), 36-54.

2. Yang, C.; Tibbitt, M. W.; Basta, L.; Anseth, K. S. Mechanical memory and dosing influence stem cell fate. Nature Materials 2014, 13 (6), 645-52.

3. Kim, H. N.; Jiao, A.; Hwang, N. S.; Kim, M. S.; Kang, D. H.; Kim, D. H.; Suh, K. Y. Nanotopography-guided tissue engineering and regenerative medicine. Advanced Drug Delivery Reviews 2012, 65 (4), 536-58.

4. Kim, D.-H.; Provenzano, P. P.; Smith, C. L.; Levchenko, A. Matrix nanotopography as a regulator of cell function. The Journal of Cell Biology 2012, 197 (3), 351-360.

5. Wells, R. G. The role of matrix stiffness in regulating cell behavior. Hepatology 2016, 47 (4), 1394-1400.

6. Discher, D. E.; Janmey, P.; Wang, Y. L. Tissue cells feel and respond to the stiffness of their substrate. Science (New York, N.Y.) 2005, 310 (5751), 1139-43.

7. Prager-Khoutorsky, M.; Lichtenstein, A.; Krishnan, R.; Rajendran, K.; Mayo, A.; Kam, Z.; Geiger, B.; Bershadsky, A. D. Fibroblast polarization is a matrix-rigidity-dependent process controlled by focal adhesion mechanosensing. Nature Cell Biology 2011, 13, 1457-1465.

8. Fischer, R. S.; Myers, K. A.; Gardel, M. L.; Waterman, C. M. Stiffness-controlled threedimensional extracellular matrices for high-resolution imaging of cell behavior. Nature Protocol 2012, 7 (11), 2056-66. 
9. Wang, K. Carbon nanotubes induced fibrogenesis on nanostructured substrates. Environmental Science: Nano 2017, 4 (3), 689-699.

10. Chen, W. Q.; Weng, S. N.; Zhang, F.; Allen, S.; Li, X.; Bao, L. W.; Lam, R. H. W.; Macoska, J. A.; Merajver, S. D.; Fu, J. P. Nanoroughened surfaces for efficient capture of circulating tumor cells without using capture antibodies. ACS Nano 2013, 7 (1), 566-575.

11. Chen, W.; Allen, S. G.; Reka, A. K.; Qian, W.; Han, S.; Zhao, J.; Bao, L.; Keshamouni, V. G.; Merajver, S. D.; Fu, J. Nanoroughened adhesion-based capture of circulating tumor cells with heterogeneous expression and metastatic characteristics. BMC Cancer 2016, 16, 614.

12. Baker, B. M.; Chen, C. S. Deconstructing the third dimension - how 3D culture microenvironments alter cellular cues. Journal of Cell Science 2012, 125 (13), 3015-3024.

13. Huh, D.; Torisawa, Y. S.; Hamilton, G. A.; Kim, H. J.; Ingber, D. E. Microengineered physiological biomimicry: organs-on-chips. Lab on a Chip 2012, 12 (12), 2156-64. 


\section{Chapter 1: Introduction}

\section{The nature of in vivo condition}

The nature of in vivo environment where cells typically resident in is consist of various topographical structures and different degrees of stiffness. In the cell microenvironment, the ECM plays a significant role in regulating the phenotype and function of cells. ${ }^{1}$ The role of this dynamic structure is not only to provide solid support surrounding the cells, but also transduce physical signals to cells, thus regulating cell phenotype and function. The composition of ECM was identified years ago, ${ }^{1,2,3}$ and the important role of ECM has been more and more realized recently. The complex network of ECM is formed by a diversity of macromolecules secreted by cells, including different types of collagen, proteoglycans, glycoproteins, extracellular vesicles and many other structures, result in serious diversification in ECM structure. ${ }^{1,4,5,6,7,8,9,10}$ Tissues that come from different organs may contain different ECM structure. Such diversity and variation are a natural selection that would satisfy the different biological related function requirement from different organ systems. For example, the extracellular components in the alveolar region of the lung include both noncellular interstitium and basement membranes. ${ }^{11}$ Most basement membranes are consist of proteins like type IV collagen, entactin and laminin, as well as proteoglycans. ${ }^{12}$ However, the constituents of lung interstitium are fibrillar collagens, elastic fibers, and proteoglycans. $^{11,13,14}$

Typically, the various macromolecules present in ECM often exhibit three-dimensional

nanotopography, as shown in Figure 1-1 (a). ${ }^{15}$ Furthermore, the differential composition of ECM structure in different organs results in various stiffness, as shown in Figure 1-1 (b). ${ }^{15}$ These biophysical cues, including nanotopographical cue and stiffness cue, are highly organized within 
the $\mathrm{ECM}^{1}$, where the regulation of ECM allows cells to exhibit different phenotypes and functions. $^{15}$
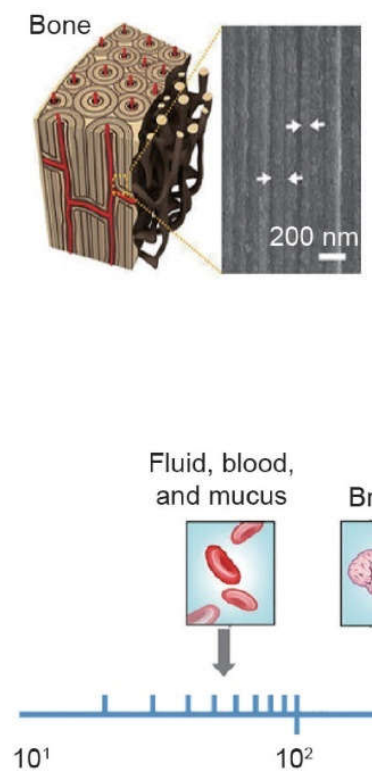
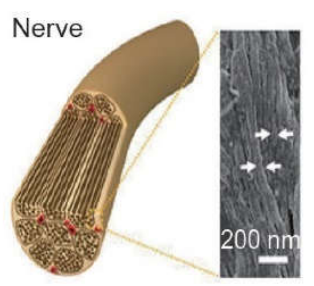

Endothelia

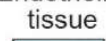

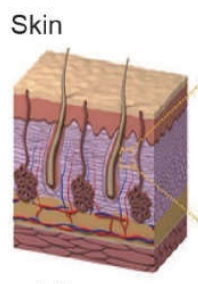

(a)
Alveolar interstitium
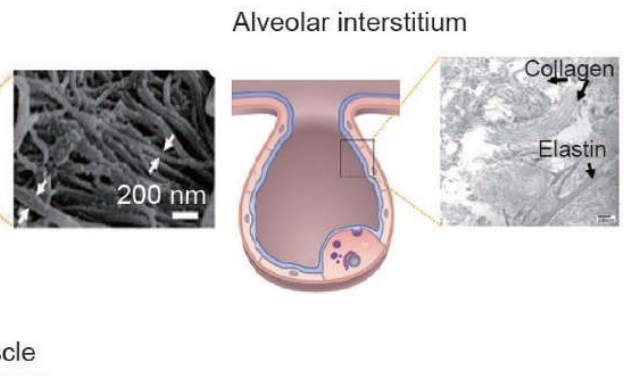

Muscle
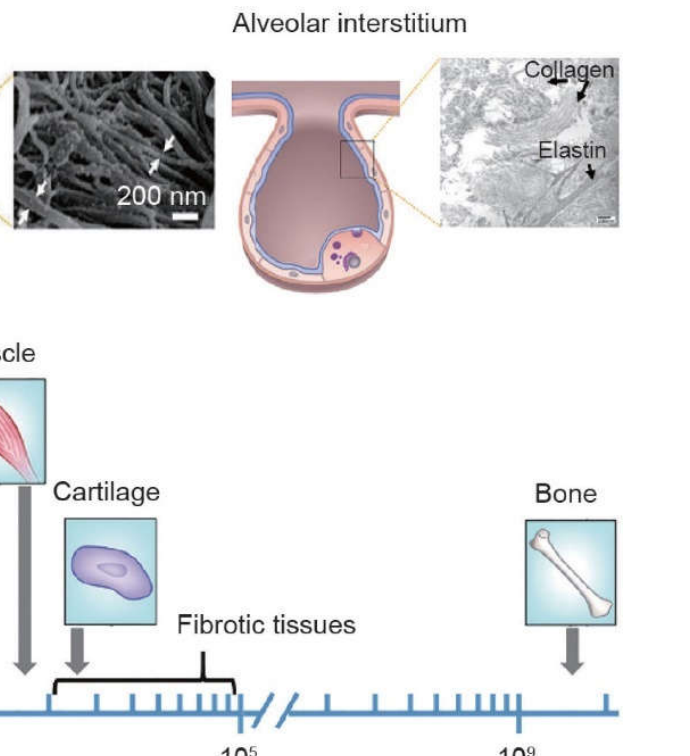

(b)

Figure 1-1: The biophysical cues that exist in typical human tissues. (a) Illustration of the threedimensional nanotopographical structures in different human tissues. The enlarged box shows SEM images of the nanostructures in bone, nerve, skin and alveolar interstitium. (b) Different human tissues fall into a wide range of stiffness from $10 \mathrm{~Pa}$ to over $1 \mathrm{GPa}$ (Adapted with permission from Ref. [15])

Growing and compelling evidence has shown that other than the chemical cues that can provide modulations to cells, the mechanical properties of these physical cues (topography and rigidity) plays significant roles in directing the cell fate, cell elongation, motility, migration and differentiation, thus have an impact on various ongoing process in vivo. ${ }^{16,17,18,19,20}$ As for topography cue, for example, the nervous system is composed of a complex network of threedimensional topographical structures, which covers a broad range of size for each component. ${ }^{16}$ In 
vivo studies have suggested that some of the topographical features guide cell migration during the development of cerebral cortex ${ }^{21}$ and cerebellum ${ }^{22}$. However, since there are constant alterations in chemical composition that intrinsically present in the actual in vivo condition, it is difficult to interpret the cell behavior by topographical guidance exclusively. An increasing number of in vitro models have been established using engineered substrates to understand the topography regulated cell behaviors. Evidence has shown that roughly aligned collagen fibrils can provide contact guidance to axons in vitro, suggesting that axons can sense ECM topography. ${ }^{23}$ Recently, electron beam lithography has become widely adopted to engineer a diversity of nanostructured substrates to conduct in vitro experiments. For example, a controlled nanodisorder surface has been developed that was proved to be able to modulate the cell adhesion and direct stem cell fate, which could induce fast osteogenesis from skeletal stem cells. ${ }^{24}$ As for stiffness cue, for example, tissue stiffness could substantially change during different stages of the disease. The stiffness of normal breast tissue is $150 \mathrm{~Pa}$, where the cancerous breast tissue could become 10 times stiffer than normal tissue. ${ }^{25,26}$ The connective tissue of lung is mainly composed of collagens and elastin fibers, where the elastic moduli are around $1200 \mathrm{MPa}$ and $1 \mathrm{MPa}$, respectively, during normal condition. ${ }^{27,28}$ The expression of collagen and elastin is largely controlled. However, when experiencing pulmonary fibrosis, the stiffness of the fibrotic lung tissue increases significantly due to the excessive deposition of collagen, altering the mechanical properties of the ECM, thus changing the cellular behavior and function. ${ }^{29}$ Therefore, the ECM has been identified significantly as in maintaining the steady state of normal tissue while the disruption of homeostasis would potentially cause the development of disease. ${ }^{30}$ 


\section{Limitations of current in vitro models for disease therapy and diagnosis}

From the perspective of the natural in vivo condition, current in vitro platforms for disease therapy and diagnosis show significant drawback. The majority of the platforms for cell culture are established on TCPS, where it is much stiffer $(\mathrm{E} \sim 3 \mathrm{GPa})^{31}$ than the most human tissues in the actual in vivo condition. Moreover, TCPS is lack of three-dimensional topographical structure as it is completely flat. Therefore, most of the cells are randomly spread and largely stretched when cultured on TCPS, which is substantially deviating from their in vivo microenvironment. For example, a study has shown that substrate stiffness could direct human mesenchymal stem cells (hMSCs) fate, and the increase of the time that stem cells were cultured on TCPS tended to

modulate hMSCs differentiation to osteoblasts. ${ }^{31}$ As shown in Figure 1-2 (b), compared to culturing strictly on soft substrate (So7), increased mechanical dosing on day 10 (DT10/So7) significantly resulted in hMSCs differentiation towards osteogenesis. When hMSCs were precultured on TCPS for 1 to 10 days, most hMSCs tended to lose their multipotency and could only differentiate into osteoblasts. 
(a) $\square$ TCPS

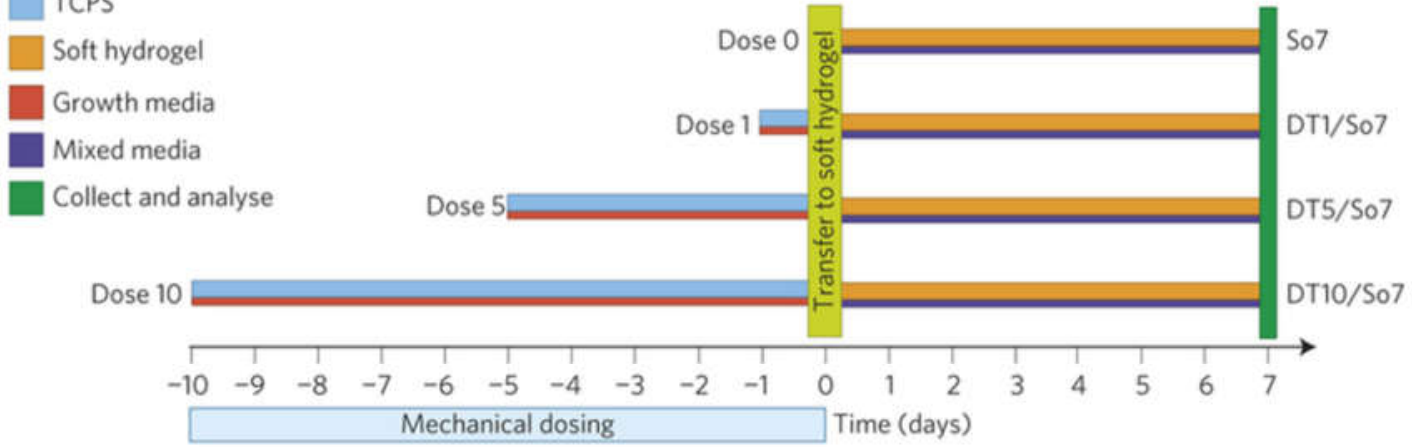

(b)
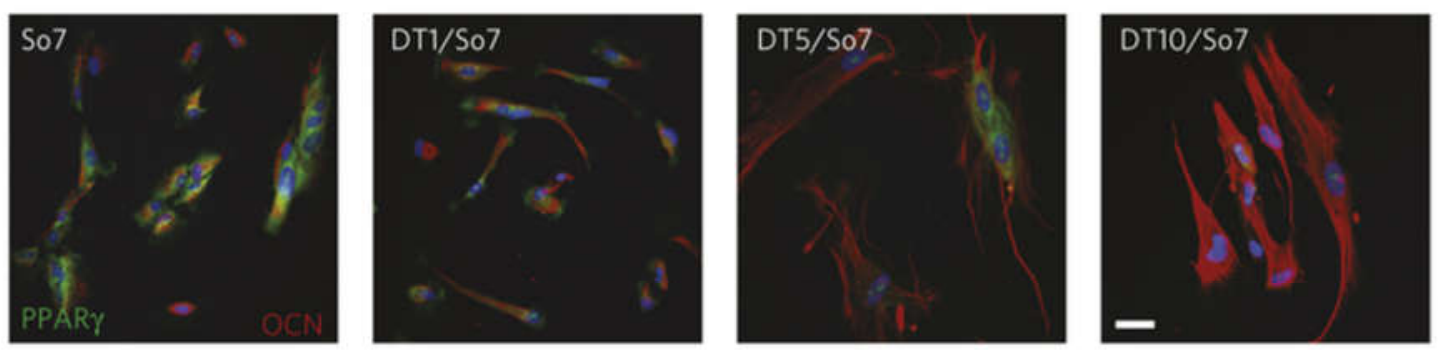

(c)
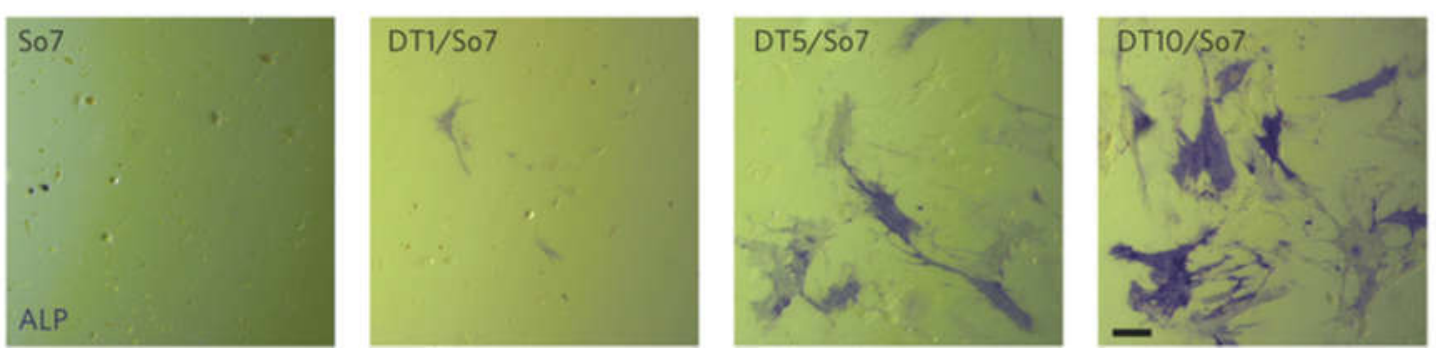

Figure 1-2: hMSCs differentiation directed by pre-culturing them on TCPS for different days. (a) hMSCs were first cultured on TCPS for 1 day, 5 days and 10 days and then transferred to soft hydrogel substrate, followed by 7 days of culturing. hMSCs cultured strictly on the soft substrate from day 0 was used as a control (So7) (b) Immunostaining of PPAR $\gamma$ (green) and OCN (red) of hMSCs of the aforementioned samples after 7 days culturing on soft hydrogels. (PPAR $\gamma$ is mainly present in adipose tissue, colon and macrophages, which is often used as adipogenesis marker. OCN is produced by osteoblasts, which is often used as a biochemical marker for bone formation.) (c) Staining for ALP (osteogenic markers) of hMSCs of the aforementioned samples before transferred to soft hydrogels. The scale bars are $20 \mu \mathrm{m}$. (Adapted with permission from Ref. [31]) 
The ECM also play a significant role in cell spreading. When cultured on TCPS, cells tend to increase proliferation and the formation of actin fibers and focal adhesions. ${ }^{32,33,34,35,36}$ For example, one study has shown that increased cell number has been observed due to the promotion of cell proliferation when cultured on TCPS compared with polyacrylamide (PAAm) hydrogels $(\sim$ 0.3 to $55 \mathrm{kPa})^{37}$ Another study compared the proliferation of cells cultured on TCPS and the fabricated highly aligned microfibrous tubular scaffold, where the results showed that cell proliferation was significantly higher on TCPS than the engineered scaffold, which had similar mechanical properties compared to the native esophagus. ${ }^{38}$

Therefore, taking the limitations of current in vitro model into consideration, instead of using flat, rigid TCPS surfaces, novel physiologically relevant platforms that incorporate both topographical cue and stiffness cue should be established to closely mimic the in vivo conditions.

\section{Biophysical cues modulation of cell phenotype and function}

Stiffness cue. A wide range of natural as well as engineered materials with a stiffness varying from several pascal to hundreds gigapascal that have been applied in different biological related studies (see Table 1), including hard materials like silicon (Young's modulus ranging from 50.9 to $\left.180 \mathrm{GPa}^{39}\right)$, glass $\left(50-90 \mathrm{GPa}^{40}\right)$, TCPS $\left(\sim 3 \mathrm{GPa}^{31}\right)$. However, since the ECM exhibits various degree of stiffness in the actual in vivo condition, and there are lots of tissues which cover the range below the magnitude of gigapascal (see Figure 1-1b), engineered soft materials have been more and more commonly used to conduct in vitro models to mimic the stiffness in different tissues for disease detection and modeling.

For example, elastic polymer polydimethylsiloxane (PDMS) has been widely adopted as substrates/ matrices for biological related study, not only because its great biocompatibility, but 
also for the fact that it is a versatile polymeric material which stiffness could be tuned by varying the base material and curing agent, as well as the curing time/ temperature. PDMS typically has an elastic modulus around $1 \mathrm{MPa}$ and holds the great potential of tunable stiffness. One study has shown the ability to tune the stiffness of PDMS from $800 \mathrm{kPa}$ to $10 \mathrm{MPa}$ by varying the base material and crosslinker reagent from 1:2 to $1: 19$ under different curing temperature and time ${ }^{41} \mathrm{~A}$ much soft stiffness in the lower limit range has been reported that by varying the base material and crosslinker reagent ratio from 100:1 to 10:1, the PDMS substrates could achieve a range from 0.1 $\mathrm{kPa}$ to $2.3 \mathrm{MPa}^{42}$ Poly(ethylene glycol) (PEG) based hydrogel is another commonly used soft material, which has been realized as a suitable, biocompatible soft material that is widely applied in a diversity of cellular and biomedical related applications, including 3D in vitro model for cell study, ${ }^{43}$ cell encapsulation, ${ }^{44}$ tissue scaffold for regenerative medicine. ${ }^{45}$ The stiffness of PEG is highly tunable via the cross-linking polymerization process by varying the ratio between precursors and cross-linkers. The stiffness of PEG is typically lower than $\sim 1 \mathrm{kPa}^{46} \mathrm{An}$ elastic modulus range from $4 \mathrm{kPa}$ to $70 \mathrm{kPa}$ has been reported by using a radical-free, Michael addition to prepare PEG hydrogel, ${ }^{47,48}$ in which range has covered many soft tissues in human body ${ }^{49}$ PEGbased hydrogel can also cover a much more rigid elasticity range from $10 \mathrm{kPa}$ to $1 \mathrm{MPa}$ by changing the cross-linking density and mechanism. Specifically, the protein accumulation effects by the crosslinking process have been studied and investigated ${ }^{50}$ Polyacrylamide (PAAm) gel has been more and more routinely used as an engineered soft substrate for studying the mechanosensing in various in vitro models. ${ }^{51}$ Typically, mostly used PAAm gels are in a very soft range and the stiffness is $\sim 1 \mathrm{kPa}$ but they are also highly tunable by varying the ratio of the two components for polymerization, acrylamide and bis-acrylamide. A wide range of 1.3-166 kPa has been reported (Young's modulus was calculated from shear modulus in the original reference, $v$ is 
assumed to be 0.5$).{ }^{52}$ A wider range has also been reported up to $740 \mathrm{kPa}$ in the upper limit of the stiffness. $^{42}$

Table 1-1: Different materials and their stiffness as in Young's modulus.

\begin{tabular}{|l|l|c|}
\hline \multicolumn{1}{|c|}{ Material } & \multicolumn{1}{|c|}{ Young's Modulus } & Reference \\
\hline Silicon & $50.9-180 \mathrm{GPa}$ & {$[39]$} \\
Glass & $50-90 \mathrm{GPa}$ & {$[40]$} \\
PCPS & $\sim 3 \mathrm{GPa}$ & {$[31]$} \\
PDMS & $0.8-10 \mathrm{MPa}$ & {$[41]$} \\
& $0.1 \mathrm{kPa}-2.3 \mathrm{MPa}$ & {$[42]$} \\
PEG & $4-70 \mathrm{kPa}$ & {$[47],[48]$} \\
& $10 \mathrm{kPa}-1 \mathrm{MPa}$ & {$[50]$} \\
PAAm & $1.3-166 \mathrm{kPa}$ & {$[52]$} \\
& $2 \mathrm{~Pa}-55 \mathrm{kPa}$ & {$[53]$} \\
& $0.5-740 \mathrm{kPa}$ & {$[42]$} \\
\hline
\end{tabular}

The effect of cellular response to different stiffness has been extensively studied. The variation of stiffness could affect cell adhesion, ${ }^{54}$ cell spreading area, actin organization and cell elongation, ${ }^{53,54,55,56}$ cell migration, ${ }^{54,55,56}$ cell proliferation, growth and apoptosis, ${ }^{57}$ cellular contractility, ${ }^{54,55,58}$ and stem cell differentiation. ${ }^{31,59}$

Among the studies conducted to investigate the cellular response to substrate stiffness, fibroblasts have been widely adopted as a cell model, besides, epithelial cells, endothelial cells and neuron cells were also used. Extensive reports have shown that cell spreading increased with the increase of substrate stiffness increase, along with a noticeable formation and organization of actin stress fiber as for fibroblasts. ${ }^{53,54,55,56}$ For example, one group reported that fibroblasts on soft substrate $(2.68 \pm 0.99 \mathrm{kPa})$ have poor cell adhesion, which results in a poorly spread morphology 
and has the tendency to aggregate with neighboring cells to form spheroids that are tightly attached and tissue-like. Moreover, the focal adhesions observed on the soft substrate were short, limited quantity and dot-like. On the contrary, cells cultured on the stiff substrate $(7.69 \pm 2.85 \mathrm{kPa})$ exhibit similar behavior as that on TCPS surface, with a stronger cell adhesion, elongation, and large cell spreading area, as well as a great number of large, elongated focal adhesions. ${ }^{54}$

Cell migration, which is involved in a number of physiological process in vivo, can also be affected and guided by substrate stiffness in vitro. For example, PAAm hydrogel sheets that incorporated with different gradient of stiffness have been engineered to test the cell migration of NIH 3 T3 fibroblast cells, with the results showing that preferentially, NIH 3 T3 cells tended to migrate toward the stiff side of the PAAm sheets with a decreased migration speed. ${ }^{55}$ Another important aspect is that matrix stiffness can also have an impact on activating the signaling pathways of cell contractility. ${ }^{58}$ For example, tumors generally have stiffer elastic moduli than normal tissues where Rho proteins are found to be overexpressed in stiff tumors. ${ }^{60}$ Therefore, it has been found that increased in matrix stiffness resulted in elevated cell contractility because Rho activity has been identified to be closely associated with generating cell contractility. ${ }^{58,60,61}$

Substrate stiffness also affects cell proliferation, growth and apoptosis. NIH 3T3 cells and PAAm gels were used in one study to test the cell proliferation affected by different matrix stiffness, where the cell proliferation showed a 2 -fold increase on stiff PAAm gels $(0.06 \%$ bisacrylamide) compared to that on soft PAAm gels (0.012\% bis-acrylamide) after $24 \mathrm{~h}$ incubation and the difference has been increased up to 4 -fold after $48 \mathrm{~h}$ of incubation. ${ }^{57}$

Substrate rigidity could also substantially affect stem cell differentiation. For example, one study investigated the stem cell differentiation directed by matrix stiffness using mesenchymal 
stem cells (MSCs). Results showed that MSCs on soft substrates $(0.1-1 \mathrm{kPa})$ were largely differentiated into neurogenic cell types; on intermediate stiff substrates $(11 \mathrm{kPa})$, the differentiation was directed to myogenic cell types while on the stiffest substrates (34 $\mathrm{kPa})$, osteogenic differentiation occurred at the most. ${ }^{59}$ It has been suggested that the direction of MSCs differentiation tended to develop towards the direction of mimicking the actual in vivo environment, where these three stiffness represented brain, muscle and bone tissues. ${ }^{62}$

Given that the mechanical properties of substrates have a wide range of impact on cell behaviors, substrate stiffness regulation can be well adopted in clinical studies for disease detection and modeling. One of the applications is the impacts of substrate stiffness on cellular uptake of nanoparticles for cancer diagnosis and clinical therapy. One systematical study showed that higher membrane tension that existed in cells on stiffer substrate $(3.81 \pm 0.12 \mathrm{kPa}$ for intermediate gels and $5.71 \pm 0.51 \mathrm{kPa}$ for stiff gels) caused barrier that prevented the nanoparticles from entering the cells, whereas cells on soft gels $(1.61 \pm 0.11 \mathrm{kPa})$ had lower membrane tension that promoted the cell uptake of nanoparticles. ${ }^{63}$ Moreover, this study shed light on the potential application in cancer cell targeting and detection using nanoparticles to inhibit tumor growth by taking the advantages of the stiffness different between tumors and normal tissues. ${ }^{63}$

Nanotopographical cue. Nanotopographical cue has been more and more realized as an important mechanical property that could modulate cell behaviors for disease detection and modeling. One of the reasons is that nanoscale topographies existed in numerous human tissues that are closely related the function of the specific organ (see Figure 1-3). For example, threedimensional hierarchical structures and organizations can be seen in many tissues like bone, ligaments and tendon, blood vessels. ${ }^{64}$ Specifically, as shown in Figure 1-3, the bone tissue contains dense-packed, organized cylindrical structures. Such structures possibly existed because 
of the supportive and protective function of the bone, which could be able to sustain the possible external force. Particularly, as previously mentioned, the ECM is composed of a diversity of welldefined, three-dimensional nanostructures such as collagens fibers, elastins, laminins, all of which have a feature size in the nanometers range, where cells are highly sensitive to. ${ }^{65}$
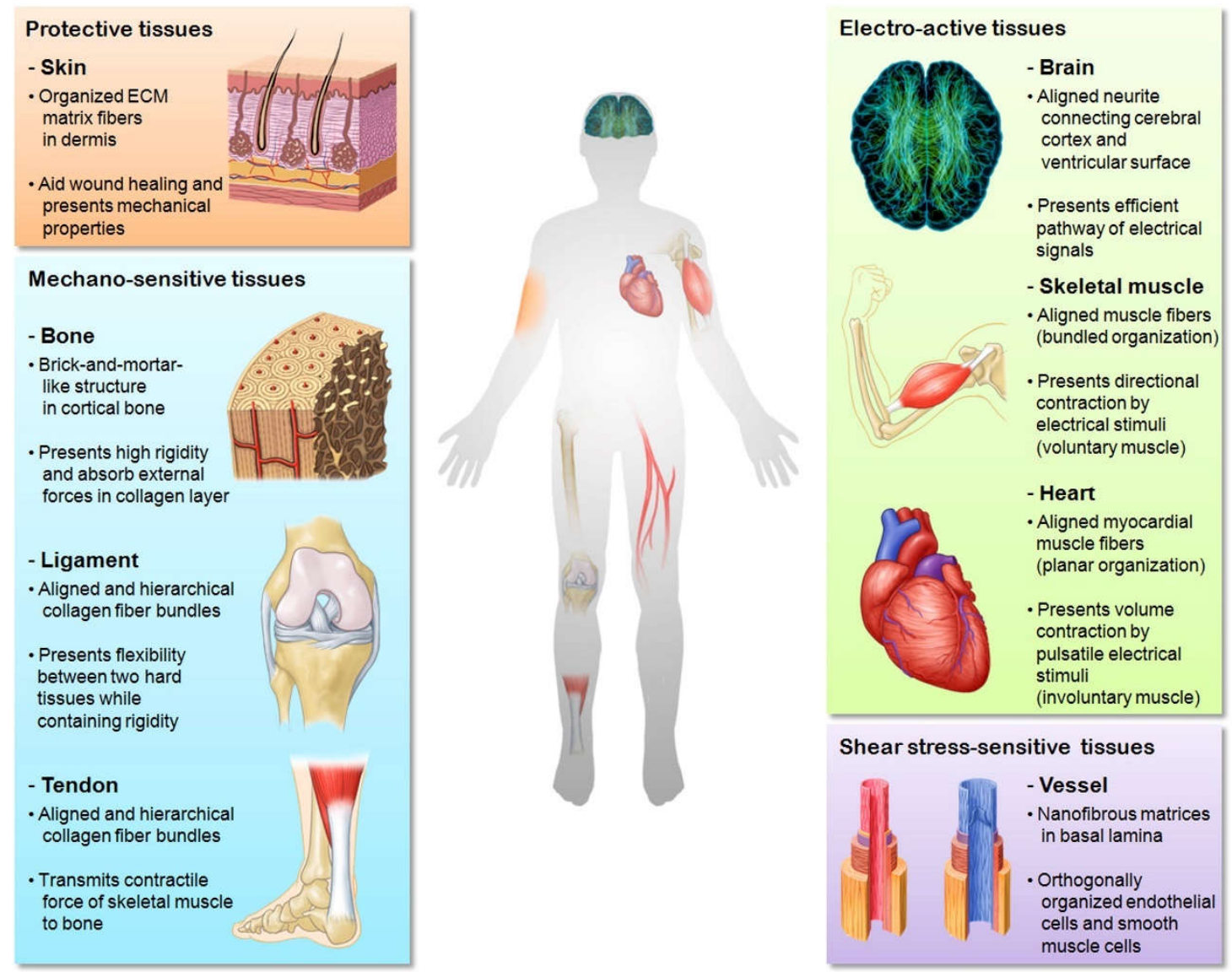

Figure 1-3: Nanotopographical features exhibited in various tissues. According to the living environment and the functions of the tissue, there are four major categories: protective tissues, mechano-sensitive tissues, electro-active tissues and shear stress-sensitive tissues. (Adapted with permission from Ref. [64])

Taking the advantage of the rapid evolution of modern nanotechnologies, it is now possible and convenient to generate the designed nanostructures with various shapes and dimensions. For 
example, a high resolution with a lateral dimension of $30 \mathrm{~nm}$ feature size could be obtained with two-photon lithography, which could be potentially used in fabricating nanoscale structures with a large scale like photonic crystals. ${ }^{66}$ Self-assembly techniques that can fabricate various complex miro- and nano-sized features, also gain many of the interests in the field of nanofabrication, ${ }^{67}$ including block copolymer micelle nanolithography $(\mathrm{BCMN})^{68,69,70}$ and colloidal lithography ${ }^{7}$ were also used to form a large area of nanopatterns at a relatively low cost. Moreover, electron beam lithography (EBL) and focused ion beam lithography were largely developed to generate well-defined patterns with a high resolution of $\sim 5 \mathrm{~nm}$ in recent decades. ${ }^{71,72}$ Besides of the high resolution, EBL technique has other advantages such as fabricating customized patterns, performing pattern fabrication without a mask and eliminating the diffraction problem. The EBL fabricated nanotopographies could be further served as the molds to prepare the PDMS replicas.

According to the different shape of the repeating unit of the nanofeature, the designed nanotopographies that have been used in tissue engineering can be divided into two types, the isotropic nanotopography (nanopillars, nanopits, nanorod arrays) and the anisotropic nanotopography (nanogratings, aligned fibers). Besides, there is also nanotopography gradient, where the isotropic or the anisotropic nanotopography can be presented at a density gradient (see Figure 1-4). ${ }^{73}$ Different design, shapes, as well as the variation of dimension of the nanotopographies, may have different impact on cell behaviors, including cell adhesion, cell spreading (elongation, alignment), cell migration, and stem cell differentiation. 

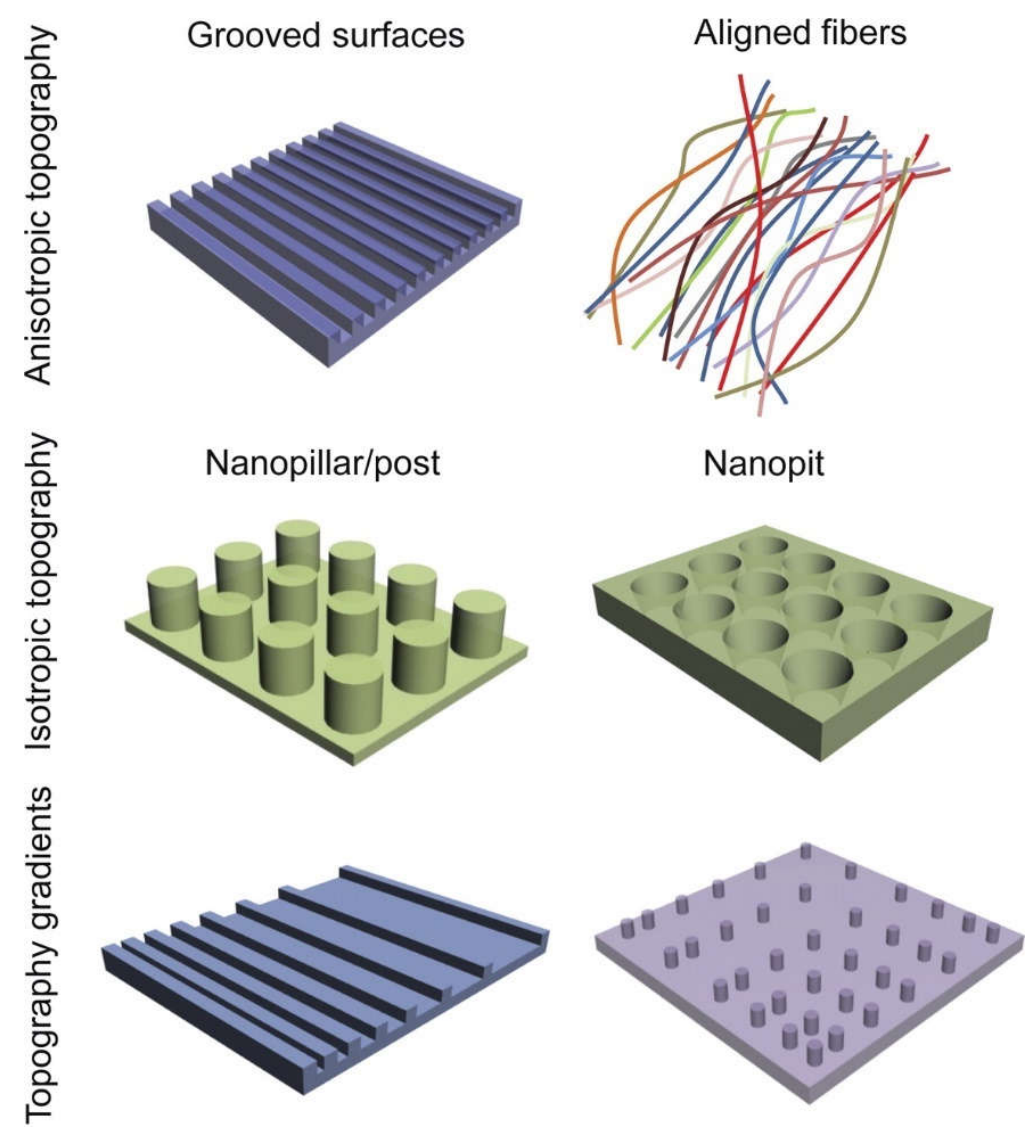

Figure 1-4: Classification of nanotopograophies according to the shape, including anisotropic topography (nanogroove, aligned fibers), isotropic nanotopography (nanopillar, nanopost and nanopit arrays) and topography gradients. (Adapted with permission from Ref. [73])

Isotropic nanotopographies are uniform, homogeneous repeating units, which provides discrete contact guidance in every direction. Cell behavior could be altered by isotropic nanotopographies from numerous aspects including increased ${ }^{74}$ or reduced cell adhesion, ${ }^{75}$ limited cell spreading, ${ }^{76,77}$ cell migration ${ }^{78}$ and directed stem cell differentiation. ${ }^{24,76}$ For example, one group discovered that compared to bare polyethylene glycol (PEG) surfaces, fabricated PEG nanopillars could enhance the cell adhesion of cultured cardiomyocytes for the reason that those pillars could not only serve as anchor posts for cell to attach on by extruding filopodia and 
lamellipodia, but also favor the actin formation. ${ }^{74}$ The influence of nanotopography on cell adhesion is highly dependent on the shape of the nanotopography. Another study reported a reduced adhesion complex formation and a limited cell spreading on highly-ordered nanopit arrays compared to the planar control. ${ }^{75}$ It seemed that the nanopit topography could disrupt or inhibit the adhesion formation. A similar study has been done by fabricating square (sq) and hexagonal (hex) ordered nanopits that proved to reduce cell spreading and the adhesion formation. ${ }^{77}$ Cell migration mostly occurred on anisotropic nanogratings, where there have been limited studies conducted on isotropic nanotopographies. One study that systematically investigated the mechanical properties modulated cell migration by combining the substrate stiffness and topographical cues, which showed that the cell migration was highly dependent on the substrate anisotropy, and the migration orientation was appeared to be along the spatial direction of pillar arrangement. ${ }^{78}$ Another important aspect is the influence on stem cell differentiation. Results suggested that the MSCs differentiation could be altered by varying the order of isotropic nanotopographies. It was noted on DSQ50 nanopits, which is a disordered square array with dots displaced randomly by up to 50 $\mathrm{nm}$ on both axes from their position in a true square, exhibited bone nodule formation whereas the highly ordered hexagon and square array decreased the cell adhesion and low amount of osteoblastic differentiation marker was detected. ${ }^{24}$

In contrast to the isotropic nanotopographies, anisotropic topographies provide continuous contact guidance in a single direction, which results in different impact on cell behaviors, including enhanced cell elongation and alignment, ${ }^{79}, 80,81$ increased $^{82}$ or reduced cell adhesion, ${ }^{81}$ cell proliferation, ${ }^{79,80,81,82}$ directional migration ${ }^{79,83}$ and stem cell differentiation. ${ }^{80,84}$ For example, endothelial progenitor cells (EPCs) cultured on nanogratings that featured $1200 \mathrm{~nm}$ in width and $600 \mathrm{~nm}$ in height showed a highly elongated morphology aligned with the groove direction, 
reduced cell proliferation and an enhanced directional migration along with an overall high speed. ${ }^{79}$ It has also been realized that the influence on cell proliferation may closely related to the dimension of the nanotopographies. One study showed that compared to flat PDMS, cell proliferation all showed a reduction on nanogratings with $350 \mathrm{~nm}, 1 \mu \mathrm{m}$ and $10 \mu \mathrm{m}$ in width but it decreased more significantly as the width getting smaller. ${ }^{80}$ Other than the lateral dimension of the nanogratings, height also serves as an important factor in affecting the cell spreading and proliferation. One study reported that the enhancement or reduction of cell proliferation and cell spreading followed a height dependent manner. In comparison to control, cell spreading area was increased on nanogratings with $13 \mathrm{~nm}$ in height and decreased on higher islands with $95 \mathrm{~nm}$ in height. $^{85}$ 


\section{References}

1. Mwenifumbo, S.; Stevens, M. M. ECM Interactions with Cells from the Macro- to Nanoscale. In Biomedical Nanostructures, Gonsalves, K. E.; Halberstadt, C. R.; Laurencin, C. T.; Nair, L. S., Eds.; John Wiley \& Sons, Inc.: Hoboken, NJ, USA, 2007, pp 223-260.

2. Jarvelainen, H.; Sainio, A.; Koulu, M.; Wight, T. N.; Penttinen, R. Extracellular matrix molecules: potential targets in pharmacotherapy. Pharmacological Reviews 2009, 61 (2), 198-223.

3. Klein, G. The extracellular matrix of the hematopoietic microenvironment. Experientia 1995, $51(9-10), 914-26$.

4. Aumailley, M.; Gayraud, B. Structure and biological activity of the extracellular matrix. Journal of Molecular Medicine (Berlin, Germany) 1998, 76 (3-4), 253-65.

5. Pizzo, A. M.; Kokini, K.; Vaughn, L. C.; Waisner, B. Z.; Voytik-Harbin, S. L. Extracellular matrix (ECM) microstructural composition regulates local cell-ECM biomechanics and fundamental fibroblast behavior: a multidimensional perspective. Journal of Applied Physiology 2004, $98(5), 1909-21$.

6. Roskelley, C. D.; Srebrow, A.; Bissell, M. J. A hierarchy of ECM-mediated signalling regulates tissue-specific gene expression. Current Opinion in Cell Biology 1995, 7 (5), 736-47.

7. Wallner, E. I.; Yang, Q.; Peterson, D. R.; Wada, J.; Kanwar, Y. S. Relevance of extracellular matrix, its receptors, and cell adhesion molecules in mammalian nephrogenesis. American Journal of Physiology 1998, 275 (4 Pt 2), F467-77. 
8. Zagris, N. Extracellular matrix in development of the early embryo. Micron (Oxford, England: 1993) 2000, 32 (4), 427-38.

9. Stevens, M. M.; George, J. H. Exploring and engineering the cell surface interface. Science (New York, N.Y.) 2005, 310 (5751), 1135-8.

10. Derya, M.; Yilmaz, I.; Aytekin, M. The role of extracellular matrix in lung diseases. Biology and Medicine 2014, 6 (2).

11. Dunsmore, S. E.; Rannels, D. E. Extracellular matrix biology in the lung. American Journal of Physiology - Lung Cellular and Molecular Physiology 1996, 270 (1), L3-L27.

12. Aratani, Y.; Kitagawa, Y. Enhanced synthesis and secretion of type IV collagen and entactin during adipose conversion of 3T3-L1 cells and production of unorthodox laminin complex. Journal of Biological Chemistry 1988, 263 (31), 16163-9.

13. White, E. S. Lung extracellular matrix and fibroblast function. Annals of the American Thoracic Society 2015, 12 (Suppl 1), S30-3.

14. Goncalves, C. A.; Figueiredo, M. H.; Bairos, V. A. Three-dimensional organization of the elastic fibres in the rat lung. Anatomical Record 1995, 243 (1), 63-70.

15. Yang, Y.; Wang, K.; Gu, X.; Leongc, K. W. Biophysical regulation of cell behavior - cross talk between substrate stiffness and nanotopography. Engineering 2017, 3 (1), 36-54.

16. Moore, S. W.; Sheetz, M. P. Biophysics of substrate interaction: influence on neural motility, differentiation, and repair. Developmental Neurobiology 2011, 71 (11), 1090-101. 
17. Huang, J. L.; Youhua, T.; Huafeng, Z.; Yi, Z.; Pingwei, X.; Junwei, C.; Yeh-Chuin, P.; Ke, T.; Ning, W.; Bo. Soft fibrin gels promote selection and growth of tumorigenic cells. Nature Materials 2012, 11, 734-741.

18. Rosa, A. L.; Kato, R. B.; Castro Raucci, L. M.; Teixeira, L. N.; de Oliveira, F. S.; Bellesini, L. S.; de Oliveira, P. T.; Hassan, M. Q.; Beloti, M. M. Nanotopography drives stem cell fate toward osteoblast differentiation through alphalbeta1 integrin signaling pathway. Journal of Cellular Biochemistry 2013, 115 (3), 540-8.

19. Ng, M. R.; Besser, A.; Danuser, G.; Brugge, J. S. Substrate stiffness regulates cadherindependent collective migration through myosin-II contractility. Journal of Cell Biology 2012, 199 (3), 545-63.

20. Oreffo, M. J. D.; Nikolaj, G.; Richard, O. C. Harnessing nanotopography and integrinmatrix interactions to influence stem cell fate. Nature Materials 2014, 13, 558-569.

21. Rakic, P. Mode of cell migration to the superficial layers of fetal monkey neocortex. Journal of Comparative Neurology 1972, 145 (1), 61-83.

22. Hynes, R. O.; Patel, R.; Miller, R. H. Migration of neuroblasts along preexisting axonal tracts during prenatal cerebellar development. Journal of Neuroscience 1986, 6 (3), 867-876.

23. Ebendal, $\mathrm{T}$. The relative roles of contact inhibition and contact guidance in orientation of axons extending on aligned collagen fibrils in vitro. Experimental Cell Research 1976, 98 (1), 15969. 
24. Dalby, M. J.; Gadegaard, N.; Tare, R.; Andar, A.; Riehle, M. O.; Herzyk, P.; Wilkinson, C. D. W.; Oreffo, R. O. C. The control of human mesenchymal cell differentiation using nanoscale symmetry and disorder. Nature Materials 2007, 6 (12), 997-1003.

25. Kass, L.; Erler, J. T.; Dembo, M.; Weaver, V. M. Mammary epithelial cell: influence of extracellular matrix composition and organization during development and tumorigenesis. The International Journal of Biochemistry \& Cell Biology 2007, 39 (11), 1987-1994.

26. Butcher, D. T.; Alliston, T.; Weaver, V. M. A tense situation: forcing tumour progression. Nature Reviews Cancer 2009, 9 (2), 108-22.

27. Sherratt, M. J.; Baldock, C.; Haston, J. L.; Holmes, D. F.; Jones, C. J.; Shuttleworth, C. A.; Wess, T. J.; Kielty, C. M. Fibrillin microfibrils are stiff reinforcing fibres in compliant tissues. Journal of Molecular Biology 2003, 332 (1), 183-93.

28. Akhtar, R.; Sherratt, M. J.; Watson, R. E.; Kundu, T.; Derby, B. Mapping the micromechanical properties of cryo-sectioned aortic tissue with scanning acoustic microscopy. Materials Research Society Symposium Proceedings 2009, 1132 E (1132-Z03-07), ukpmcpa27262.

29. Suki, B.; Bates, J. H. Extracellular matrix mechanics in lung parenchymal diseases. Respiratory Physiology \& Neurobiology 2008, 163 (1-3), 33-43.

30. Handorf, A. M.; Zhou, Y.; Halanski, M. A.; Li, W. J. Tissue stiffness dictates development, homeostasis, and disease progression. Organogenesis 2015, 11 (1), 1-15. 
31. Yang, C.; Tibbitt, M. W.; Basta, L.; Anseth, K. S. Mechanical memory and dosing influence stem cell fate. Nature Materials 2014, 13 (6), 645-52.

32. Califano, J. P.; Reinhart-King, C. A. Substrate stiffness and cell area predict cellular traction stresses in single cells and cells in contact. Cellular and Molecular Bioengineering 2010, $3(1), 68-75$.

33. Fu, J.; Wang, Y. K.; Yang, M. T.; Desai, R. A.; Yu, X.; Liu, Z.; Chen, C. S. Mechanical regulation of cell function with geometrically modulated elastomeric substrates. Nature Methods 2010, 7 (9), 733-6.

34. Georges, P. C.; Janmey, P. A. Cell type-specific response to growth on soft materials. Journal of Applied Physiology 2005, 98 (4), 1547-53.

35. Rhee, S.; Jiang, H.; Ho, C. H.; Grinnell, F. Microtubule function in fibroblast spreading is modulated according to the tension state of cell-matrix interactions. Proceedings of the National Academy of Sciences of the United States of America 2007, 104 (13), 5425-30.

36. Mih, J. D.; Marinkovic, A.; Liu, F.; Sharif, A. S.; Tschumperlin, D. J. Matrix stiffness reverses the effect of actomyosin tension on cell proliferation. Journal of Cell Science 2012, 125 (24), 5974-83.

37. Mih, J. D.; Sharif, A. S.; Liu, F.; Marinkovic, A.; Symer, M. M.; Tschumperlin, D. J. A multiwell platform for studying stiffness-dependent cell biology. PLOS One 2011, 6 (5), e19929. 
38. Tan, Y. J.; Leong, K. F.; An, J.; Chian, K. S.; Tan, X.; Yeong, W. Y. Fabrication and in vitro analysis of tubular scaffolds by melt-drawing for esophageal tissue engineering. Materials Letters 2015, 159 (15), 424-427.

39. Hopcroft, M. A.; Nix, W. D.; Kenny, T. W. What is the young's modulus of silicon? Journal of Microelectromechanical Systems 2010, 19 (2), 229-238.

40. Modulus of elasticity or young's modulus - and tensile modulus for common materials. http://www.engineeringtoolbox.com/young-modulus-d 417.html.

41. Seghir, R.; Arscott, S. Extended PDMS stiffness range for flexible systems. Sensors and Actuators A: Physical 2015, 230 (1), 33-39.

42. Trappmann, B.; Gautrot, J. E.; Connelly, J. T.; Strange, D. G.; Li, Y.; Oyen, M. L.; Cohen Stuart, M. A.; Boehm, H.; Li, B.; Vogel, V.; Spatz, J. P.; Watt, F. M.; Huck, W. T. Extracellularmatrix tethering regulates stem-cell fate. Nature Materials 2012, 11 (7), 642-9.

43. Kloxin, M. E. S.; Lisa, A. S.; April, M. Hydrogel scaffolds as in vitro models to study fibroblast activation in wound healing and disease. Biomaterials Science 2014, 2 (5), 634-650.

44. Komeri, R.; Muthu, J. Injectable, cytocompatible, elastic, free radical scavenging and electroconductive hydrogel for cardiac cell encapsulation. Colloids and Surfaces B: Biointerfaces 2017, 157, 381-390.

45. Smith, A. S. T.; Yoo, H.; Yi, H.; Ahn, E. H.; Lee, J. H.; Shao, G.; Nagornyak, E.; Laflamme, M. A.; Murry, C. E.; Kim, D. H. Micro- and nano-patterned conductive graphene-PEG 
hybrid scaffolds for cardiac tissue engineering. Chemical Communications (Cambridge, England) 2017.

46. Nemir, S.; West, J. L. Synthetic materials in the study of cell response to substrate rigidity. Annals of Biomedical Engineering 2010, 38 (1), 2-20.

47. Lutolf, M. P.; J, A. H. Synthesis and physicochemical characterization of end-linked poly(ethylene glycol)-co-peptide hydrogels formed by michael-type addition. Biomacromolecules 2003, 4 (3), 713-722.

48. Lutolf, M. P.; Lauer-Fields, J. L.; Schmoekel, H. G.; Metters, A. T.; Weber, F. E.; Fields, G. B.; Hubbell, J. A. Synthetic matrix metalloproteinase-sensitive hydrogels for the conduction of tissue regeneration: engineering cell-invasion characteristics. Proceedings of the National Academy of Sciences of the United States of America 2003, 100 (9), 5413-8.

49. Swift, J.; Ivanovska, I. L.; Buxboim, A.; Harada, T.; Dingal, P. C.; Pinter, J.; Pajerowski, J. D.; Spinler, K. R.; Shin, J. W.; Tewari, M.; Rehfeldt, F.; Speicher, D. W.; Discher, D. E. Nuclear lamin-A scales with tissue stiffness and enhances matrix-directed differentiation. Science (New York, N.Y.) 2013, 341 (6149), 1240104.

50. Lee, S.; Tong, X.; Yang, F. The effects of varying poly(ethylene glycol) hydrogel crosslinking density and the crosslinking mechanism on protein accumulation in three-dimensional hydrogels. Acta Biomaterialia 2014, 10 (10), 4167-74. 
51. Missirlis, D.; Spatz, J. P. Combined effects of PEG hydrogel elasticity and cell-adhesive coating on fibroblast adhesion and persistent migration. Biomacromolecules 2013, 15 (1), 195 205.

52. Fischer, R. S.; Myers, K. A.; Gardel, M. L.; Waterman, C. M. Stiffness-controlled threedimensional extracellular matrices for high-resolution imaging of cell behavior. Nature Protocol 2012, 7 (11), 2056-66.

53. Yeung, T.; Georges, P. C.; Flanagan, L. A.; Marg, B.; Ortiz, M.; Funaki, M.; Zahir, N.; Ming, W.; Weaver, V.; Janmey, P. A. Effects of substrate stiffness on cell morphology, cytoskeletal structure, and adhesion. Cell Motility and the Cytoskeleton 2004, 60 (1), 24-34.

54. Guo, W. H.; Frey, M. T.; Burnham, N. A.; Wang, Y. L. Substrate rigidity regulates the formation and maintenance of tissues. Biophysical Journal 2006, 90 (6), 2213-20.

55. Lo, C. M.; Wang, H. B.; Dembo, M.; Wang, Y. L. Cell movement is guided by the rigidity of the substrate. Biophysical Journal 2000, 79 (1), 144-52.

56. Robert J. Pelham, Jr.; Yu-li, W. Cell locomotion and focal adhesions are regulated by substrate flexibility. Proceedings of the National Academy of Sciences of the United States of America 1997, 94 (25), 13661-13665.

57. Wang, H. B.; Dembo, M.; Wang, Y. L. Substrate flexibility regulates growth and apoptosis of normal but not transformed cells. American Physiological Society - Cell Physiology 2000, 279 (5), C1345-50. 
58. Paszek, M. J.; Zahir, N.; Johnson, K. R.; Lakins, J. N.; Rozenberg, G. I.; Gefen, A.; Reinhart-King, C. A.; Margulies, S. S.; Dembo, M.; Boettiger, D.; Hammer, D. A.; Weaver, V. M. Tensional homeostasis and the malignant phenotype. Cancer Cell 2005, 8 (3), 241-54.

59. Engler, A. J.; Sen, S.; Sweeney, H. L.; Discher, D. E. Matrix elasticity directs stem cell lineage specification. Cell 2006, 126 (4), 677-89.

60. Fritz, G.; Just, I.; Kaina, B. Rho GTPases are over-expressed in human tumors. International Journal of Cancer 1999, 81 (5), 682-7.

61. Burridge, M. C.-W. Rho-stimulated contractility drives the formation of stress fibers and focal adhesions. The Journal of Cell Biology 1996, 133 (6), 1403.

62. Solon, J.; Levental, I.; Sengupta, K.; Georges, P. C.; Janmey, P. A. Fibroblast adaptation and stiffness matching to soft elastic substrates. Biophysical Journal 2007, 93 (12), 4453-61.

63. Huang, C.; Butler, P. J.; Tong, S.; Muddana, H. S.; Bao, G.; Zhang, S. Substrate stiffness regulates cellular uptake of nanoparticles. Nano Letters 2013, 13 (4), 1611-5.

64. Kim, H. N.; Jiao, A.; Hwang, N. S.; Kim, M. S.; Kang, D. H.; Kim, D. H.; Suh, K. Y. Nanotopography-guided tissue engineering and regenerative medicine. Advanced Drug Delivery Reviews 2012, 65 (4), 536-58.

65. Kim, J.; Kim, H. N.; Lim, K. T.; Kim, Y.; Seonwoo, H.; Park, S. H.; Lim, H. J.; Kim, D. H.; Suh, K. Y.; Choung, P. H.; Choung, Y. H.; Chung, J. H. Designing nanotopographical density of extracellular matrix for controlled morphology and function of human mesenchymal stem cells. Scientific Reports 2013, 3, 3552. 
66. Juodkazis, S.; Mizeikis, V.; Seet, K. K.; Miwa, M.; Misawa, H. Two-photon lithography of nanorods in SU-8 photoresist. Nanotechnology 2005, 16 (6), 846.

67. Kajbafvala, A.; Bahmanpour, H.; Maneshian, M. H.; Li, M. Self-assembly techniques for nanofabrication. Journal of Nanomaterials 2013, 2013.

68. Black, R. R.; Lei, W.; Jeffrey, L.; Kanaiyalal, C. P.; Elizabeth, D.; Danvers, E. J.; Kim, K.; Charles, T. Image quality and pattern transfer in directed self assembly with block-selective atomic layer deposition. Journal of Vacuum Science \& Technology B, Nanotechnology and Microelectronics: Materials, Processing, Measurement, and Phenomena 2012, 30 (6).

69. Buriak, C. J.; Brian, C. O.; Nathanael, L. Y. W.; Erik, J. L.; Jillian, M. Sequential nanopatterned block copolymer self-assembly on surfaces. Langmuir 2016, 32 (23), 5890-5898.

70. Y.-K, K. D.; Jeon, S. B.; Kim, J. Y.; Seol, M. L.; Kim, S. O.; Choi. High-performance nanopattern triboelectric generator by block copolymer lithography. Nano Energy 2015, 12, 331338.

71. Vieu, C.; Carcenac, F.; Pepin, A.; Chen, Y.; Mejias, M.; Lebib, A.; Manin-Ferlazzo, L.; Couraud, L.; Launois, H. Electron beam lithography: resolution limits and applications. Applied Surface Science 2000, 164 (1), 111-117.

72. Nagase, T.; Gamo, K.; Kubota, T.; Mashiko, S. Direct fabrication of nano-gap electrodes by focused ion beam etching. Thin Solid Films 2006, 499 (1), 279-284.

73. Kim, D.-H.; Provenzano, P. P.; Smith, C. L.; Levchenko, A. Matrix nanotopography as a regulator of cell function. The Journal of Cell Biology 2012, 197 (3), 351-360. 
74. Deok-Ho, K.; Pilnam, K.; Suh, K. Y.; Seung Kyu, C.; Sang Ho, L.; Byungkyu, K. In Modulation of adhesion and growth of cardiac myocytes by surface nanotopography, 2005 IEEE Engineering in Medicine and Biology 27th Annual Conference, 17-18 Jan. 2006; 2005, pp 40914094.

75. Biggs, M. J. P.; Richards, R. G.; Gadegaard, N.; Wilkinson, C. D. W.; Dalby, M. J. The effects of nanoscale pits on primary human osteoblast adhesion formation and cellular spreading. Journal of Materials Science: Materials in Medicine 2007, 18 (2), 399-404.

76. Oh, S.; Brammer, K. S.; Li, Y. S.; Teng, D.; Engler, A. J.; Chien, S.; Jin, S. Stem cell fate dictated solely by altered nanotube dimension. Proceedings of the National Academy of Sciences of the United States of America 2009, 106 (7), 2130-5.

77. Hart, A.; Gadegaard, N.; Wilkinson, C. D.; Oreffo, R. O.; Dalby, M. J. Osteoprogenitor response to low-adhesion nanotopographies originally fabricated by electron beam lithography. Journal of Materials Science: Materials in Medicine 2007, 18 (6), 1211-8.

78. Tzvetkova-Chevolleau, T.; Stéphanou, A.; Fuard, D.; Ohayon, J.; Schiavone, P.; Tracqui, P. The motility of normal and cancer cells in response to the combined influence of the substrate rigidity and anisotropic microstructure. Biomaterials 2008, 29 (10), 1541-1551.

79. Bettinger, C. J.; Zhang, Z.; Gerecht, S.; Borenstein, J. T.; Langer, R. Enhancement of in vitro capillary tube formation by substrate nanotopography. Advanced Materials 2008, 20 (1), 99103. 
80. Yim, E. K. F.; Pang, S. W.; Leong, K. W. Synthetic nanostructures inducing differentiation of human mesenchymal stem cells into neuronal lineage. Experimental Cell Research 2007, 313 (9), 1820-1829.

81. Gerecht, S.; Bettinger, C. J.; Zhang, Z.; Borenstein, J. T.; Vunjak-Novakovic, G.; Langer, R. The effect of actin disrupting agents on contact guidance of human embryonic stem cells. Biomaterials 2007, 28 (28), 4068-77.

82. Lu, J.; Rao, M. P.; MacDonald, N. C.; Khang, D.; Webster, T. J. Improved endothelial cell adhesion and proliferation on patterned titanium surfaces with rationally designed, micrometer to nanometer features. Acta Biomaterialia 2007, 4 (1), 192-201.

83. Kim, D. H.; Han, K.; Gupta, K.; Kwon, K. W.; Suh, K. Y.; Levchenko, A. Mechanosensitivity of fibroblast cell shape and movement to anisotropic substratum topography gradients. Biomaterials 2009, 30 (29), 5433-44.

84. Lee, M. R.; Kwon, K. W.; Jung, H.; Kim, H. N.; Suh, K. Y.; Kim, K.; Kim, K. S. Direct differentiation of human embryonic stem cells into selective neurons on nanoscale ridge/groove pattern arrays. Biomaterials 2010, 31 (15), 4360-6.

85. Dalby, M. J.; Riehle, M. O.; Johnstone, H. J.; Affrossman, S.; Curtis, A. S. Polymerdemixed nanotopography: control of fibroblast spreading and proliferation. Tissue engineering 2003, 8 (6), 1099-108. 


\section{Chapter 2: Incorporating Nanotopography for Disease Detection - Adhesion-based Circulating Tumor Cell Capture}

As published in Colloids and Surfaces B: Biointerfaces, Volume 147, 1 November 2016,

Pages 291-299

https://doi.org/10.1016/j.colsurfb.2016.08.008

Lin Shi, Kai Wang, and Yong Yang, Ph.D.

Department of Chemical and Biomedical Engineering, West Virginia University, Morgantown, WV, 26506, USA

Corresponding author: Yong Yang, Ph.D., Department of Chemical and Biomedical Engineering, West Virginia University, Morgantown, WV, 26506, USA

Email: yong.yang@mail.wvu.edu 


\begin{abstract}
CTCs shed from primary tumors, transport through the bloodstream to distant sites, and cause $90 \%$ of cancer deaths. ${ }^{1}$ Although different techniques have been developed to isolate CTCs for cancer detection, diagnosis and treatment, the heterogeneity of expression of the target antigen and the significant size variance in CTCs limit clinical applications of antibody- and size-based isolation techniques. Cell adhesion using nanotopography has been suggested as a promising approach to isolate CTCs independent of surface marker expression or size of CTCs. However, the influence of nanotopography configuration (geometry and dimensions) on CTC capture efficiency has not been investigated. This study examined capture performance of several cancer cell lines of different types, surface marker expression and metastatic status on nanotopographies of various geometry and dimensions without antibody conjugation. The cancer cells exhibited differential capture performance on the nanotopographies with an efficiency up to $52 \%$. Compared with flat surfaces and isotropic, discrete nanopillars, anisotropic nanogratings favored cancer cell adhesion, thus improving the capture efficiency. The influence of nanotopography height studied, on the other hand, was less significant. This study provides useful information to optimize nanotopography to further improve CTC capture efficiency.
\end{abstract}




\section{Introduction}

Cancer metastasis, initiated by CTCs migration from primary tumors through the bloodstream to distant sites of the body, causes $90 \%$ of cancer deaths. ${ }^{1}$ Although the cellular and molecular characterization of CTCs holds great promise for cancer detection, diagnosis and treatment, the realization of this potential remains limited by current challenges associated with CTC isolation techniques. ${ }^{2}$ The major hurdles in advancing CTC isolation techniques include rarity and heterogeneity of CTCs. CTCs are extremely rare, as few as one CTC per $10^{9}$ normal blood cells in the blood of patients with metastatic cancer. ${ }^{3}$ CTCs also display heterogeneity in the expression of target antigens and variation in cell size. Nevertheless, different techniques have been developed to capture CTCs.

The most widely used CTC capture techniques rely on positive selection based on surface biomarkers such as epithelial cell adhesion molecule (EpCAM) expression on tumor cells. ${ }^{4}$ For instance, CellSearch assay, the most standardized technology, uses ferrofluids loaded with an EpCAM antibody (anti-EpCAM) to capture CTCs through a magnetic field. The advent of microfluidic technology advances CTC capture techniques. CTC capture efficiency has been improved by enhancing CTCs-antibody interactions via optimizing the microchannel dimensions, ${ }^{5}$ introducing microscale pillars, ${ }^{6}$ and generating microvortices. ${ }^{7}$ Although EpCAM is expressed in the cells of epithelial origin, the EpCAM expression on tumor cells varies with tumor type, ${ }^{8}$ some cells even express no EpCAM. ${ }^{9}$ Additionally, invasive tumor cells tend to lose their epithelial antigens via the epithelial-to-mesenchymal transition process..$^{10}$ The antibody-based capture techniques are thereby limited to the tumor cells expressing the specific antigen. ${ }^{11,12,13}$ Because of relatively low sensitivity on some tumor cells expressing low or no EpCAM, the CellSearch assay only achieved a median yield of approximately one CTC per milliliter and typically low 
purity. ${ }^{14,15}$ To overcome the limitation of heterogeneous surface marker expression, several physical properties distinguishing CTCs from most normal blood cells have been utilized to capture CTCs. The properties include the larger size of most epithelial cells and differences in density, charge, migratory properties, and some properties of specific cell types (e.g., melanocytic granules in melanoma cells). ${ }^{16,17,18}$ For instance, the size-based microsieve and microfiltration device have been developed to isolate breast, gastric, and colon tumor cells lines including EpCAM-negative tumor cells. ${ }^{17,19,20,21}$ However, the fact that CTCs are not always larger than leukocytes and monocytes have a similar size $(15-25 \mu \mathrm{m})$ to $\mathrm{CTCs}^{22}$ impedes the clinical applications of size-based capture techniques. ${ }^{23}$

Emerging compelling evidence continues to show that substrate nanotopography has a profound influence on cell adhesion, suggesting cell adhesion as a promising approach to CTCs capture. Inspired by nanostructured surface (e.g., microvilli, microridges and cilia) of cancer cells ${ }^{24}$ and enhanced cancer cells-nanotopography interactions, ${ }^{25}$ silicon nanowires, ${ }^{26,27}$ polystyrene (PS) nanotubes ${ }^{28}$ and hierarchical nanowire arrays ${ }^{29}$ have been fabricated and conjugated with antiEpCAM to significantly improve sensitivity and efficiency of CTC capture. Strikingly, by taking advantage of the differential adhesion preference of cancer cells to nanotopography compared with normal blood cells, Chen et al. demonstrated high selectivity and high efficiency capture of CTCs by using nanorough glass surfaces prepared by using reactive ion etching (RIE) regardless of the surface marker expression or physical size of the CTCs. ${ }^{30}$ To successfully translate adhesion-based CTC capture technique using nanotopography to clinical settings, it is highly desirable to understand how nanotopography configuration parameters such as geometry and dimensions affect tumor cell adhesion. 
Herein, we investigated capture performance of four human cancer cell lines on representative nanotopographies. The nanotopographies of various geometry (nanoscale gratings and pillars) and dimensions (in particular height) were engineered on elastomeric PDMS substrates. The cancer cell lines were MCF7 (a luminal non-metastatic breast cancer cell line), MDA-MB-231 (a basal aggressive metastatic breast cancer cell line), A549 (an adenocarcinomic basal epithelial cell line), and HeLa (a cervical cancer cell line). Thereby, we were able to examine the influence of geometry and dimensions of nanotopography on cell adhesion and capture performance of the cancer cells of different cell types, surface marker expression (EpCAM positive MCF7 and A549 cells vs EpCAM negative MDA-MB-231 and HeLa cells), and metastatic status (non-metastatic MCF7 vs metastatic MDA-MB-231). This study helped our understanding of nanotopography enhanced CTC capture. 


\section{Materials and Methods}

\section{Cell culture}

All cancer cell lines were purchased from American Type Culture Collection (ATCC; Manassas, VA). MCF7 were cultured in Eagle's Minimum Essential Medium (EMEM; ATCC) supplemented with 10\% (v/v) fetal bovine serum (FBS; Thermo Fisher Scientific, Waltham, MA), 1\% (v/v) penicillin/streptomycin (Life Technologies, Carlsbad, CA) and $0.01 \mathrm{mg} / \mathrm{ml}$ human recombinant insulin (Sigma-Aldrich, St Louis, MO). MDA-MB-231 were cultured in Minimum Essential Media (MEM; Thermo Fisher Scientific) supplemented with 10\% (v/v) FBS, 1\% (v/v) L-glutamine (Life Technologies) and 1\% (v/v) penicillin/streptomycin. HeLa and A549 cells were cultured in Dulbecco's Modified Eagle's Medium (DMEM; Sigma-Aldrich) supplemented with 10\% (v/v) FBS, 1\% (v/v) L-glutamine 1\% (v/v) penicillin/streptomycin. The cultures were maintained at $37^{\circ} \mathrm{C}$ in a humidified atmosphere containing $5 \% \mathrm{CO}_{2}$. The culture media was replaced every 3 days.

\section{Preparation of nanotopographies}

Nanotopography was generated by using EBL and replicated into PDMS substrate as previously described. ${ }^{31}, 32$ Briefly, the nanopattern was designed and written onto a poly(methylmethacrylate) (PMMA) thin film on a silicon substrate by using EBL and then etched in the silicon substrate by applying RIE process. The generated nanotopography was cast with a mixture of PDMS resin and curing agent (Sylgard 184 silicone elastomer kit; Corning, Corning, $\mathrm{NY}$ ) at a 10:1.05 w/w ratio, followed by curing at $70{ }^{\circ} \mathrm{C}$ for $4 \mathrm{~h}$. The PDMS nanotopography was expanded to a large area by applying a stitch technique. ${ }^{33}$ The stitched mold was then imprinted 
into PS substrates to make a PS master mold, from which working PDMS nanotopographies were produced.

The working PDMS nanotopographies were punched to discs fitting in the wells of a 48well plate. The discs were oxygen plasma treated at $300 \mathrm{mT}, 50 \mathrm{~W}$ for $30 \mathrm{~s}$ in a PX-250 Plasma Asher (Nordson MARCH, Concord, CA) to render a hydrophilic surface. The PDMS nanotopographies and flat surfaces as control were sterilized in $70 \%$ ethanol followed by UV exposure, each for $30 \mathrm{~min}$, and then incubated with $5 \mu \mathrm{g} / \mathrm{cm}^{2}$ collagen I (Corning) for $1 \mathrm{~h}$ prior to cell seeding.

\section{Cancer cell capture}

The cancer cells were first labeled with either CellTracker Green or CellTracker Red (Life Technologies) according to the manufacturer's instruction. Briefly, the cells were incubated in 5 $\mathrm{mM}$ CellTracker in DMEM solution (serum free) at $37^{\circ} \mathrm{C}$ for $30 \mathrm{~min}$. The cells were then trypsinized using $0.25 \%$ trypsin-EDTA (Sigma-Aldrich) after phosphate buffer saline (PBS; Sigma-Aldrich) rinse, resuspended in $1 \mathrm{~mL}$ fresh media, and diluted to the desired seeding density of 500 cells/well. The cell suspension was added onto the PDMS discs in 48-well plates and incubated for a predefined capture time (1 h, $2 \mathrm{~h}$ or $4 \mathrm{~h})$.

To achieve accurate cell counting, the whole PDMS surface with the cells was first scanned by using a Nikon Swept Field microscope with a 10x objective (Nikon, Melville, NY) at the predefined time point. Multiple images from the scanned field of $1 \mathrm{~cm} \times 1.03 \mathrm{~cm}$ rectangle were stitched to a single image using Nikon NIS-Element software, covering the whole well of 48-well plates. Subsequently, the culture media was carefully aspirated and the sample was gently rinsed 
with PBS to remove any non-adhered cells. The PDMS disc with captured cells was scanned again to count the captured cells by repeating the aforementioned scanning process.

ImageJ (http://imagej.nih.gov/ij/) was used to quantify the numbers of seeded cells and captured cells using the "analyze particle" function. The cells were highlighted by adjusting the threshold and the image was converted to a binary image prior to analyzing the particles.

\section{Cell area measurement}

MCF7 cells were pre-labeled with CellTracker Red and seeded at a density of 1000 cells $/ \mathrm{cm}^{2}$ on the PDMS substrates including nanotopographies and flat surfaces. After $4 \mathrm{~h}$ cultivation, the cells were fixed using 4\% paraformaldehyde (PFA; Electron Microscopy Sciences, Hatfield, PA) in PBS for 30 min, and mounted on a coverglass using ProLong Gold Antifade Reagent with 4,6-diamidino-2-phenylindole (DAPI; Life Technologies) overnight at room temperature. At least 50 cells were imaged using a Nikon Swept Field microscope with 40x oil objective. Cell area was quantified using ImageJ software. Firstly, the cells were highlighted by adjusting the threshold and the image was converted to a binary image. After the scale has been properly calibrated, the areas of the cells were measured using ROI (Region of Interest) manager.

\section{SEM observations}

The substrates with cells grown were rinsed with PBS and fixed in a mixture of $4 \%$ PFA and 2\% glutaraldehyde (Thermo Fisher Scientific) in PBS at ambient for $4 \mathrm{~h}$. The samples were then rinsed with deionized (DI) water and progressively dehydrated using a Baltec $\mathrm{CO}_{2}$ critical point dryer (Bal-Tec, Los Angeles, CA). The substrates with(out) cells grown were sputter-coated with a gold layer of $\sim 10 \mathrm{~nm}$ thick by using a Denton Vacuum Desk V sputter unit (Denton Vacuum, 
LLC, Moorestown, NJ, USA), and imaged in a field emission SEM (JEOL JSM-7600F, Peabody, MA).

\section{Statistical analysis}

Capture efficiency and cell areas were expressed as mean \pm standard error of mean (S.E.M). The differences between groups were analyzed by one-way ANOVA using student T-test for multiple comparisons at a confidence interval level of $95 \%$. 


\section{Results and Discussion}

\section{Design of nanotopographies}

Recent studies indicated that nanotopography modulated cell phenotype and function were dictated by the geometry (e.g., gratings, pillars and wells), dimensions and arrangement of nanofeatures, which is cell type-specific. ${ }^{34,35,36,37,38,39}$ Our studies also demonstrated that cell adhesion, nuclear volume and cell function such as proliferation, transfection and ECM protein production of human lung fibroblasts could be modulated by the geometry (nanoscale anisotropic gratings and pillars) and dimensions, in particular the height of nanotopography. ${ }^{31}$ In light of our previous results, we chose representative nanogratings (NGs) and nanopillars (NPs) of various heights in this study (see Figure 2-1). The nanotopographies had the same feature size (500 nm in line width of NGs and diameter of NPs), similar spacing (500 and $450 \mathrm{~nm}$ for the edge-to-edge spacing of NGs and NPs, respectively) and two heights (150 and $560 \mathrm{~nm}$ ). Additionally, equally spaced nanogratings of $1000 \mathrm{~nm}$ in line width were fabricated, which had $15 \%$ and $56 \%$ surface area increase for 150 and $560 \mathrm{~nm}$ heights, respectively. For the convenience of discussion, the nanotopography was labeled by using a combination of feature size, edge-to-edge spacing and height. For example, $500-0.9 \times-150$ referred to the nanogratings of $500 \mathrm{~nm}$ in diameter, 0.9 times edge-to-edge distance $(450 \mathrm{~nm})$ in spacing and $150 \mathrm{~nm}$ in height. The lateral dimensions of nanotopographies were defined by EBL and confirmed by using SEM, and the height was

controlled by RIE processing time and measure by using atomic force microscope (AFM). ${ }^{31}$ Such design of nanotopographies allowed systematic investigation of capture performance of different cancer cells on nanotopography of various configuration parameters (geometry and height). 


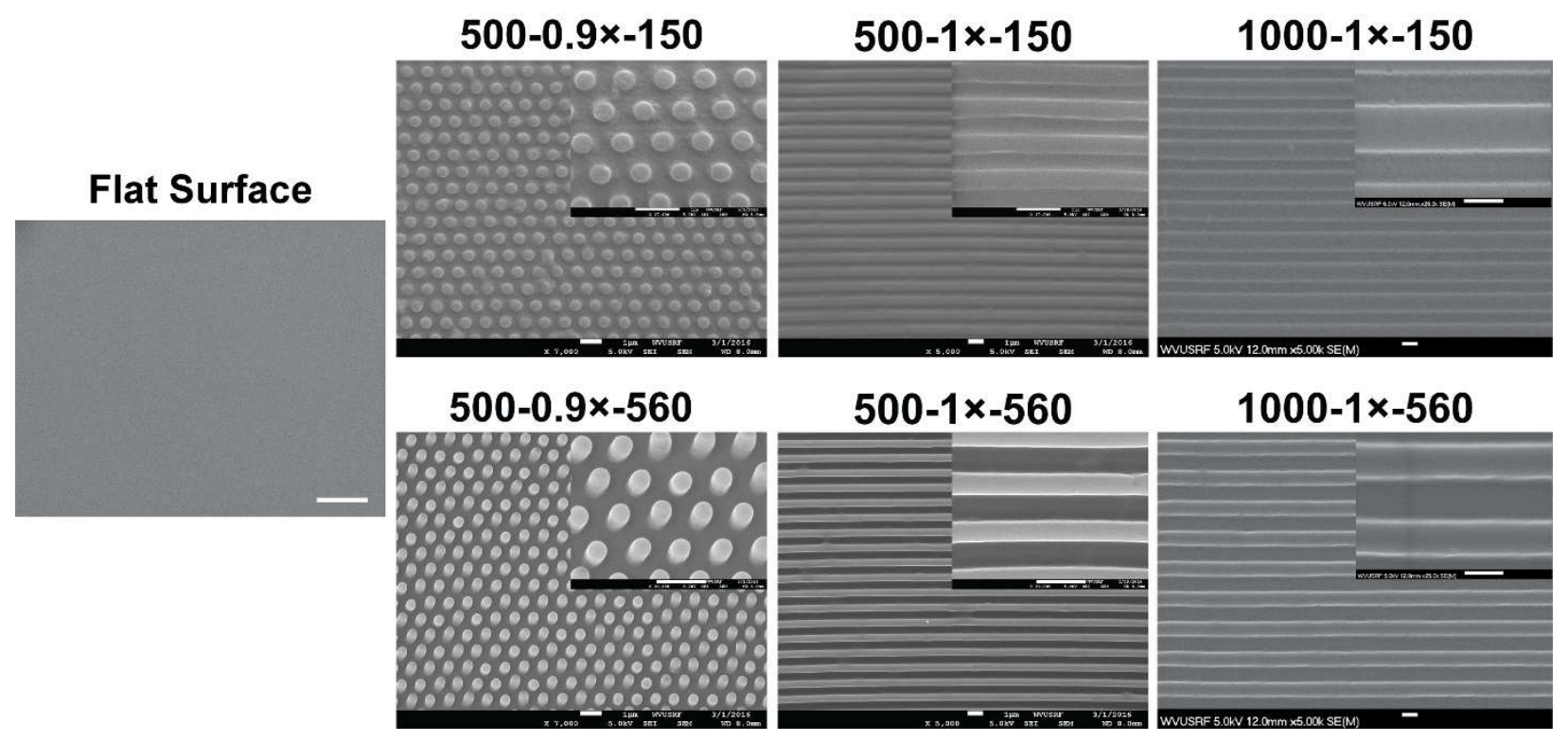

Figure 2-1: SEM micrographs of the PDMS nanotopographies and the flat substrate. The scale bars are $1 \mu \mathrm{m}$.

\section{MCF7 cell capture on nanotopographies}

We first examined the capture efficiency of MCF7 cells on the nanotopographies as a function of incubation time. Capture efficiency was defined as the ratio of the number of cells adhered to the substrate surface to the number of cells initially seeded. To avoid possible errors in initial cell counting from the cell suspension preparation step, the seeded cells were precisely counted by scanning the whole PDMS surface after the predefined time, but before rinsing off the non-adherent cells. Because early cell-nanotopography interactions were critical to mechanosensing ${ }^{40}$ and the reported CTC capture experiment was usually performed within $4 \mathrm{~h}^{26}{ }^{26}$ 30,41 the incubation time was determined at 1,2 and $4 \mathrm{~h}$. At all the time points, it was observed that some cells were captured on the PDMS substrates including the nanotopographies and the flat surfaces, as exemplified in Figure 2-2A. The measurement showed that on the same PDMS substrate, the capture efficiency increased as a function of the incubation time (see Figure 2-2B). 
The capture efficiency on the flat surfaces and the nanopillars slightly increased over time. For instance, the efficiency on the flat surfaces increased from $3.1 \pm 1.5 \%$ at $1 \mathrm{~h}$ to $4.3 \pm 2.0 \%$ and $10.4 \pm 2.3 \%$ at 2 and $4 \mathrm{~h}$, respectively. By contrast, the nanogratings displayed a remarkable enhancement on MCF7 capture, and the efficiency reached up to $41.0 \pm 5.0 \%$ on $500-1 \times-150$ at 4 h. For the same nanotopography geometry, the decrease in height did not result in significantly different capture efficiency on the nanopillars (except the capture at $2 \mathrm{~h}$ ), yet improved MCF7 capture on the nanogratings, $20.7 \pm 1.3 \%$ on $500-1 \times-560$ vs $29.1 \pm 0.3 \%$ on $500-1 \times-150$ at $2 \mathrm{~h}$, and $27.9 \pm 3.9 \%$ on $500-1 \times-560$ vs $41.0 \pm 5.0 \%$ on $500-1 \times-150$ at $4 \mathrm{~h}$. The results suggested that while the nanotopographies could improve CTC capture, the nanogratings were more effective on MCF7 capture than the nanopillars, and increase in the height of nanogratings undermined MCF7 cell capture. 

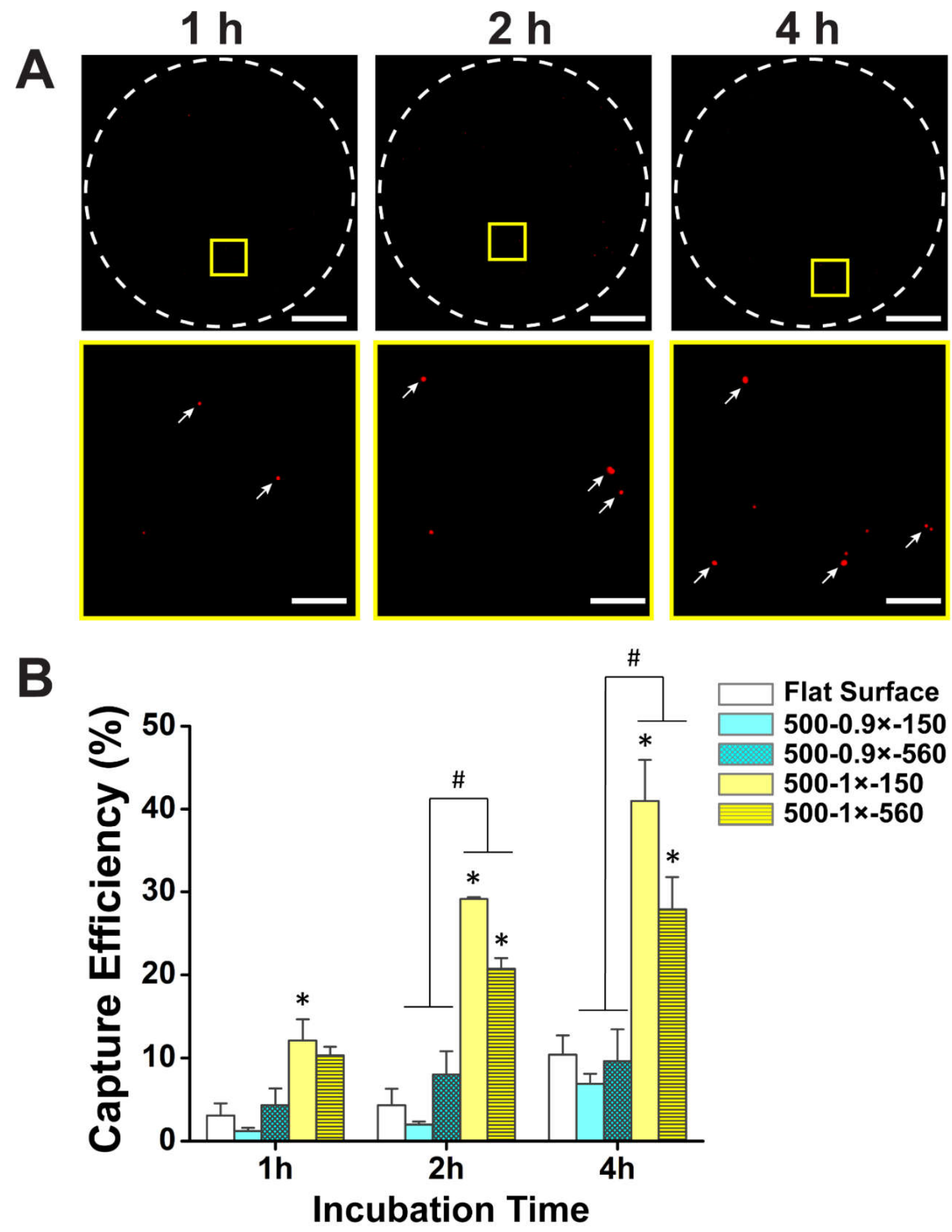

Figure 2-2: MCF7 cell capture on the nanotopographies. (A) Fluorescent images of MCF7 captured on nanogratings 500-1×-150. Top row: Field scan images of MCF7 cells captured at 1,2 
and $4 \mathrm{~h}$ of incubation time. The scale bars are $2 \mathrm{~mm}$. Bottom row: enlarged view of boxed area in the top row. The arrows point to the captured cells in red. The scale bars are $250 \mu \mathrm{m}$. (B) Capture efficiency of MCF7 on the nanotopographies as a function of time. *: Significant different $(p<$ $0.05)$ from the flat controls and \#: significant difference $(p<0.05)$ between two groups.

Intuitively, enhanced cell adhesion was associated with a larger cell area. We thus measured the cell spreading area and examined its correlation with capture efficiency on the nanotopographies. As shown in Figure 2-3A, MCF7 cells displayed approximately round morphology on the flat surfaces and the nanopillars but a mixture of round and partially elongated morphology on the nanogratings (SEM images in Figure 2-4). Cell area measurement summarized in Figure 2-3B revealed that MCF7 cells on the nanogratings exhibited average areas (418.8 \pm 21.5 $\mu \mathrm{m}^{2}$ on $500-1 \times-150$, and $443.8 \pm 22.0 \mu \mathrm{m}^{2}$ on $\left.500-1 \times-560\right)$ similar to the flat controls $(410.84 \pm$ $\left.13.96 \mu \mathrm{m}^{2}\right)$, but significantly larger than those on the nanopillars $\left(107.77 \pm 5.13 \mu \mathrm{m}^{2}\right.$ on $500-1.9 \times-$ 150 , and $155.63 \pm 10.62 \mu \mathrm{m}^{2}$ on $\left.500-1.9 \times-560\right)(p<0.001)$. It was also noted that cell areas on the deeper nanotopographies were larger than their shallow counterparts. The observation that the nanogratings induced a larger cell area than the nanopillars was consistent with the MCF7 capture results, indicating increased cell spreading area facilitated the cell capture. However, the increase in height of the nanotopographies from 150 to $560 \mathrm{~nm}$, accompanied with an increased substrate surface area, resulted in an enlarged the cell area, contradictory to the influence of height on MCF7 capture efficiency. To further understand nanotopography modulated cell adhesion, we examined cell-nanotopography interactions by conducting SEM observations. As shown in Figure 2-4, MCF7 cells were well spread on the flat surfaces. However, the cells displayed a round and compact morphology on the nanopillars. The cells on the nanogratings, on the other hand, spread along the nanograting direction. Moreover, the protrusion of lamellipodia and filopodia on the 
nanotopographies was not obviously affected by the height difference. It was speculated that although the increase in the height enlarged the area of adherent cells, the adhesion of non-invasive MCF7 on the deeper nanotopography might be weakened, leading to decreased capture efficiency.
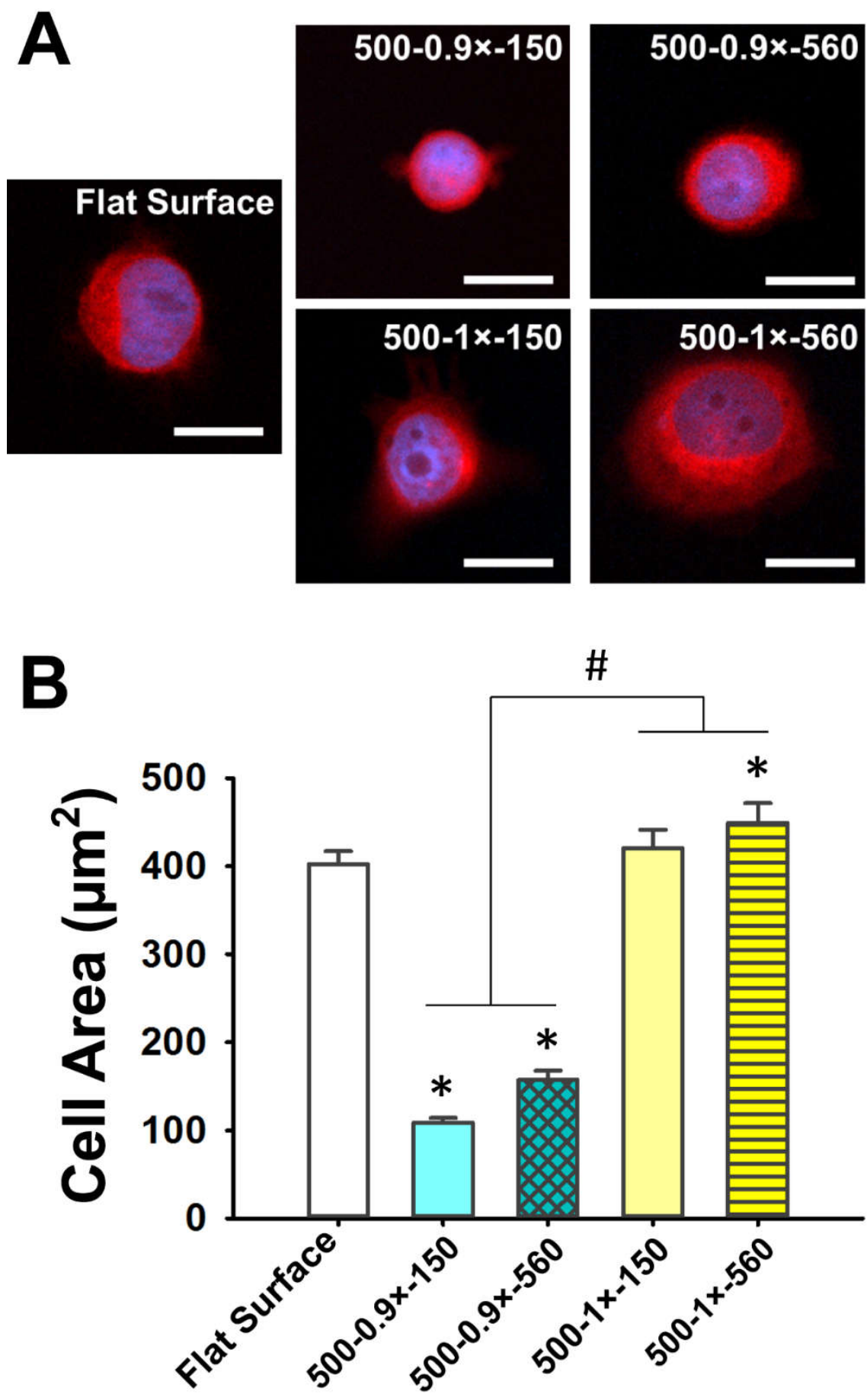
Figure 2-3: (A) Fluorescent images of captured MCF7 cells on the nanotopographies and flat surfaces. The cell was labeled with CellTracker (red) and the nucleus was stained with DAPI (blue). The scale bars are $10 \mu \mathrm{m}$. (B) Cell area measurement of captured MCF7 cells on the nanotopographies and flat surfaces. *: Significant different $(p<0.05)$ from the flat controls and \#: significant difference $(p<0.05)$ between two groups.
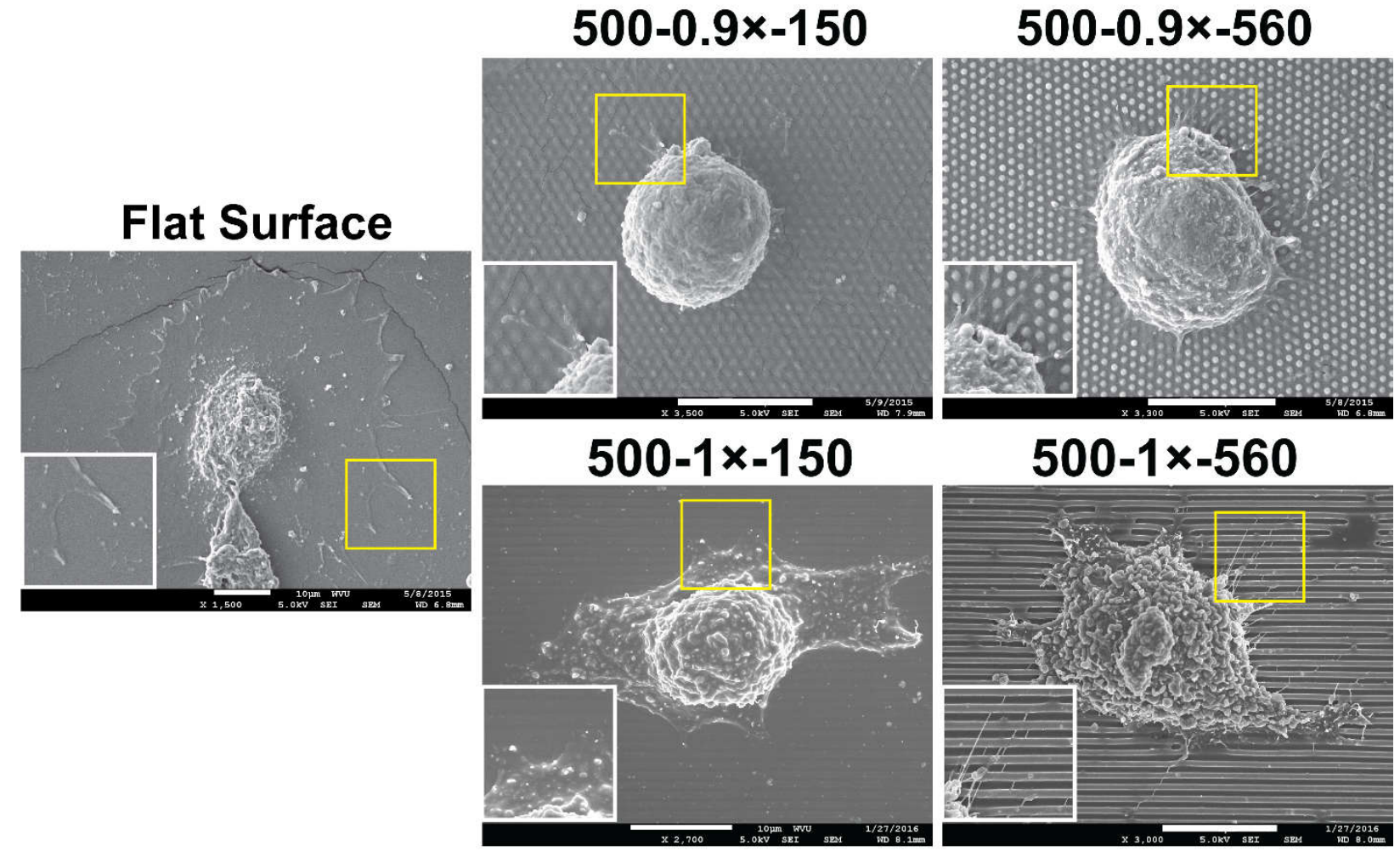

Figure 2-4: SEM micrographs of MCF7 cells adhered to the nanotopographies and flat surface. Insets provide an enlarged view of cell-substrate interactions from the boxed area. The scale bars are $10 \mu \mathrm{m}$.

It has been suggested that isotropic nanopillars tend to decrease the surface wettability, and consequently reduce protein adsorption, leading to an unfavorable cell adhesion. ${ }^{42,43}$ That provides a possible explanation for differential influence of nanogratings versus nanopillars on MCF7 cell 
capture. Our previous study suggests that the anisotropic nanogratings provide continuous contact guidance for the formation and growth of focal adhesions, thus promoting cell adhesion. The highly ordered, discrete nanopillars, on the contrary, tend to disrupt the development of focal adhesions, accompanied with reduced cell spreading area. Evidently, anisotropic nanogratings are favorable for cell adhesion, leading to increased capture efficiency.

\section{Cell type specific capture on nanotopographies}

We further explored nanotopography enhanced CTC capture by extending to more cancer cells of different cell types, surface marker expression and metastatic status. Given the increased MCF7 capture efficiency with incubation time and commonly used capture duration, we assessed CTC capture performance only at $4 \mathrm{~h}$ and summarized it in Figure 2-5.
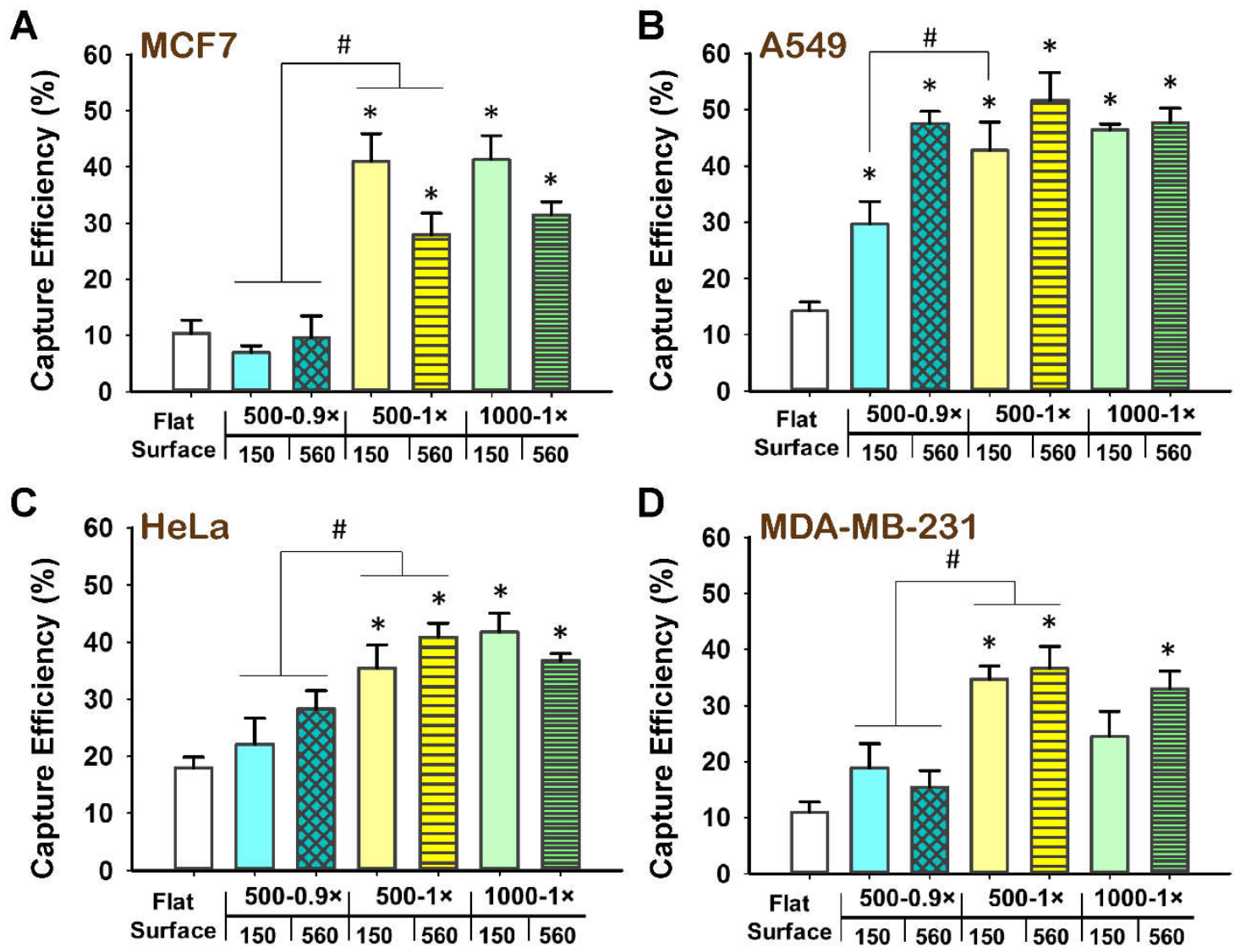
Figure 2-5: Capture efficiency of MCF7, A549, MDA-MB-231 and HeLa cells after $4 \mathrm{~h}$ of incubation on the nanotopographies and flat surfaces. *: Significant different $(p<0.05)$ from the flat controls and \#: significant difference $(p<0.05)$ between two groups.

A549 lung cancer cells were EpCAM positive similar to MCF7 cells, but demonstrated different capture efficiency from MCF7 cells in response to the alteration in geometry and height of the nanotopographies. Deeper nanotopography achieved significantly higher capture efficiency than its shallow counterpart, i.e., $51.7 \pm 4.9 \%$ on $500-1 \times-560$ vs $38.2 \pm 3.3 \%$ on $500-1 \times-150(p<$ $0.0371)$, and $47.5 \pm 2.2 \%$ on $500-0.9 \times-560$ vs $29.7 \pm 4.0 \%$ on $500-0.9 \times-150(p<0.0141)$. By comparison, MCF7 cells reached the highest efficiency on the shallow nanogratings $500-1 \times-150$. The nanogratings also increased the capture efficiency compared with the nanopillars of the same height, but not statistically significant. The observations indicated that A549 cells were sensitive to the height yet not to the geometry of nanotopography. SEM observations showed that A549 cells on all nanotopographies spread more than the flat controls (see Figure 2-6A). Although the cells distributed randomly on the nanopillars and stretched along nanogratings, the nanotopography geometry did not have evident influence on cell area. 


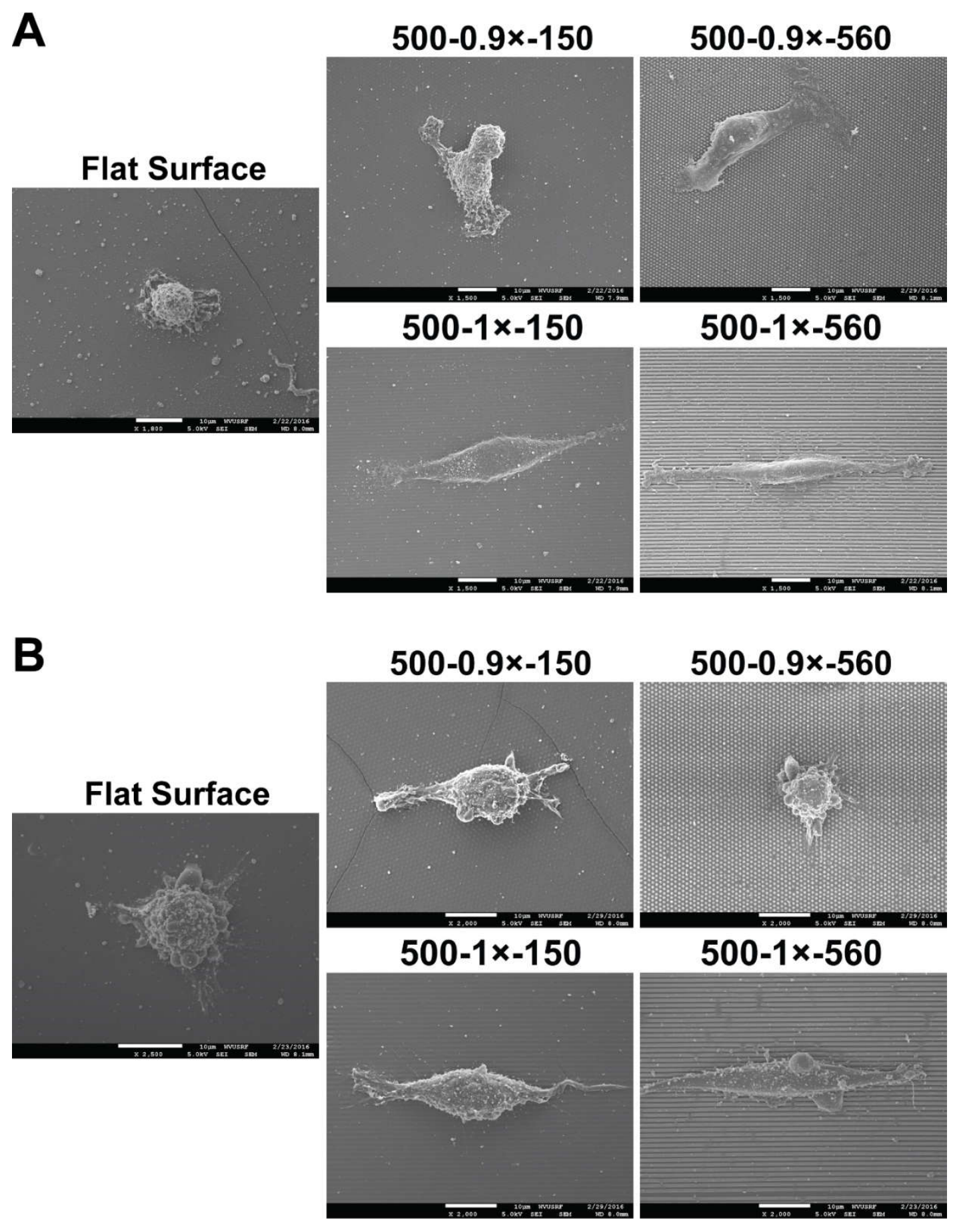

Figure 2-6: SEM micrographs of (A) A549 and (B) HeLa cells on the nanotopographies and flat surfaces. The scale bars are $10 \mu \mathrm{m}$. 
Compared to non-metastatic MCF7 cells, the aggressive metastatic MDA-MB-231 breast cancer cells exhibited similar yet different capture performance on the nanotopographies. MDAMB-231 cells captured on the nanogratings reached relatively higher efficiency, indicating that the nanogratings could more effectively enhance the cell adhesion than the nanopillars. However, the influence of nanotopography height on the cell capture was not significant. It was speculated that MDA-MB-231 cells, different from the epithelial-like MCF7 cells, were mesenchymal-like cells and invasive, and thus could readily reach the bottom of the nanotopography. In this regard, the difference in cell-nanotopography adhesion caused by the height change imposed insignificant influence on the cell capture.

EpCAM negative HeLa cells displayed similarity and difference in the capture performance on the nanotopographies in comparison with MCF7 and A549 cells. The nanogratings favored HeLa cell capture compared with the nanopillars of the same height, which was similar to MCF7 cells but different from A549 cells. Deeper nanotopographies, on the other hand, improved the capture efficiency, which was similar to A549 cells but different from MCF7 cells. Compared with A549 cells, HeLa cells were more sensitive to geometry but less sensitive to the height, which was supported by the SEM observations (see Figure 2-6B).

Despite the differential capture efficiency that these cancer cells demonstrated on the nanotopographies, general trends were observed regarding the influence of nanotopography on CTC capture. The nanogratings usually favored cancer cell adhesion. For example, the capture efficiency on the nanogratings was significantly higher than that on the nanopillars of the same height for MCF7, MDA-MB-231 and HeLa cells. The capture efficiency of A549 cells on the nanogratings was also slightly higher than that on the nanopillars. In current study, increase in height can help capture of these cancer cells, in particular A549 cells. 
Compared to high capture efficiency using anti-EpCAM modified nanotopographies, the capture efficiency demonstrated in this study was relatively low (up to $52 \%$ ). In this study, the height of the nanotopographies was up to $560 \mathrm{~nm}$, far shorter than $2.6 \mu \mathrm{m}$, the reported characteristic length of long brushes of cancer cells. ${ }^{24}$ In addition to the antibody enhancement, the previous studies used nanopillars of a height up to $12-15 \mu \mathrm{m}^{26}$, which significantly improve cell-nanotopography interactions. The RIE generated glass surfaces, which had a roughness of 150 $\mathrm{nm}$ but no anti-EpCAM conjugation, could achieve an efficiency of up to $80 \%{ }^{30}$ The improved CTC capture could be attributed to the higher surface free energy of RIE-etched glass surface compared to RIE-treated PDMS substrates. In light of the current study, the CTC capture efficiency is expected to be improved by optimizing the configuration of nanotopography and surface modification. 


\section{Conclusion}

While more and more studies have been done to realize the significant role that nanotopography played in regulating cell behavior, there have been increased applications in the clinical settings as well. This study fabricated two types of nanotopographies: anisotropic nanogratings and isotropic nanopillars by using EBL and incorporated nanotopographical cue into disease detection for CTCs capture, which systematically evaluated the influence of nanotopography configuration, i.e., geometry and dimension on capture performance of human cancer cell lines of different cell types, surface marker expression and metastatic status. The results showed that compared to flat substrates, nanotopography could enhance cell adhesion and thus improved capture efficiency. Generally speaking, the nanogratings improved cell adhesion and facilitated cancer cell capture although the capture efficiency was also cell type specific. The cancer cells were less sensitive to the height range studied.

For MCF7 cells, the capture efficiency could reach up to $41 \%$ on $500-1 \times-150 \mathrm{~nm}$ nanogratings after 4 hours of incubation, suggesting that although nanotopography could enhance cell adhesion, nanogratings were more favorable for cell capture compared to nanopillars. The cell spreading area measurement revealed that cells on nanogratings exhibited significantly larger area than that on nanopillars. SEM observations also showed enhanced cell-substrate interactions on nanogratings for all four types of cancer cell lines compared to nanopillars and flat surfaces.

The significance of this study is to systematically investigate the effects of shapes and dimensions of nanotopographies on tumor cell capturing. The novelty of our study is to identify the enhanced cell adhesion by nanogratings and apply the nanotopography into adhesion-based CTCs capture while most studies have been focusing on fabricating nanopillar arrays to perform 
CTCs capture by enhanced cell-substrate interaction. Our study shows that the nanogratings can provide continuous contact guidance for focal adhesion formation while discrete nanopillars disrupt the growth of focal adhesions. Meanwhile, the research focus on nanogratings affected cell behavior mostly landed on cell alignment, while we explored the enhanced cell adhesion that caused by the continuous contact guidance provided by nanogratings, which was also a novelty for this study. By optimizing the nanotopography configuration and performing appropriate surface modification for different types of cancer cell lines, the CTCs capture efficiency was expected to be improved. This study is expected to shed light on optimization of nanotopography to improve adhesion-based CTC capture technique for disease detection. 


\section{References}

1. Ozkumur, E.; Shah, A. M.; Ciciliano, J. C.; Emmink, B. L.; Miyamoto, D. T.; Brachtel, E.; Yu, M.; Chen, P.-i.; Morgan, B.; Trautwein, J.; Kimura, A.; Sengupta, S.; Stott, S. L.; Karabacak, N. M.; Barber, T. A.; Walsh, J. R.; Smith, K.; Spuhler, P. S.; Sullivan, J. P.; Lee, R. J.; Ting, D. T.; Luo, X.; Shaw, A. T.; Bardia, A.; Sequist, L. V.; Louis, D. N.; Maheswaran, S.; Kapur, R.; Haber, D. A.; Toner, M. Inertial focusing for tumor antigen-dependent and -independent sorting of rare circulating tumor cells. Science Translational Medicine 2013, 5 (179), 179ra47.

2. Yu, M.; Stott, S.; Toner, M.; Maheswaran, S.; Haber, D. A. Circulating tumor cells: approaches to isolation and characterization. The Journal of Cell Biology 2011, 192 (3), 373-82.

3. Cristofanilli, M.; Budd, G. T.; Ellis, M. J.; Stopeck, A.; Matera, J.; Miller, M. C.; Reuben, J. M.; Doyle, G. V.; Allard, W. J.; Terstappen, L. W. M. M.; Hayes, D. F. Circulating tumor cells, disease progression, and survival in metastatic breast cancer. The New England Journal of Medicine 2004, 351 (8), 781-791.

4. Armstrong, A.; Eck, S. L. EpCAM: a new therapeutic target for an old cancer antigen. Cancer Biology \& Therapy 2003, 2 (4), 320-6.

5. Adams, A. A.; Okagbare, P. I.; Feng, J.; Hupert, M. L.; Patterson, D.; Göttert, J.; McCarley, R. L.; Nikitopoulos, D.; Murphy, M. C.; Soper, S. A. Highly efficient circulating tumor cell isolation from whole blood and label-free enumeration using polymer-based microfluidics with an integrated conductivity sensor. Journal of the American Chemical Society 2008, 130 (27), 86338641. 
6. Nagrath, S.; Sequist, L. V.; Maheswaran, S.; Bell, D. W.; Irimia, D.; Ulkus, L.; Smith, M. R.; Kwak, E. L.; Digumarthy, S.; Muzikansky, A.; Ryan, P.; Balis, U. J.; Tompkins, R. G.; Haber, D. A.; Toner, M. Isolation of rare circulating tumour cells in cancer patients by microchip technology. Nature 2007, 450 (7173), 1235-9.

7. Stott, S. L.; Hsu, C. H.; Tsukrov, D. I.; Yu, M.; Miyamoto, D. T.; Waltman, B. A.; Rothenberg, S. M.; Shah, A. M.; Smas, M. E.; Korir, G. K.; Floyd, F. P., Jr.; Gilman, A. J.; Lord, J. B.; Winokur, D.; Springer, S.; Irimia, D.; Nagrath, S.; Sequist, L. V.; Lee, R. J.; Isselbacher, K. J.; Maheswaran, S.; Haber, D. A.; Toner, M. Isolation of circulating tumor cells using a microvortex-generating herringbone-chip. Proceedings of the National Academy of Sciences of the United States of America 2010, 107 (43), 18392-7.

8. Punnoose, E. A.; Atwal, S. K.; Spoerke, J. M.; Savage, H.; Pandita, A.; Yeh, R. F.; Pirzkall, A.; Fine, B. M.; Amler, L. C.; Chen, D. S.; Lackner, M. R. Molecular biomarker analyses using circulating tumor cells. PLOS One 2010, 5 (9), e12517.

9. Fehm, T.; Solomayer, E. F.; Meng, S.; Tucker, T.; Lane, N.; Wang, J.; Gebauer, G. Methods for isolating circulating epithelial cells and criteria for their classification as carcinoma cells. Cytotherapy 2005, 7 (2), 171-85.

10. Christiansen, J. J.; Rajasekaran, A. K. Reassessing epithelial to mesenchymal transition as a prerequisite for carcinoma invasion and metastasis. Cancer Research 2006, 66 (17), 8319-26.

11. Paterlini-Brechot, P.; Benali, N. L. Circulating tumor cells (CTC) detection: clinical impact and future directions. Cancer Letters 2007, 253 (2), 180-204. 
12. Sieuwerts, A. M.; Kraan, J.; Bolt, J.; van der Spoel, P.; Elstrodt, F.; Schutte, M.; Martens, J. W.; Gratama, J. W.; Sleijfer, S.; Foekens, J. A. Anti-epithelial cell adhesion molecule antibodies and the detection of circulating normal-like breast tumor cells. Journal of the National Cancer Institute 2009, 101 (1), 61-6.

13. Dharmasiri, U.; Balamurugan, S.; Adams, A. A.; Okagbare, P. I.; Obubuafo, A.; Soper, S. A. Highly efficient capture and enumeration of low abundance prostate cancer cells using prostatespecific membrane antigen aptamers immobilized to a polymeric microfluidic device. Electrophoresis 2009, 30 (18), 3289-300.

14. Allard, W. J.; Matera, J.; Miller, M. C.; Repollet, M.; Connelly, M. C.; Rao, C.; Tibbe, A. G.; Uhr, J. W.; Terstappen, L. W. Tumor cells circulate in the peripheral blood of all major carcinomas but not in healthy subjects or patients with nonmalignant diseases. Clinical Cancer Research 2004, 10 (20), 6897-904.

15. Attard, G.; Swennenhuis, J. F.; Olmos, D.; Reid, A. H.; Vickers, E.; A'Hern, R.; Levink, R.; Coumans, F.; Moreira, J.; Riisnaes, R.; Oommen, N. B.; Hawche, G.; Jameson, C.; Thompson, E.; Sipkema, R.; Carden, C. P.; Parker, C.; Dearnaley, D.; Kaye, S. B.; Cooper, C. S.; Molina, A.; Cox, M. E.; Terstappen, L. W.; de Bono, J. S. Characterization of ERG, AR and PTEN gene status in circulating tumor cells from patients with castration-resistant prostate cancer. Cancer Research 2009, 69 (7), 2912-8.

16. Isobe, T.; Ikeda, Y.; Ohta, H. Comparison of sizes and shapes of tumor cells in plasma cell leukemia and plasma cell myeloma. Blood 1979, 53 (5), 1028-30. 
17. Zheng, S.; Lin, H.; Liu, J. Q.; Balic, M.; Datar, R.; Cote, R. J.; Tai, Y. C. Membrane microfilter device for selective capture, electrolysis and genomic analysis of human circulating tumor cells. Journal of Chromatography A 2007, 1162 (2), 154-61.

18. Konigsberg, R.; Obermayr, E.; Bises, G.; Pfeiler, G.; Gneist, M.; Wrba, F.; de Santis, M.; Zeillinger, R.; Hudec, M.; Dittrich, C. Detection of epcam positive and negative circulating tumor cells in metastatic breast cancer patients. Acta Oncologica 2011, 50 (5), 700-10.

19. Mohamed, H.; McCurdy, L. D.; Szarowski, D. H.; Duva, S.; Turner, J. N.; Caggana, M. Development of a rare cell fractionation device: application for cancer detection. IEEE Transactions on Nanobioscience 2004, 3 (4), 251-6.

20. Lin, H. K.; Zheng, S.; Williams, A. J.; Balic, M.; Groshen, S.; Scher, H. I.; Fleisher, M.; Stadler, W.; Datar, R. H.; Tai, Y. C.; Cote, R. J. Portable filter-based microdevice for detection and characterization of circulating tumor cells. Clinical Cancer Research 2010, 16 (20), 5011-8.

21. Hosokawa, M.; Hayata, T.; Fukuda, Y.; Arakaki, A.; Yoshino, T.; Tanaka, T.; Matsunaga, T. Size-selective microcavity array for rapid and efficient detection of circulating tumor cells. Analytical Chemistry 2010, 82 (15), 6629-35.

22. Gauthier, J.; Harel, P. Human leukocytes: their size distribution and mean corpuscular volume. Canadian Medical Association Journal 1967, 97 (13), 793-6.

23. Marrinucci, D.; Bethel, K.; Bruce, R. H.; Curry, D. N.; Hsieh, B.; Humphrey, M.; Krivacic, R. T.; Kroener, J.; Kroener, L.; Ladanyi, A.; Lazarus, N. H.; Nieva, J.; Kuhn, P. Case study of the morphologic variation of circulating tumor cells. Human Pathology 2007, 38 (3), 514-9. 
24. Iyer, S.; Gaikwad, R. M.; Subba-Rao, V.; Woodworth, C. D.; Sokolov, I. Atomic force microscopy detects differences in the surface brush of normal and cancerous cells. Nature Nanotechnology 2009, 4 (6), 389-93.

25. Fischer, K. E.; Alemán, B. J.; Tao, S. L.; Hugh Daniels, R.; Li, E. M.; Bünger, M. D.; Nagaraj, G.; Singh, P.; Zettl, A.; Desai, T. A. Biomimetic nanowire coatings for next generation adhesive drug delivery systems. Nano Letters 2009, 9 (2), 716-20.

26. Wang, S.; Wang, H.; Jiao, J.; Chen, K. J.; Owens, G. E.; Kamei, K.; Sun, J.; Sherman, D. J.; Behrenbruch, C. P.; Wu, H.; Tseng, H. R. Three-dimensional nanostructured substrates toward efficient capture of circulating tumor cells. Angewandte Chemie International Edition 2009, 48 (47), 8970-3.

27. Wang, S.; Liu, K.; Liu, J.; Yu, Z.; Xu, X.; Zhao, L.; Lee, T.; Lee, E.; Reiss, J.; Lee, Y.; Chung, L.; Huang, J.; Rettig, M.; Seligson, D.; Duraiswamy, K.; Shen, C.; Tseng, H. Highly efficient capture of circulating tumor cells by using nanostructured silicon substrates with integrated chaotic micromixers. Angewandte Chemie International Edition 2011, 50 (13), 30843088.

28. Liu, X. L.; Chen, L.; Liu, H. L.; Yang, G.; Zhang, P. C.; Han, D.; Wang, S. T.; Jiang, L. Bio-inspired soft polystyrene nanotube substrate for rapid and highly efficient breast cancer-cell capture. NPG Asia Materials 2013, 5.

29. Zhang, F. L.; Jiang, Y.; Liu, X. L.; Meng, J. X.; Zhang, P. C.; Liu, H. L.; Yang, G.; Li, G. N.; Jiang, L.; Wan, L. J.; Hu, J. S.; Wang, S. T. Hierarchical nanowire arrays as three-dimensional 
fractal nanobiointerfaces for high efficient capture of cancer cells. Nano Letters 2016, 16 (1), 766772.

30. Chen, W. Q.; Weng, S. N.; Zhang, F.; Allen, S.; Li, X.; Bao, L. W.; Lam, R. H. W.; Macoska, J. A.; Merajver, S. D.; Fu, J. P. Nanoroughened surfaces for efficient capture of circulating tumor cells without using capture antibodies. ACS Nano 2013, 7 (1), 566-575.

31. Wang, K.; Bruce, A.; Mezan, R.; Kadiyala, A.; Wang, L.; Dawson, J.; Rojanasakul, Y.; Yang, Y. Nanotopographical modulation of cell function through nuclear deformation. ACS Applied Materials \& Interfaces 2016, 8 (8), 5082-92.

32. Wang, K.; Leong, K. W.; Yang, Y. Expanding nanopatterned substrates using stitch technique for nanotopographical modulation of cell behavior. Journal of Visualized Experiments 2016, (118), e54840-e54840.

33. Yang, Y.; Kulangara, K.; Sia, J.; Wang, L.; Leong, K. Engineering of a microfluidic cell culture platform embedded with nanoscale features. Lab on a Chip 2011, 11 (9), 1638-1646.

34. Teixeira, A. I.; Abrams, G. A.; Bertics, P. J.; Murphy, C. J.; Nealey, P. F. Epithelial contact guidance on well-defined micro- and nanostructured substrates. Journal of Cell Science 2003, 116 (10), 1881-1892.

35. Yim, E. K. F.; Pang, S. W.; Leong, K. W. Synthetic nanostructures inducing differentiation of human mesenchymal stem cells into neuronal lineage. Experimental Cell Research 2007, 313 (9), 1820-1829. 
36. McMurray, R.; Gadegaard, N.; Tsimbouri, P.; Burgess, K.; McNamara, L.; Tare, R.; Murawski, K.; Kingham, E.; Oreffo, R.; Dalby, M. Nanoscale surfaces for the long-term maintenance of mesenchymal stem cell phenotype and multipotency. Nature Materials 2011, 10 (8), 637-644.

37. Chen, W.; Villa-Diaz, L. G.; Sun, Y.; Weng, S.; Kim, J. K.; Lam, R. H.; Han, L.; Fan, R.; Krebsbach, P. H.; Fu, J. Nanotopography influences adhesion, spreading, and self-renewal of human embryonic stem cells. ACS Nano 2012, 6 (5), 4094-103.

38. Jeon, H.; Koo, S.; Reese, W. M.; Loskill, P.; Grigoropoulos, C. P.; Healy, K. E. Directing cell migration and organization via nanocrater-patterned cell-repellent interfaces. Nature Materials 2015, 14 (9), 918-23.

39. Dalby, M. J.; Gadegaard, N.; Tare, R.; Andar, A.; Riehle, M. O.; Herzyk, P.; Wilkinson, C. D. W.; Oreffo, R. O. C. The control of human mesenchymal cell differentiation using nanoscale symmetry and disorder. Nature Materials 2007, 6 (12), 997-1003.

40. Gautrot, J. E.; Malmstrom, J.; Sundh, M.; Margadant, C.; Sonnenberg, A.; Sutherland, D. S. Nanoscale surfaces for the long-term maintenance of mesenchymal stem cell phenotype and multipotency. Nano Letters 2014, 14 (7), 3945-3952.

41. Kwon, K. W.; Choi, S. S.; Lee, S. H.; Kim, B.; Lee, S. N.; Park, M. C.; Kim, P.; Hwang, S. Y.; Suh, K. Y. Label-free, microfluidic separation and enrichment of human breast cancer cells by adhesion difference. Lab on a Chip 2007, 7 (11), 1461-8. 
42. Biggs, M. J.; Richards, R. G.; Gadegaard, N.; Wilkinson, C. D.; Dalby, M. J. Regulation of implant surface cell adhesion: characterization and quantification of s-phase primary osteoblast adhesions on biomimetic nanoscale substrates. Journal of Orthopaedic Research 2007, 25 (2), 273-82.

43. Lossdorfer, S.; Schwartz, Z.; Wang, L.; Lohmann, C. H.; Turner, J. D.; Wieland, M.; Cochran, D. L.; Boyan, B. D. Microrough implant surface topographies increase osteogenesis by reducing osteoclast formation and activity. Journal of Biomedical Materials Research Part A 2004, $70(3), 361-9$. 


\title{
Chapter 3: Incorporating Substrate Stiffness for Disease Modeling - In Vitro Model of Cell Sensing Nanomaterials
}

\begin{abstract}
As the rapid development of modern nanotechnology, engineered nanomaterials have been used in a wide range of fields because of their unique properties, including physics, chemistry, biochemistry, biomedical engineering, and so many other disciplines. In the same time, an arising issue has been more and more realized by the researchers that nanomaterials toxicity may cause potential risk to the human body.

This study focused on understanding the effects of substrate stiffness on fibrogenic responses of human lung fibroblasts to multi-wall carbon nanotubes (MWCNTs). In most living tissue, cells resident in a complex microenvironment where these cells interact with the ECM and the neighboring cells. The interactions between cells and ECM could regulate the cell behavior. Similar to in vivo, in vitro models have been reported that cells have the ability to sense the stiffness of synthetic substrate and, the variation of substrate stiffness could affect cell phenotype and function. Most existing in vitro models focused on conducting the experiment using the rigid TCPS surfaces, which were much stiffer than the actual in vivo cell microenvironment. Thus, the behavior and nanomaterial responsiveness of cells could be largely changed due to the deviation of substrate stiffness when cultured on TCPS. Therefore, it is of the critical need to create physiologically relevant tissue models to mimic the in vivo environment by introducing stiffness cue.
\end{abstract}


This study used the synthesized polyacrylamide (PAAm) hydrogel to represent the normal and fibrotic conditions of lung tissues to conduct in vitro models. The fibrogenic responses and mechanosensing of fibroblasts to MWCNTs at different stiffness conditions have been explored. This study provides an understanding of the regulatory pathways and mediators of fibrogenic activities, which will potentially help identify therapeutic targets against fibrosis. 


\section{Introduction}

Cells live in a dynamic microenvironment that is regulated by the ECM. ECM is a network composed of a wide variety of macromolecules secreted by cells, including the fibers such as collagen, which is the most abundant protein in ECM, even in human body. ${ }^{1,2}$ A majority of the composition of ECM have been known to have a nanoscaled structure, like the collagen I fibrils, which are $300 \mathrm{~nm}$-long, staggered large-diameter banded fibrils typically found in lung, bone and skin tissue. ${ }^{3}$ The intrinsic diverse composition of ECM contributes to the fact that it could serve many functions, including supporting and interacting with the surrounding cells, ${ }^{4}$ providing various growth factors, exchanging signals with cells to control the local environment. ${ }^{5}$ Depending on ECM composition and interstitial fluid, the ECM exhibits various degree of stiffness, ranging from $<1 \mathrm{kPa}$ to $>1 \mathrm{GPa}$ for human tissues. ${ }^{6,7} \mathrm{~A}$ growing body of evidence has shown that the mechanical cues of ECM critically influence numerous developmental, physiological and pathological processes in vivo, ${ }^{8,9}$ and have a profound influence on cell phenotype and function in vitro. ${ }^{10}$

Inspired by the composition of ECM and cell microenvironment, a number of researches have been conducted to study the influence of surface topography and substrate stiffness on cell behavior. It has been found that cell could be highly sensitive when responding to a synthetic surface with different topographical cues as well as stiffness cues. This study focused on how substrate stiffness regulated cell phenotype and function. Figure 3-1 shows a schematic illustration of changes in cell behavior when changing the matrix stiffness from soft to stiff. ${ }^{11,12}$ 

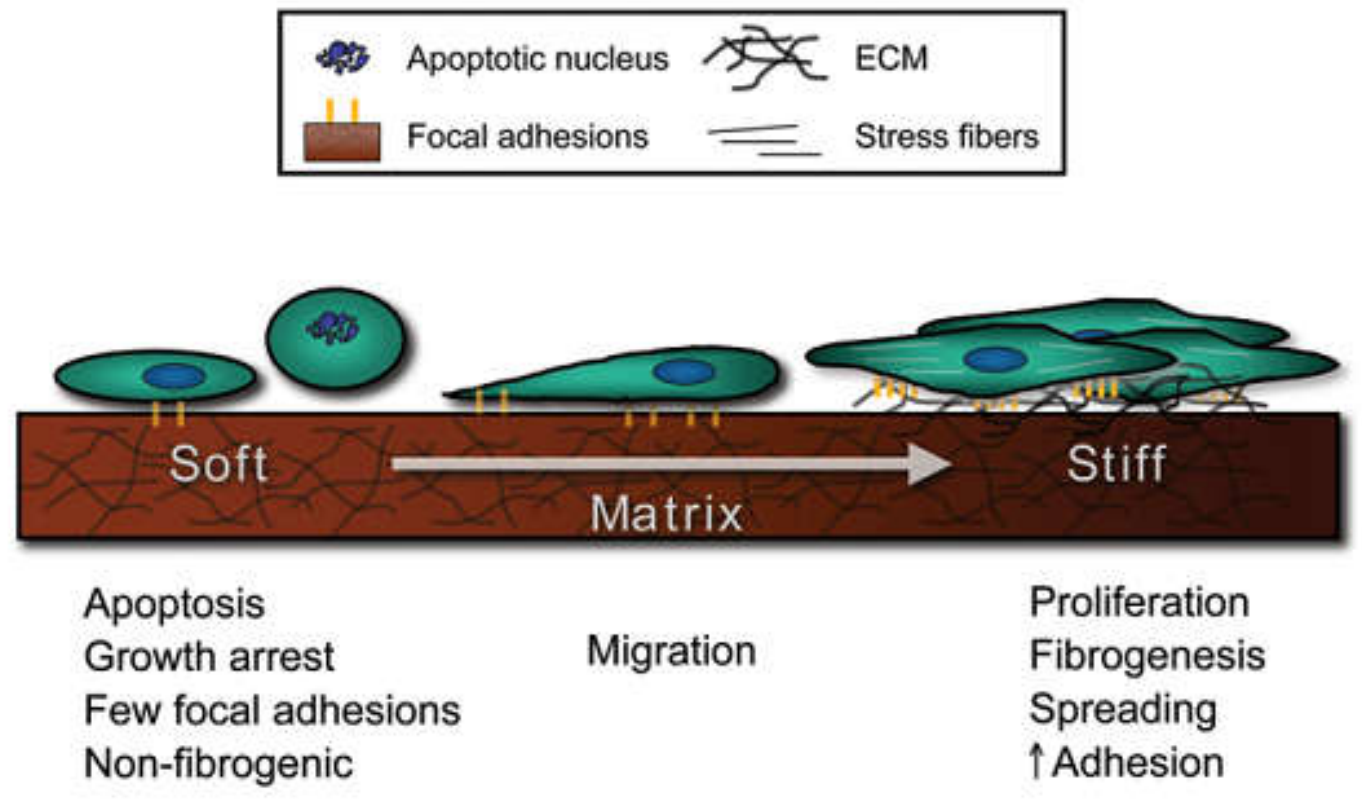

Figure 3-1: Cell behaviors regulated by the variation of matrix mechanics. This schematic illustration shows several behavioral changes (cell growth, proliferation, apoptosis, cell migration, cell adhesion, cell spreading and fibrogenesis response) when changing the matrix stiffness from soft to stiff. (Adapted with permission from Ref. [11])

Generally speaking, cells on soft substrate tends to be rounded and less adhesive and proliferative while on the contrary, cells on the stiff substrate are more proliferative and fibrogenic. Focal adhesions (FAs), as the first and essential step of cell responding to the substrate, have been seen on the stiff matrix and the cells have a spread phenotype. The dynamic changes of focal adhesion induced by substrate stiffness could largely have an impact on cell phenotype and eventually cell function. The signally pathway of cell sensing substrate stiffness as well as surface topography are shown in Figure 3-2. ${ }^{13}$ 

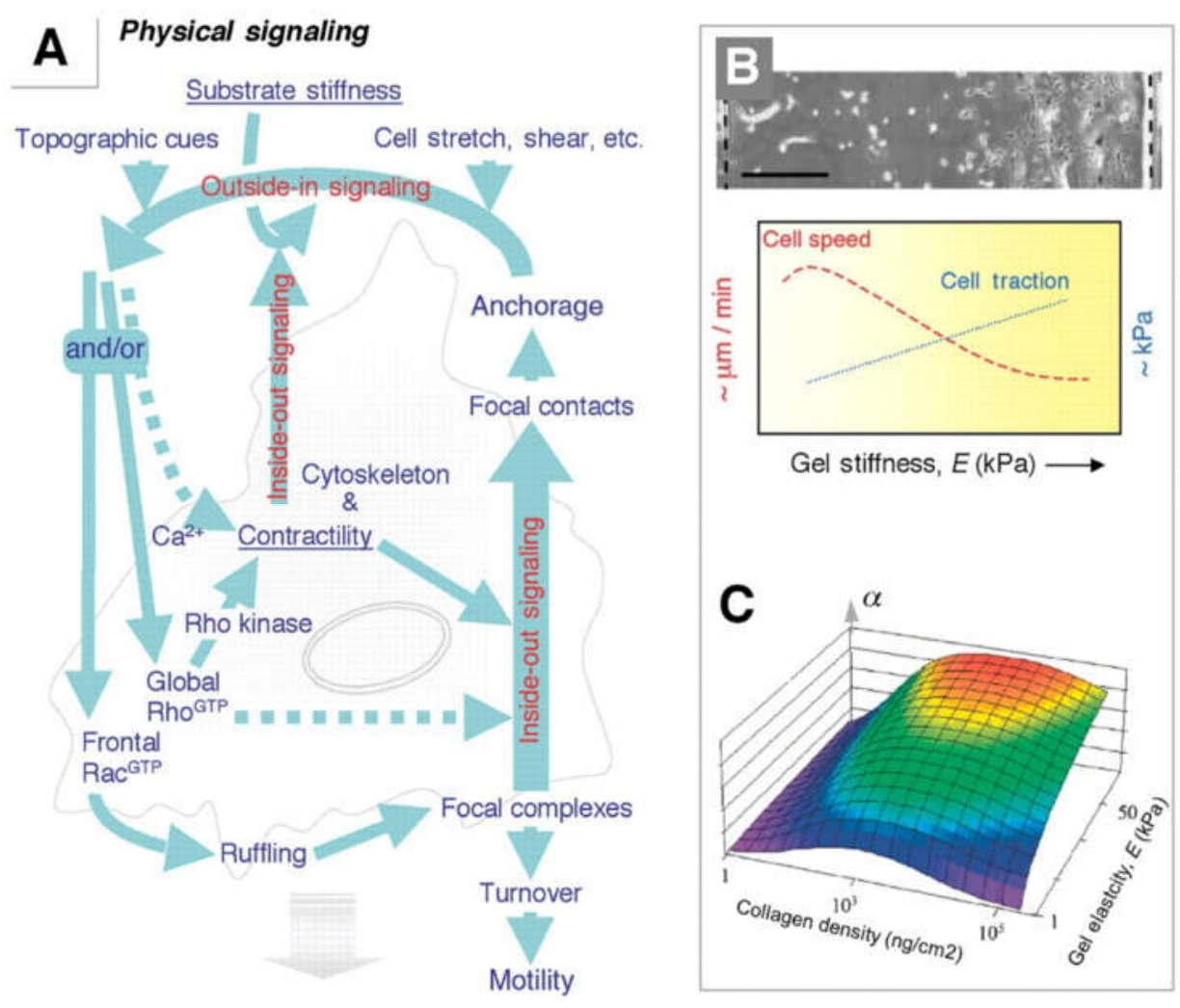

Figure 3-2: Cell contractility, motility and spreading influenced by the mechanical properties of the substrate. (Adapted with permission from Ref. [13]) (A) Influence of substrate stiffness and topography on cell contractility as described by physical and biochemical signally pathways. ${ }^{14}$ (B) Cell motility speed and traction force change with the increase of gel stiffness. Cells tend to have higher motility speed with less tension on soft substrate, ${ }^{15}$ which results in migration from soft towards stiff on a gradient gel. ${ }^{16}$ (C) Nonlinear response obtained from a thermodynamic model of cell spreading area versus collagen density and gel elasticity. ${ }^{17}$

In our study, we conducted an in vitro tissue model based on using the stiffness cue to regulate cell phenotype and function through cell-substrate interaction to examine the cellular response to MWCNTs. 
While the quick development of synthesizing advanced nanomaterials, the toxicity of the nanomaterials to human body has more and more been realized by the researchers. For example, CNTs, a novel material that has been used in a variety of biomedical applications as intracellular transporters due to their intrinsic ability to cross cell membranes. ${ }^{18}$ Like many other synthetic nanomaterials, CNTs have been rapidly developed for the past decade, which brought an increasing concern of its toxicity to the human body. CNTs could cause potential damage to human lung tissue by inhalation and enter into the respiratory tract. ${ }^{19} \mathrm{CNTs}$ interacts with lung fibroblasts could cause damage to the tissue and has been reported to be responsible for lung fibrosis. ${ }^{20}$ Other injuries to the lung could occur like inflammation and tissue damage. The invasion of CNTs to fibroblasts could result in many biological changes including cell proliferation, differentiation and collagen production. ${ }^{19}$ The activation and proliferation fibroblast could cause the disturbances of collagen production, which leads to fibrosis. ${ }^{21}$ The increase of collagen production could be a sign of lung fibrosis. ${ }^{22}$

Thus, it is of great significance to evaluate the potential toxic effects of CNTs. Both in $v i v o^{23,24,25}$ and in vitro ${ }^{26,27,28}$ studies have been conducted to assess their toxicity and influence on causing cellular dysfunction. To evaluate the toxicity of nanomaterials, animal studies are necessary but expensive, time-consuming and facility limited; while the most important limitation of current in vitro models using flat, stiff plastic surfaces under static conditions is that they do not recapitulate characteristics of the ECM with which cells interact in vivo and thus cell behaviors on such surfaces significantly deviate from their in vivo counterparts. ${ }^{10}$ Cell could sense the environment and respond to the physical signals that pass through the substrate. Therefore, cell could behave completely different when culturing on stiff substrate compared to the actual in vivo situation. Therefore, it is of great significance to develop in vitro biomimetic models which can 
provide reliable, rapid and inexpensive methods for toxicity testing and risk assessment of nanomaterials. By taking the stiffness cues into consideration to evaluate the cell sensing nanomaterials, we could physiologically mimic the cell microenvironment, thus providing more convincing results.

A number of researches have been done using fibroblasts as a cell model to study the cell response to substrate elasticity from a variety of perspective. ${ }^{29}, 30,31,32$ Figure $3-3$ here shows the effect of substrate stiffness on stress fibers of fibroblast. Stress fibers are more prominent in cells that are grown on rigid than on soft substrates. ${ }^{33}$

a
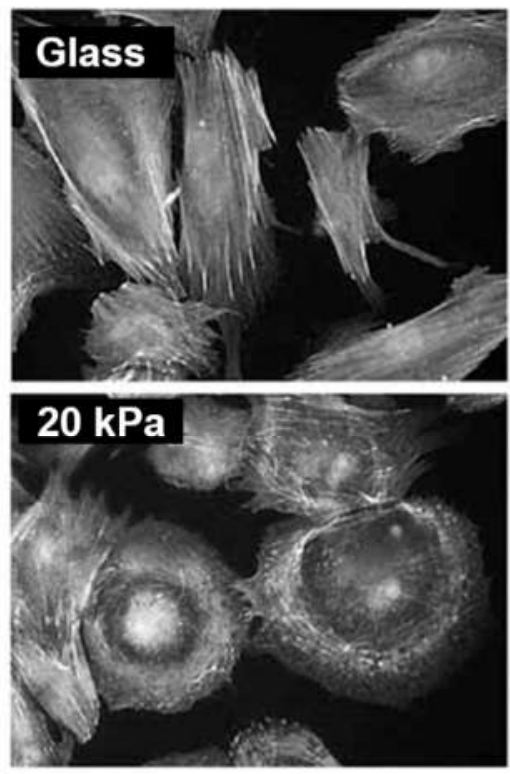

b

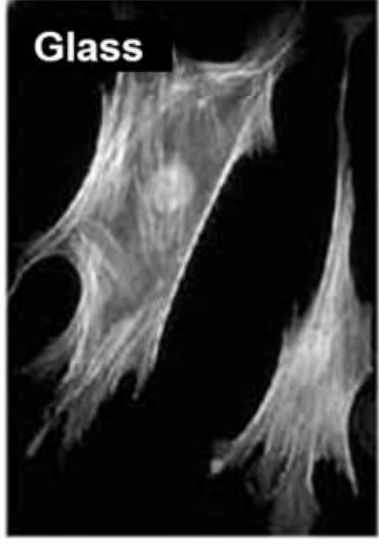

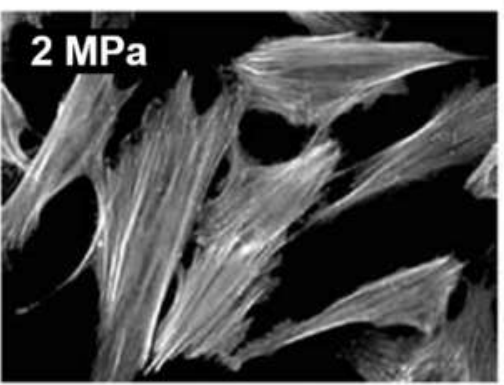
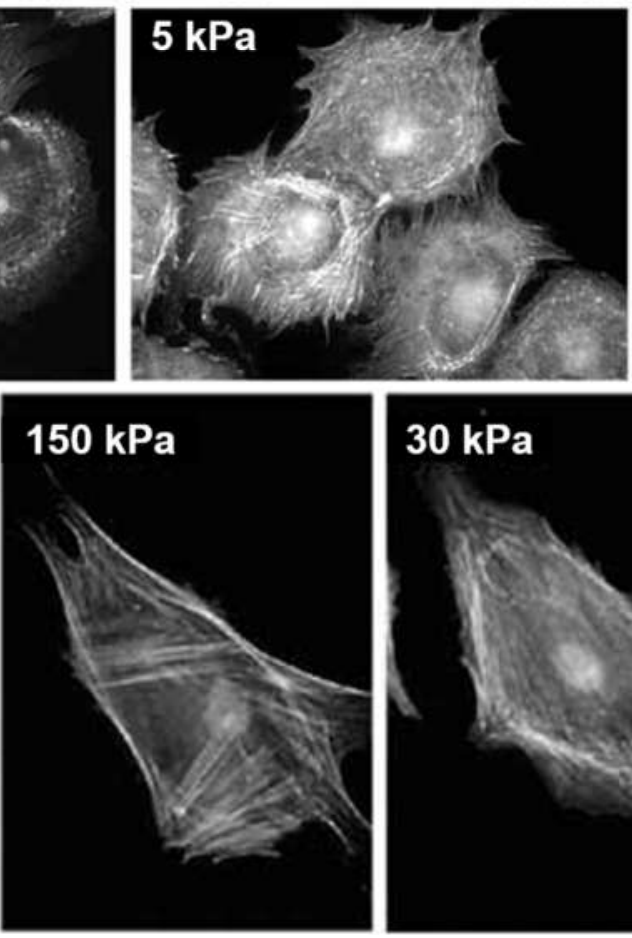
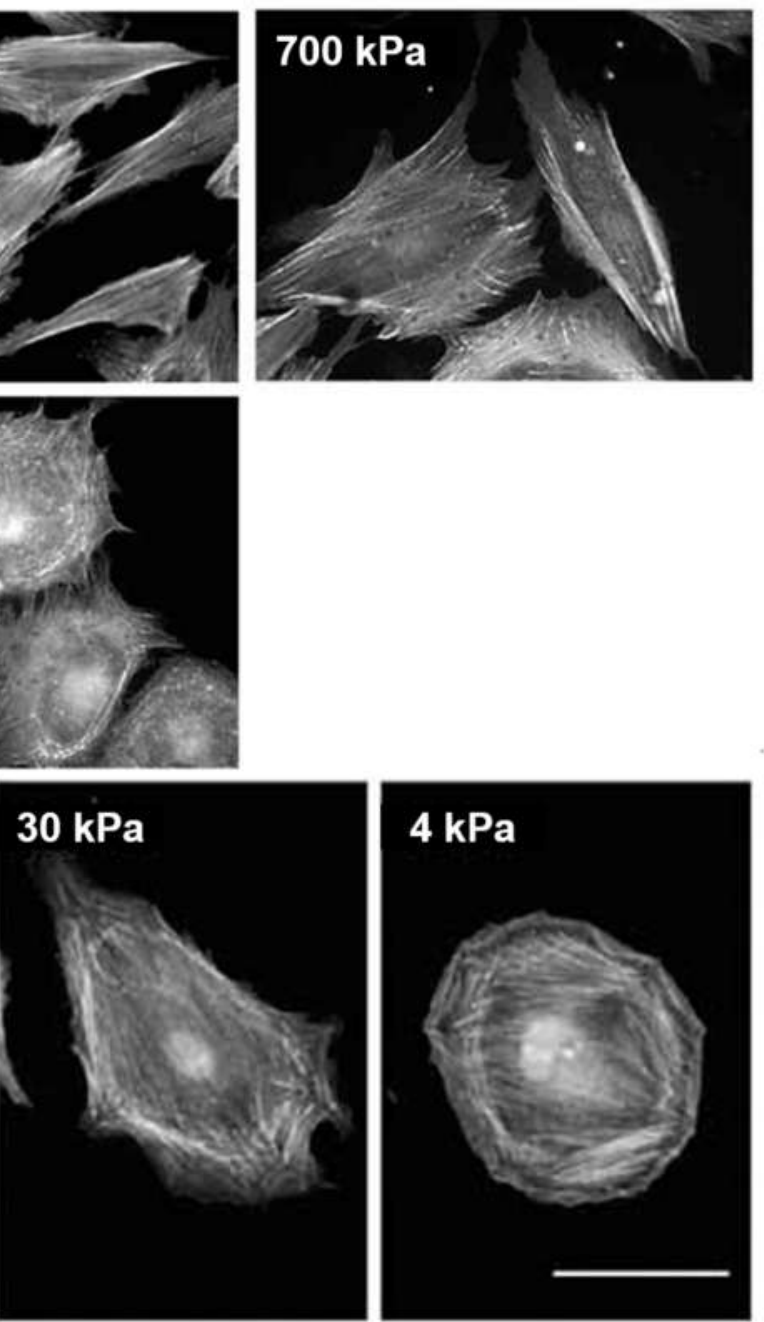

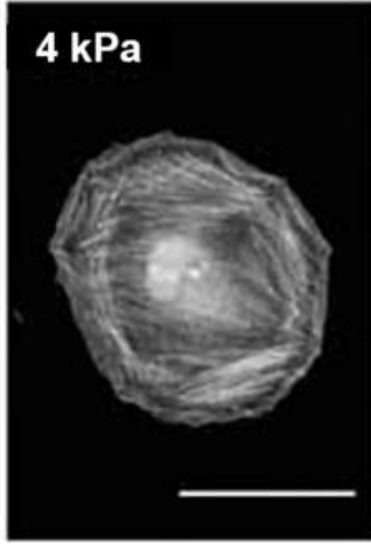


Figure 3-3: Effect of substrate stiffness on cell elongation and polarization. Human foreskin fibroblasts (HFFs) were fixed with 3\% PFA in PBS containing 0.25\% Triton X-100 $6 \mathrm{~h}$ after cell seeding and immunofluorescent stained with TRITC-phalloidin. The images show HFFs spreading on glass coated with fibronectin or engineered substrates PDMS (a) or PAAm (b) with various stiffness. The scale bar is $40 \mu \mathrm{m}$. (Reproduced with permission from Ref. [34])

So far, few reports have been shown to integrate the stiffness cue into the toxicity study for cellular response to CNTs. In this study, our hypothesis is that substrate stiffness can regulate fibroblast sensing CNTs through cell-substrate interaction. Therefore, the objective of this project is to develop an in vitro cell-based model integrated with stiffness cues of physiological relevance to assess the toxicity of nanomaterials. In this view, we systematically investigated the stiffness effects on the fibrogenic response of normal human lung fibroblasts (NHLFs) to MWCNTs.

\section{Toxicity study}

Currently, both in vivo and in vitro have been established for toxicity study. Animal models have been used to test the toxicity effect by injecting the CNTs to animals. ${ }^{35}$ Pulmonary

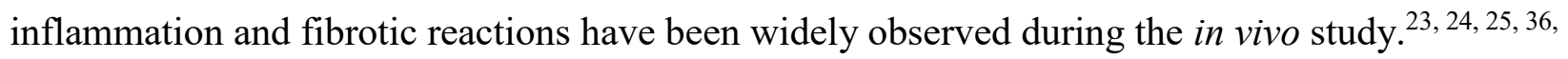

37 Though in vivo study could provide a reliable result, it has the intrinsic limitation of complex process, expensive and humanity. In vitro study, however, is more controllable and easy. Traditionally, in vitro studies for toxicity are mostly based on rigid TCPS plate. Few reports have emerged of toxicity study of fibroblasts on substrate tunable stiffness. In fact, the elastic moduli of TCPS are much more rigid than lung tissue, ${ }^{38}$ leading to an unavoidable drawback of the most in vitro study - it cannot physiologically mimic the in vivo microenvironment, as cell phenotypes 
and function could be largely regulated by its environment. ${ }^{12}$ Thus, it is critical to develop a physiologically relevant in vitro model for toxicity study.

\section{Cellular responses to substrate stiffness cue}

Cells live in a complex microenvironment, which is composed of the ECM and the neighboring cells. ECM is secreted by cells and, conversely, giving support to the surrounding cells. ${ }^{4}$ The elasticity of ECM from different tissue can vary from soft to stiff, based on the function of the different organ. The stiffness of ECM has recently been shown to have a great impact on cell phenotype and regulating cell functions, including cell contraction ${ }^{13}$, cell proliferation ${ }^{39}$ and cell migration ${ }^{40}$. Therefore, by engineering a substrate with tunable stiffness, we could try to mimic the in vivo tissue softness instead of using the TCPS rigid culture plate doing in vitro study. Besides, cellular responses to different substrate stiffness could also be studied, which could guide us to develop a biomimetic cell culture platform to closely mimic the in vivo microenvironment. Furthermore, by optimizing the substrate, we can systematically assess the toxicity testing in a more reliable way. 


\section{Materials and Methods}

\section{Preparation of PAAm hydrogel substrate}

The protocol of synthesizing PAAm hydrogel has been widely reported. ${ }^{41,42,43,44}$ We chose two different stiffness: $3 \mathrm{kPa}$ and $100 \mathrm{kPa}$ to represent the range from soft to stiff. Different from conventional stiff TCPS (reported Young's modulus $3.6 \mathrm{GPa}^{45}$ ), $3 \mathrm{kPa}$ could physiologically mimic the stiffness of lung tissue as reported normal lung tissue has Young's modulus varying from 1-5 $\mathrm{kPa} .{ }^{38,46}$ However, studies have shown that fibrotic lung tissue is much stiffer, where the stiffness could range from $20-100 \mathrm{kPa} .{ }^{38,47}$ The process of preparing PAAm gel for cell study based on the "sandwich-gel" approach is shown in Figure $3-4 .{ }^{44}$ Briefly, there are 5 major steps:

1) Activate the surface of coverglass. This process is critical because it will allow PAAm gel to adhere to the glass surface. Failing of the activation process will result in gel peeling from the coverglass.

Firstly, $25 \mathrm{~mm}$ coverslips were cleaned by immersing in 70\% ethanol and sonicating for approximately 1-2 min. The coverslips were air dried or dried by Kimwipes. After the coverglass was completely cleaned and dried, they were placed in glass dishes which are $10 \mathrm{~mm}$ in diameter (approximate 6-8 coverslips per dish for $25 \mathrm{~mm}$ coverslips) and then immersed with $0.1 \mathrm{M} \mathrm{NaOH}$. Carefully do not let coverslips overlap each other, placing them as far from each other as possible and then incubate for 3 min. While waiting for the incubation of $\mathrm{NaOH}, 0.5 \%$ (3aminopropyl)trimethoxysilane (3-APTMS) were prepared (approximate $25 \mathrm{~mL}$ for one dish) in the chemical hood by diluting 97\% stock solution in DI water. After 3 min incubation was completed, $\mathrm{NaOH}$ was recycled to the same bottle. 
Secondly, working inside the chemical hood, all coverslips were then immersed with prepared $0.5 \%$ 3-APTMS, and then incubated for $30 \mathrm{~min}$. While waiting for the incubation of 3-APTMS, $0.5 \%$ glutaraldehyde (approximate $25 \mathrm{~mL}$ for one dish) were prepared in the chemical hood by diluting $50 \%$ stock solution in DI water. (Note: $0.5 \%$ glutaraldehyde must be freshly prepared) After 30 min incubation of 3-APTMS, the chemical was disposed into its own waste container. The coverslips were rinsed with DI water in the same dish three times on rocker (little less or equal to the maximum speed), for 10 min each wash.

Finally, after three times wash was completed, all coverslips were immersed in prepared $0.5 \%$ glutaraldehyde solution and incubated for another $30 \mathrm{~min}$. After $30 \mathrm{~min}$, glutaraldehyde was disposed into its own waste container. Rinse the coverslips again three times as described previously. After three times wash was completed, the coverslips were dried completely using Kimwipe. The coverslips activation was completed and it could be good for several weeks in a dry area.

2) PAAm gel polymerization. There are four components involved in the polymerization process: acrylamide, N,N'-Methylenebis(acrylamide), Ammonium persulfate (APS) and $\mathrm{N}, \mathrm{N}, \mathrm{N}^{\prime}, \mathrm{N}^{\prime}$-Tetramethylethylenediamine (TEMED).

Firstly, prepare every component for gel polymerization: $40 \%$ acrylamide (A) stocking solution, 2\% bis-acrylamide (B) stocking solution, $50 \mathrm{mM} \mathrm{4-(2-}$ hydroxyethyl)-1-piperazineethanesulfonic acid (HEPES) buffer, 10\% APS and TEMED. $40 \%$ acrylamide stocking solution was prepared by dissolving acrylamide powder into DI water by wt $\%$ to achieve the desired concentration. The preparation of $2 \%$ bis-acrylamide stocking solution was similar as described above. $50 \mathrm{mM}$ HEPES 
buffer was first prepared by first dissolving HEPES powder in DI water to achieve a concentration of $1 \mathrm{M}$. Dilute $1 \mathrm{M}$ HEPES solution with DI water to achieve the final concentration of $50 \mathrm{mM}$. Using $\mathrm{NaOH}$ or $\mathrm{HCl}$ and a $\mathrm{pH}$ meter to adjust the $\mathrm{pH}$ to 8.2. The $50 \mathrm{mM}$ HEPES solution was autoclaved prior to use. 10\% APS was prepared by dissolving ammonium persulfate powder into DI water by wt $\%$ to achieve the desired concentration. Then the stocking solution was aliquoted into small tubes with $100 \mu \mathrm{L}$ per tube and stored in $-20^{\circ} \mathrm{C}$ freezer.

Secondly, PAAm gel was prepared by mixing A stocking solution, B stocking solution first, then HEPES buffer was added to reach the desired acrylamide percentage. To be able to tune the stiffness, the concentration of A and B was varied during the mixing process according to Table 1 . Then working in the chemical hood, for $500 \mu \mathrm{L}$ polyacrylamide solution, $1.5 \mu \mathrm{L}$ TEMED were added to the solution, after mixing a little bit by vortex, $5 \mu \mathrm{L} \mathrm{10 \%} \mathrm{APS} \mathrm{was} \mathrm{added} \mathrm{to} \mathrm{the} \mathrm{mixture.} \mathrm{The} \mathrm{mixture} \mathrm{was}$ then vortexed again.

Finally, $115-120 \mu \mathrm{L}$ (for each $25 \mathrm{~mm}$ coverslip) drop of the solution was pipetted on a big square glass plate (glass plate were pre-treated both sides with rain-x solution to make both surfaces hydrophobic). The activated coverslips were quickly placed on top of each drop before it began to polymerize. The "sandwich" gels were incubated at room temperature for approximately $20 \mathrm{~min}$ or until the gels are fully polymerized. After polymerization, the coverslips were carefully peeled off from the glass plate, PAAm gels stayed on coverslips. Immerse PAAm gels in $50 \mathrm{mM}$ HEPES buffer overnight to achieve equilibrium. 
Table 3-1: Polyacrylamide Young's modulus table. The formula shows the amount needed for acrylamide (A), bis-acrylamide (B), HEPES, TEMED and 10\% APS to make a $500 \mu \mathrm{L}$ mixture for the desired Young's modulus.

\begin{tabular}{|c|c|c|c|c|c|c|c|}
\hline $\begin{array}{c}\text { PAAm } \\
\text { stiffness }\end{array}$ & $\begin{array}{c}\text { Final } \\
\text { concentration } \\
\mathbf{A}+\mathbf{B}\end{array}$ & $\begin{array}{c}\mathbf{4 0} \% \\
\text { Acrylamide } \\
(\boldsymbol{\mu L})\end{array}$ & $\begin{array}{c}\mathbf{2 \%} \text { Bis- } \\
\text { acrylamide } \\
(\boldsymbol{\mu} \mathbf{L})\end{array}$ & $\begin{array}{c}\text { 50 mM } \\
\text { HEPES } \\
(\boldsymbol{\mu} \mathbf{L})\end{array}$ & $\begin{array}{c}\text { TEMED } \\
(\boldsymbol{\mu} \mathbf{L})\end{array}$ & $\begin{array}{c}\mathbf{1 0 \%} \\
\mathbf{A P S} \\
(\boldsymbol{\mu} \mathbf{L})\end{array}$ & $\begin{array}{c}\text { Young's } \\
\text { modulus } \\
(\mathbf{k P a})\end{array}$ \\
\hline Soft & $5 \%+0.1 \%$ & 62.5 & 25 & 412.5 & 1.5 & 5 & 3 \\
\hline Rigid & $12 \%+0.5 \%$ & 150 & 125 & 225 & 1.5 & 5 & 100 \\
\hline
\end{tabular}

3) Activate PAAm gel surface. This process is critical for cell study because it will allow ECM conjugation on the PAAm surface. Failing of activation PAAm gel will result in cell detaching from the gel surface.

Firstly, a sheet of parafilm was placed on the bottom of a big petri dish. A vial of 24 $\mu \mathrm{L}$ aliquoted sulfosuccinimidyl 6-(4'-azido-2'-nitrophenylamino)hexanoate (sulfoSANPAH) was thawed at room temperature, then $600 \mu \mathrm{L} 50 \mathrm{mM}$ HEPEs buffer was added to the vial to make a $1 \mathrm{mg} / \mathrm{mL}$ work solution (sulfo-SANPAH was $25 \mathrm{mg} / \mathrm{mL}$ in DMSO).

Secondly, the gels were taken out of the HEPES buffer and the excess buffer was wicked off with a Kimwipe. The coverslips were placed on the parafilm sheet supported by a $150-\mathrm{mm}$ petri dish with gel side up. $200 \mu \mathrm{L}$ working solution was added to each gel (for a $25 \mathrm{~mm}$ coverslip). The petri dish was placed under UV lamp and the distance between the top of the gel and the UV lamp was $5 \mathrm{~cm}$. The gels were under long wave exposure for 6 min and then the chemical was carefully sucked out using Kimwipe. The PAAm gels were placed back into UV chamber in the same position and were under UV exposure for another $6 \mathrm{~min}$. 
Finally, the PAAm gels were taken out of the UV chamber and immersed into HEPES buffer solution. The gels were washed with HEPES buffer three times for 10 min each, until the red color fade away.

4) Coat PAAm gel with ECM protein. Fibronectin coating on the activated PAAm gel surface to allow the cell to attach.

Firstly, fibronectin working solution was prepared by diluting the stock solution into $50 \mathrm{mg} / \mathrm{mL}$.

Then, a wet chamber was prepared using a $15 \mathrm{~mm}$ dish with parafilm placing on the bottom and wet paper towels on the side. $200 \mu \mathrm{L}$ fibronectin drops were added on the parafilm sheet.

Finally, the PAAm gels were face down on the fibronectin solution drops and incubated overnight at $4{ }^{\circ} \mathrm{C}$ or $5 \mathrm{hr}$ at room temperature.

5) Seed cell on coated PAAm gel surface. After surface conjugation of fibronectin, the hydrogels were rinsed three times with sterile PBS under bio-hood and followed by UV exposure for $30 \mathrm{~min}$.

Activate glass surface

Polymerized polyacrylamide

Activate polyacrylamide surface

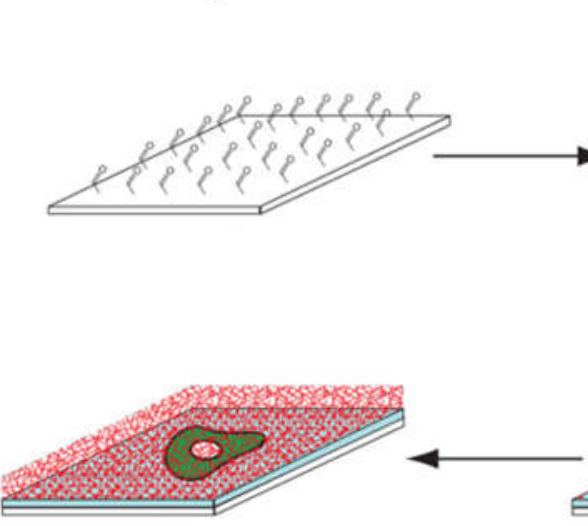

Polymerized collagen gel
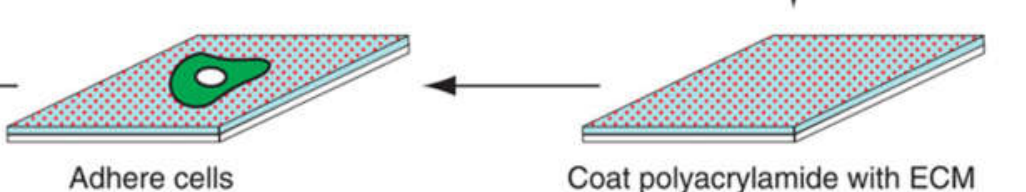

Coat polyacrylamide with ECM 
Figure 3-4: Schematic illustration of the sandwich gel assembly process. (i) Activation of glass surfaces with $\mathrm{NaOH}, 3-\mathrm{APTMS}$ and glutaraldehyde. (ii) Polyacrylamide gel polymerization on the top of the activated glass. (iii) Conjugation of sulfo-SANPAH on the surface of the polyacrylamide gel by exposing gel surfaces to UV light, allowing the photoactivatable nitrophenyl azide group to bond with the polyacrylamide. (iv) Finally, the NHS ester (N-hydroxysuccinimide) group in sulfoSANPAH is able to bond with the future ECM proteins like fibronectins or collagens, which is essential for cells (green) to be able to adhere to the polyacrylamide surface (v). (Reproduced with permission from Ref. [44], step vi will be excluded from our study)

\section{Preparation, dispersion, and characterization of MWCNTs}

MWCNTs were used for toxicity study. The MWCNTs solution was prepared as previously reported. ${ }^{48}$ Briefly, $1 \mathrm{mg}$ of MWCNTs was dispersed in $1 \mathrm{~mL}$ of phosphate buffered saline (PBS; Life Technologies, Carlsbad, CA, USA) containing $5 \mathrm{mg}$ of bovine serum albumin (BSA; SigmaAldrich, St. Louis, MO, USA) by slightly sonicating in a biological safety hood. The MWCNTs stock solution was stored at $4{ }^{\circ} \mathrm{C}$ for long term use. When added to the cells, the MWCNTs was further diluted in the culture medium to obtain the desired concentrations $\left(0.06-0.6 \mu \mathrm{g} / \mathrm{cm}^{2}\right)$ before use. The in vitro CNT exposure doses were determined based on in vivo CNT exposure data normalized to the alveolar surface area in mice. Previously, the in vitro surface area dose of CNTs used was of $0.08-0.16 \mu \mathrm{g} / \mathrm{cm}^{2}$, relevant to in vivo exposure doses of $40-80 \mu \mathrm{g} / \mathrm{mouse}{ }^{49}$ In this study, the doses of $0.06-0.6 \mu \mathrm{g} / \mathrm{cm}^{2}$ were chosen to cover the aforementioned range.

The length (L) and width (W) of individual dry CNT were $8.19 \pm 1.7 \mu \mathrm{m}(\mathrm{L})$ and $81 \pm 5$ nm (W). The size of MWCNTs was measured by using AFM. AFM measurement was performed in tapping mode using a Veeco NanoScope MultiMode scanning probe microscope under ambient 
conditions. Topography images were recorded at the fundamental resonance frequency of the cantilever, with a typical scan rate of $1 \mathrm{~Hz}$ and a resolution of 512 samples per line.

Production of collagen I was assessed by incubating the cells with MWCNTs at different doses for $72 \mathrm{~h}$ on TCPS surfaces as well as PAAm gel surfaces followed by western blot analysis. Previous studies showed that MWCNTs at high doses $\left(\geq 0.6 \mu \mathrm{g} / \mathrm{cm}^{2}\right)$ caused severe cytotoxicity. ${ }^{49}$ Because of the dose-dependent collagen I production, the dose of $0.2 \mu \mathrm{g} / \mathrm{cm}^{2}$ was chosen for assessment of the substrate stiffness mediated fibrogenic response of the fibroblasts to MWCNTs. ${ }^{50}$

\section{Primary cell culture}

NHLFs were used as our model for cell study due to the fact that lung fibroblasts are a representative cell type that presents in the lung interstitium, which is considered to be associated with collagen production during fibrogenesis. ${ }^{20,32,51}$ NHLFs were cultured in fibroblast basal medium (FBM) supplemented with 2\% FBS, 0.1\% recombinant human fibroblast growth factor basic (rhFGF-B), 0.1\% insulin, 0.1\% gentamicin/amphotericin-B (Lonza, Walkersville, MD, USA), $100 \mathrm{U} / \mathrm{ml}$ penicillin and $100 \mu \mathrm{g} / \mathrm{ml}$ streptomycin. Cells were used between passages 3-6.

\section{Characterization of cellular response}

Cell proliferation, immunofluorescent staining, and western blotting were used to conduct various experiments to examine the cellular response of NHLFs to substrate stiffness.

Cell viability. Cell viability on PAAm gel with two different stiffness, $3 \mathrm{kPa}$ and $100 \mathrm{kPa}$, as well as on TCPS was evaluated by using CellTiter $96{ }^{\circledR} \mathrm{AQ}_{\mathrm{ueous}}$ One Solution Cell Proliferation Assay. The data on TCPS was used as a control. NHLFs were seeded on PAAm gels (3 $\mathrm{kPa}$ and $100 \mathrm{kPa}$ ) that were made on $8 \mathrm{~mm}$ coverglass, which could fit into 48 -well plate. Cells seeded 
directly on TCPS in 48-well plate were used as a control. For each group, three parallel samples were prepared. Cells were allowed overnight to fully attach to the substrate. MWCNTs with a concentration of $0.2 \mu \mathrm{g} / \mathrm{cm}^{2}$ were added on the following day and incubated with the cells. After $72 \mathrm{~h}$ of incubation, cell viability assay was performed by using CellTiter $96{ }^{\circledR} \mathrm{AQ}_{\text {ueous }}$ One Solution Cell Proliferation kit according to the manufacturer protocol. Briefly, the PAAm gels with cells were transferred to a new 48-well plate and the cell proliferation kit reagent, CellTiter $96{ }^{\circledR}$ AQueous One Solution Reagent, was diluted in fibroblasts growth media by a concentration of 1:5 and added to the new plate. For TCPS samples, the original media was replaced by the same amount of cell proliferation reagent. The 48 -well plates were then incubated for an additional $4 \mathrm{~h}$ at $37{ }^{\circ} \mathrm{C}$. After 4 hours of incubation, $200 \mu \mathrm{L}$ solution was sucked out from each well and added to a 96-well plate. The absorbance of each well at a wavelength of $490 \mathrm{~nm}$ was measured by means of an FLUOstar OPTIMA Microplate Reader (BMG LABTECH, Cary, NC, USA). The culture medium containing the reagent was set as background.

Immunofluorescent staining. NHLFs on $3 \mathrm{kPa}, 100 \mathrm{kPa}$ PAAm gel as well as on TCPS substrates were fixed with $4 \%$ PFA for 30 min at room temperature, permeabilized with PBS containing $0.2 \%$ Triton-X 100 for $20 \mathrm{~min}$ at room temperature, and blocked using a PBS solution containing $0.03 \mathrm{~g} / \mathrm{mL} \mathrm{BSA,} 1 \%$ goat serum (Sigma-Aldrich), and $0.2 \%$ Triton-X 100 for $1 \mathrm{~h}$. Primary antibody was conjugated in PBS solution with $0.2 \%$ Triton-X 100 for $2 \mathrm{~h}$ in ambient condition. The samples were then washed with PBS solution containing $0.2 \%$ Triton-X 100 for three times, 5 min for each wash. After the completion of washing, the secondary antibody was conjugated in the same solution for $1 \mathrm{~h}$ in dark at room temperature. F-actin was stained with Alexa Fluor 488 phalloidin (Life Technologies), alpha-smooth muscle actin ( $\alpha$-SMA) was stained with anti- $\alpha$-SMA mouse polyclonal antibody (Abcam) and the nuclei were counterstained and mounted 
using ProLong Gold Antifade Reagent with DAPI. The fluorescent images were taken by using a Nikon Ti Eclipse Fluorescence Microscope. The confocal images were taken by using Zeiss Violet Confocal Microscope. 3D deconvolution was processed by using Imaris (Bitplane USA, Concord, MA).

Reactive oxygen species (ROS) staining. NHLFs were seeded on the $3 \mathrm{kPa}$ PAAm gel substrates at a density of 15000 cells per $\mathrm{cm}^{2}$ and $100 \mathrm{kPa}$ PAAm gel substrates at a density of 10000 cells per $\mathrm{cm}^{2}$. Cells cultured on TCPS at a density of 7500 cells per $\mathrm{cm}^{2}$ were set as the control. Cells were cultured and allowed fully attached overnight and treated with $0.2 \mu \mathrm{g} / \mathrm{cm}^{2}$ MWCNTs on the following day. Cells were then incubated with MWCNTs for another $16 \mathrm{~h}$. The culture medium was then replaced with $1 \mathrm{~mL}$ Hank's balanced salt solution (HBSS) containing 10 $\mu \mathrm{M}$ dichlorodihydrofluorescein diacetate (DCFDA) and incubated for an additional $30 \mathrm{~min}$. The cells were finally fixed using 4\% PFA solution and the nuclei were visualized using ProLong Gold Antifade Reagent with DAPI. At least 10 images for each group were taken under the Nikon Ti Eclipse fluorescence microscope with the same setting. The fluorescence intensities of images were analyzed by using ImageJ and the ROS production per cell was calculated by subtracting the background fluorescence intensity from Image fluorescence intensity, then divided by cell number.

Western blot. The western blotting assay was performed as previously reported. ${ }^{52}$ Passage 3 NHLFs were seeded on the $3 \mathrm{kPa}$ PAAm gel substrates at a density of 15000 cells per $\mathrm{cm}^{2}$ and $100 \mathrm{kPa}$ PAAm gel substrates at a density of 10000 cells per $\mathrm{cm}^{2}$. Cells cultured on TCPS at a density of 7500 cells per $\mathrm{cm}^{2}$ were set as the control. Cells were cultured and allowed fully attached overnight and treated with $0.2 \mu \mathrm{g} / \mathrm{cm}^{2}$ MWCNTs on the following day. After incubation with MWCNTs for $72 \mathrm{~h}$, the whole cell protein was extracted by lysing cells with radioimmune precipitation assay (RIPA) buffer (Santa Cruz Biotechnology, CA, USA) containing protease and 
phosphatase inhibitors for 30 min on ice. The cell protein was then separated by $10 \%$ sodium dodecyl sulfate-polyacrylamide gel electrophoresis (SDS-PAGE) and transferred to polyvinylidene difluoride (PVDF) membranes (EMD Millipore, Darmstadt, Germany). The PVDF membranes were then blocked with $5 \%$ nonfat milk in $1 \times$ Tris-buffered saline with $0.1 \%$ Tween20 (TBST), followed by blotting with primary antibodies at $4{ }^{\circ} \mathrm{C}$ overnight with shaking, and incubating with a horseradish peroxidase-conjugated secondary antibody (Sigma-Aldrich) for $1 \mathrm{~h}$ at room temperature. Protein bands were visualized using enhanced chemiluminescence detection reagents (EMD Millipore) and acquired by using a C DiGit Blot Scanner (LI-COR Biosciences, Lincoln, NE, USA). The immunoblotting acquired was then analyzed by using ImageJ software (https://imagej.nih.gov/ij/).

\section{Rho-associated Protein Kinase (ROCK) inhibitor Y27632 treatment}

Y27632, a specific drug to inhibit ROCK pathway was used to inhibit Rho kinase without changing other kinase pathways. ${ }^{53,54}$ After cells were seeded and attached overnight, Y27632 was added on the following day 2 hours before MWCNTs treatment. The desired concentration was achieved by diluting the stock $10 \mathrm{mM}$ Y27632 solution with fibroblast complete growth media. See Table 2 for the predefined concentration used in the experiment. Observation of the cells using bright field microscope to see if there are any morphology changes after Y27632 has been added. See supporting information for the bright field images taken to record the daily changes of the cell morphologies. 
Table 3-2: The administrative dosage adding pattern for Y27632 treatment.

\begin{tabular}{|c|c|c|c|c|}
\hline Total dosage & \multicolumn{3}{|c|}{$10 \boldsymbol{\mu M}$} & $16 \boldsymbol{M M}$ \\
\hline Day 1 & $3 \mu \mathrm{M}$ & $5 \mu \mathrm{M}$ & $10 \mu \mathrm{M}$ & $8 \mu \mathrm{M}$ \\
\hline Day 2 & $3 \mu \mathrm{M}$ & $5 \mu \mathrm{M}$ & & $8 \mu \mathrm{M}$ \\
\hline Day 3 & $4 \mu \mathrm{M}$ & & & \\
\hline
\end{tabular}

\section{Statistical analysis}

The data will be presented as mean \pm standard error of mean (S.E.M.). Student's $t$-test will be used to determine the statistical difference. The proliferation $(\mathrm{n}=3)$, collagen $\mathrm{I}$ expression $(\mathrm{n}=$ $3)$ and ROS generation $(n>10)$ of NHLFs were measured from three independent replicates for each condition. Statistically significant differences will be considered at a level of $p<0.05$. 


\section{Results and Discussion}

\section{Cell morphology}

Cell morphologies on $3 \mathrm{kPa}, 100 \mathrm{kPa}$ PAAm gel as well as on TCPS were examined first under bright field. The phase contrast images were shown on the top row in Figure 3-5. Fibroblasts displayed different morphologies as the substrate stiffness changed. The majority of the cells on soft substrate $(3 \mathrm{kPa})$ remained round shape without spreading out, indicating a weak cell-substrate interaction. Cells on the stiff substrate $(100 \mathrm{kPa})$ were similar to that on TCPS, which were elongated and stretched out mostly.

Immunofluorescent staining of F-actin was also performed to visualize the actin fibers and the cell morphology difference between $3 \mathrm{kPa}, 100 \mathrm{kPa}$ PAAm gels and TCPS. The fluorescent images were shown on the bottom row in Figure 3-5. Similar to what was observed in the bright field, cells on soft substrate $(3 \mathrm{kPa})$ remained round shape without spreading out and there was no obvious actin fiber that has been seen; cells on $100 \mathrm{kPa}$ PAAm gel as well on TCPS were largely stretched out and elongated, with more visible actin fibers. 

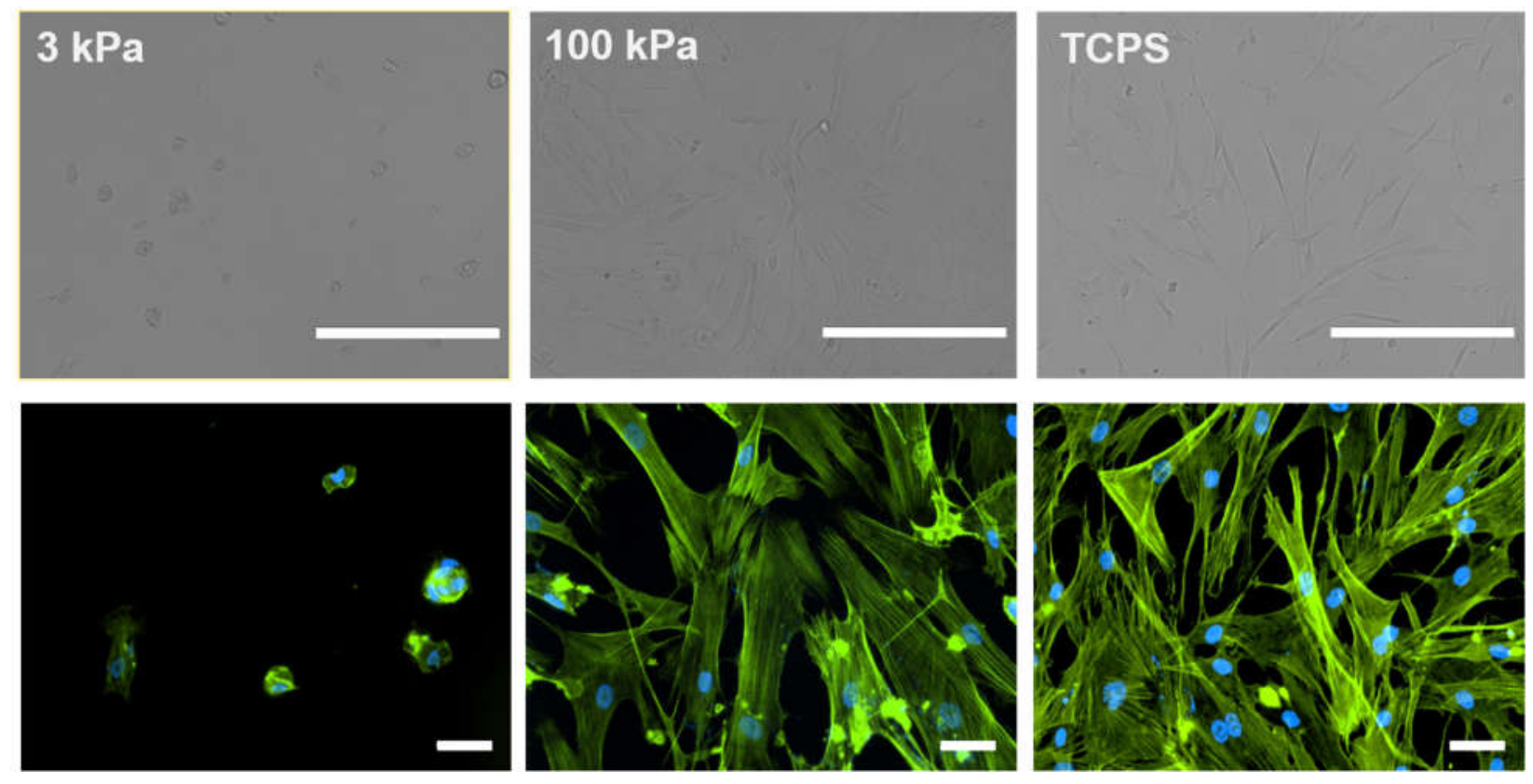

Figure 3-5: Cell morphologies of NHLFs on different PAAm gel substrates (3 kPa, $100 \mathrm{kPa})$ and TCPS. Top row: phase contrast images of NHLFs cell morphologies on different PAAm gel substrates. The scale bars are $400 \mu \mathrm{m}$. Bottom row: fluorescent images of fibroblasts cell morphologies on different PAAm gel substrates. The F-actin (green) was immunostained with Alexa Fluor 488® phalloidin and the nuclei (blue) were stained with DAPI. The scale bars are 50 $\mu \mathrm{m}$.

\section{CNT dosages determination}

To further determine the dosage of MWCNTs, cell proliferation assay on TCPS with various MWCNTs dosages was performed, with different incubation length from 1 day to 4 days. The results of cell proliferation assay on TCPS with various MWCNTs dosages are shown in Figure 3-6. Cells cultured without adding MWCNTs were used as a control. The reason of this experiment was to give an idea on the choice of different MWCNTs dosage as well as the culture length. We found that on day 3 , the CNT group with $0.06 \mu \mathrm{g} / \mathrm{cm}^{2}$ and $0.2 \mu \mathrm{g} / \mathrm{cm}^{2}$ both showed a 
significant increase in cell proliferation, while for a higher dosage of $0.6 \mu \mathrm{g} / \mathrm{cm}^{2}$, the proliferation started to decline at day 3 , and further decreased on day 4 culture. This result was consistent with the previous report that MWCNTs showed toxicity to the cells at a higher dosage doses $(\geq 0.6$ $\left.\mu \mathrm{g} / \mathrm{cm}^{2}\right) .{ }^{49}$

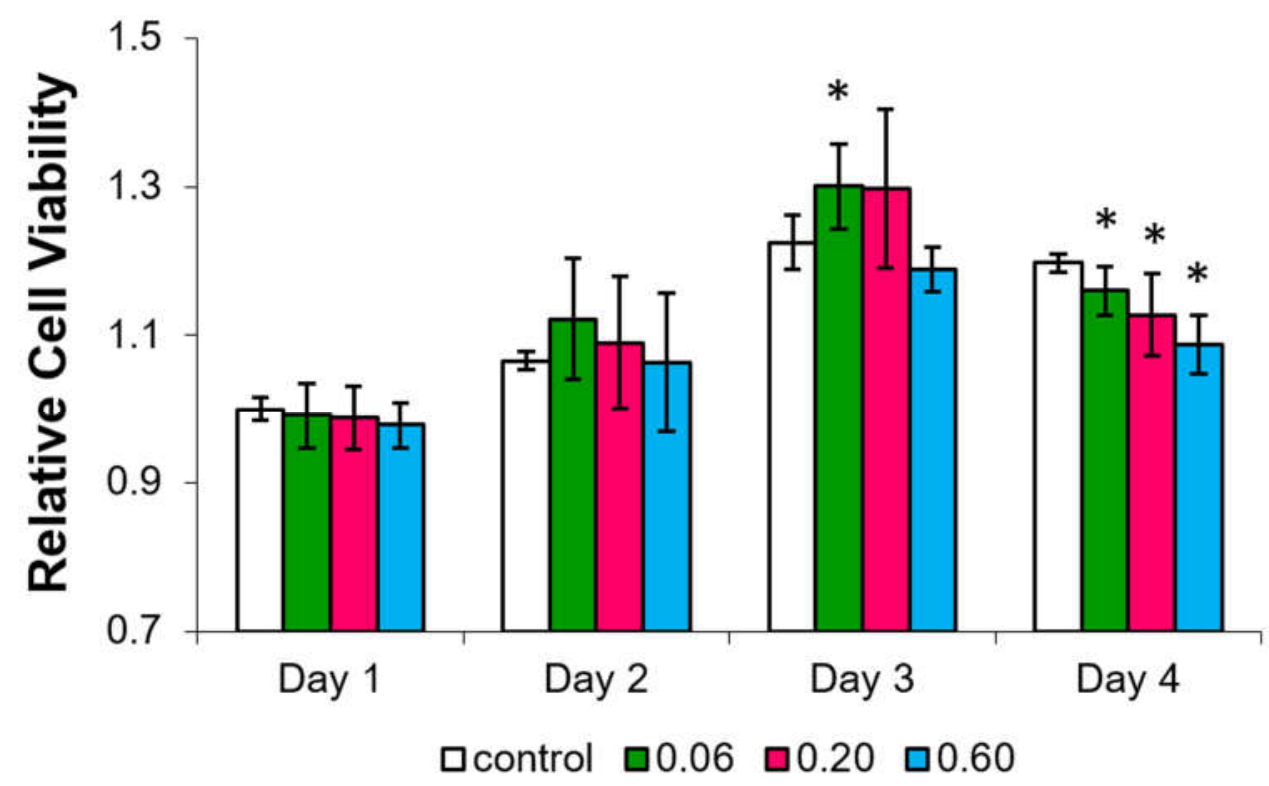

Figure 3-6: Determination of MWCNTs dosage by cell proliferation assay on TCPS. The cells were treated with MWCNTs at a dosage of $0.06 \mu \mathrm{g} / \mathrm{cm}^{2}, 0.2 \mu \mathrm{g} / \mathrm{cm}^{2}$ and $0.6 \mu \mathrm{g} / \mathrm{cm}^{2}$. Cells treated without MWCNTs were used as a control. Cells treated with different dosages of MWCNTs were incubated for 4 days. Proliferation data was obtained every 24 h. *: significant difference $(p<$ $0.05)$ from the control.

According to previous study, ${ }^{52}$ a dose of $0.2 \mu \mathrm{g} / \mathrm{cm}^{2}$ was hence chosen for establishing the in vitro model of cell sensing nanomaterials. As shown in Figure 3-7, compared to $0.06 \mu \mathrm{g} / \mathrm{cm}^{2}$, adding $0.2 \mu \mathrm{g} / \mathrm{cm}^{2}$ MWCNTs could induce more collagen production although these two dosages showed similar proliferation after $72 \mathrm{~h}$ of incubation. Meanwhile, since MWCNTs showed toxicity 
to the cells at a higher dosage doses $\left(\geq 0.6 \mu \mathrm{g} / \mathrm{cm}^{2}\right), 0.2 \mu \mathrm{g} / \mathrm{cm}^{2}$ was finally chosen for assessment of substrate stiffness regulated the fibrogenic response of NHLFs to MWCNTs.
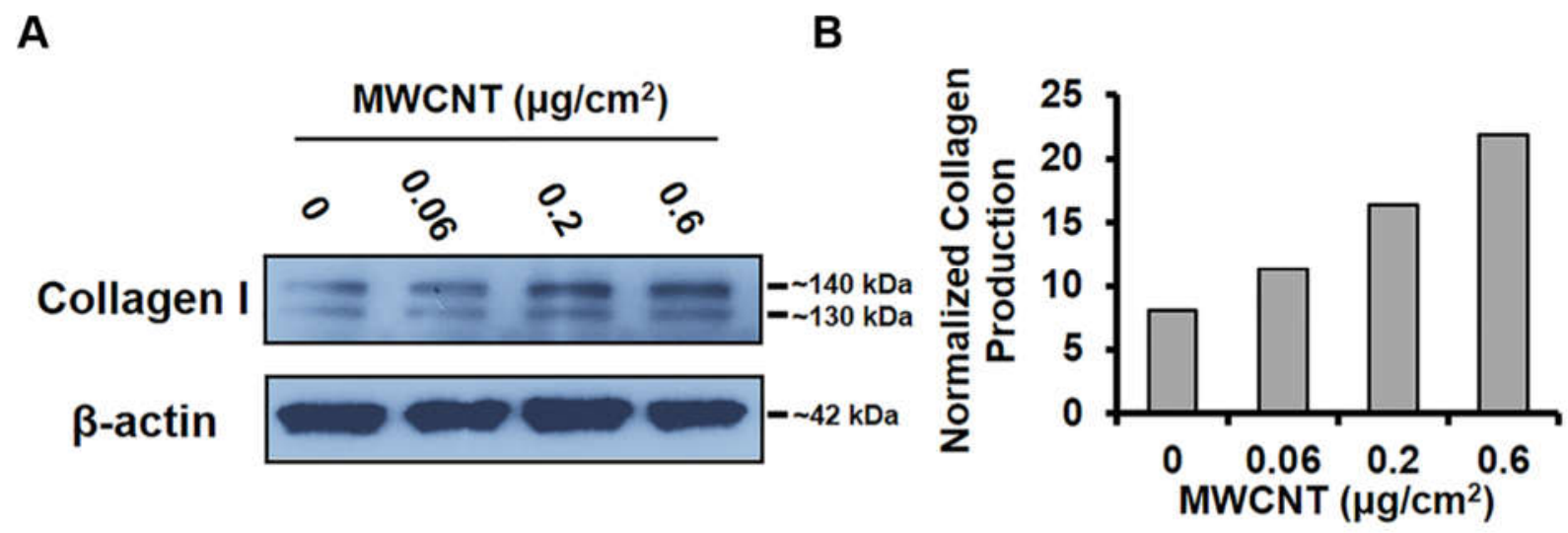

Figure 3-7: Dose-dependent collagen production of fibroblasts treated with MWCNTs. (A) Immunoblotting of collagen I. $\beta$-actin was used as the loading control. Fibroblasts were treated with MWCNTs at different dosages of $0.06,0.2$ and $0.6 \mu \mathrm{g} / \mathrm{cm}^{2}$ for $48 \mathrm{~h}$. (B) Densitometric analysis of collagen I production based on the results of the immunoblotting in (A). (Adapted with permission from Ref. [52])

\section{CNT effects on cytoskeleton structure and nuclei}

We further examined the cell cytoskeleton structure by performing immunofluorescent staining of F-actin and $\alpha$-SMA. F-actin was stained to demonstrate the presence of actin stress fibers in NHLFs in order to visualize the cytoskeleton structure. $\alpha$-SMA is a commonly used molecular marker that has been found expressed by myofibroblasts, which is highly associated with the lung fibrosis. ${ }^{55,56}$ An important hallmark during fibrogenesis is the differentiation of fibroblasts to myofibroblasts. ${ }^{57}$ 
F-actin was immunostained with Alexa Fluor $488 \circledR$ phalloidin, which is a high-affinity Factin probe. $\alpha$-SMA was stained with anti- $\alpha$-SMA mouse polyclonal antibody. The confocal images were shown in Figure 3-8. Corresponding to the previous cell morphology results, fibroblasts exhibited different morphologies as the substrate stiffness changed. Cells on $3 \mathrm{kPa}$ remained compact morphologies with no visible stress fiber. On the contrary, cells on $100 \mathrm{kPa}$ substrate were elongated and stretched out with stress fiber formation. The stress fiber formation became more obvious on TCPS substrates, suggesting that the expression of F-actin increased when increasing the substrate stiffness. The stiffer the substrate was, the more expression of Factin.

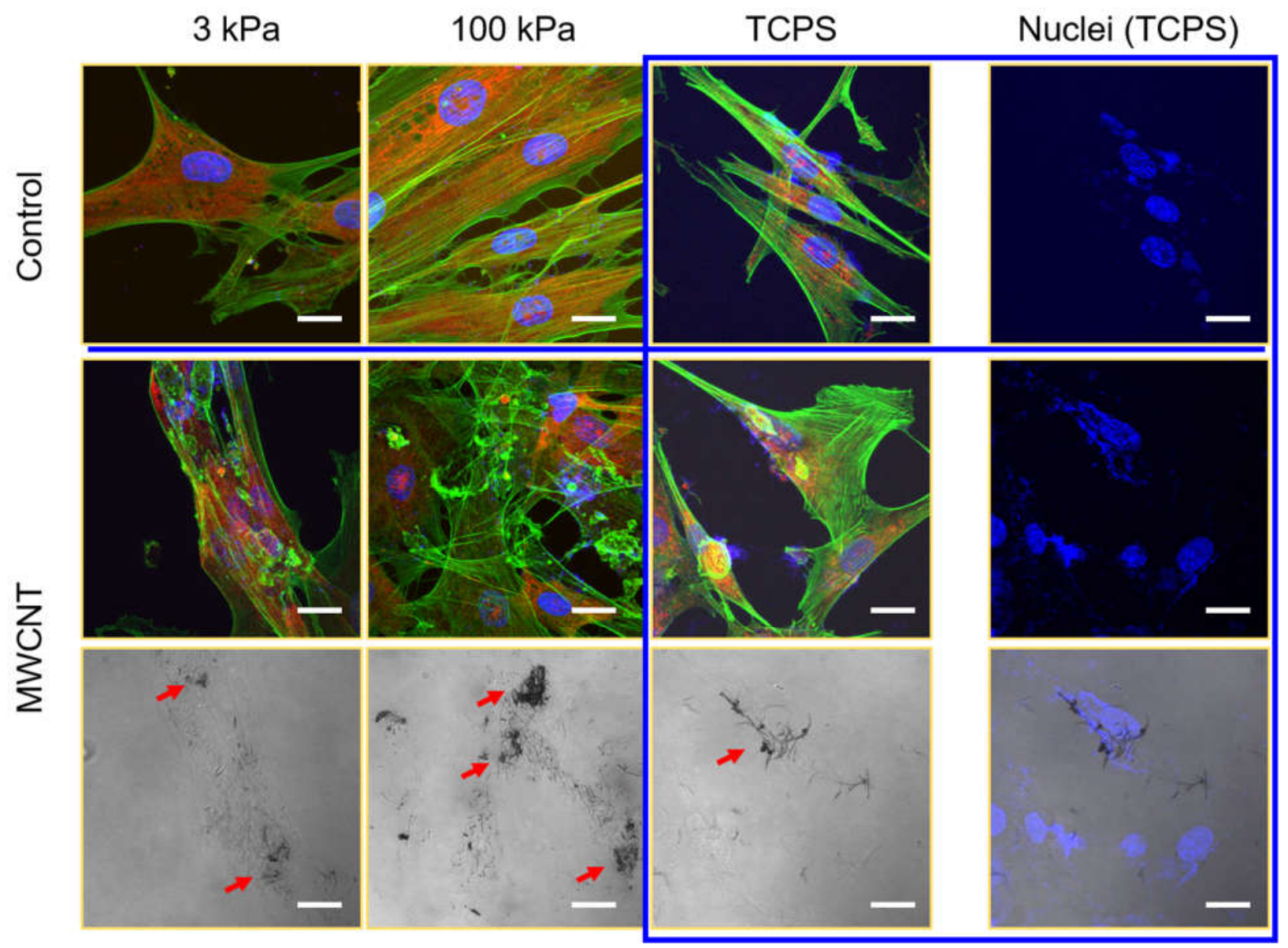


Figure 3-8: Immunofluorescent staining of F-actin, $\alpha$-SMA and nuclei of NHLFs on different substrates: $3 \mathrm{kPa}, 100 \mathrm{kPa}$ and TCPS. The last column on the right highlights the nuclei of the cells cultured on TCPS. Top row: cells treated without MWCNTs were used as controls. Second row: cells treated with $0.2 \mu \mathrm{g} / \mathrm{cm}^{2}$ MWCNTs. Third row: bright field images of the second row. The arrows point to the MWCNTs localization inside the cells. The F-actin (green) was immunostained with Alexa Fluor $488 \AA$ phalloidin, the $\alpha$-SMA (red) was stained with anti- $\alpha$-SMA mouse polyclonal antibody and the nuclei (blue) were stained with DAPI. The scale bars are $20 \mu \mathrm{m}$.

The influence of MWCNTs to cytoskeleton structure was revealed in Figure 3-8 with a combination of the second and the third row. The CNTs structures could be seen clearly in the bright field images and it was observed that when MWCNTs were present, the actin fiber was distorted or disrupted, as well as the nuclei structure shown in the last column. Without MWCNTs, the actin fiber was continuous and intact and the nuclei structure was in oval shape and smooth. The detailed explanation for this phenomenon is still unclear and is open to investigation. However, several studies have been done which revealed that CNTs or functionalized CNTs possessed the ability to penetrate cell membranes and reach the nucleus of cancer cells..$^{58,59,60,61}$ It still remains to be elucidated that how CNTs translocate across the cell membrane. One of the studies proposed that the translocation mechanism of CNTs was comparable to cell penetrating peptides (CPPs), where they were able to reach nuclei due to their positive charge and the nuclear localization signal conveyed by the amino acid sequences. ${ }^{60}$ It seemed from our results that substrate stiffness could also be responsible for the CNTs uptake mechanism inside the cells (see Figure 3-9). Compared to TCPS substrate, the nuclei of cells cultured on soft PAAm gel substrate were less disrupted. However, solid evidence and more investigation are needed to explain this observation. 

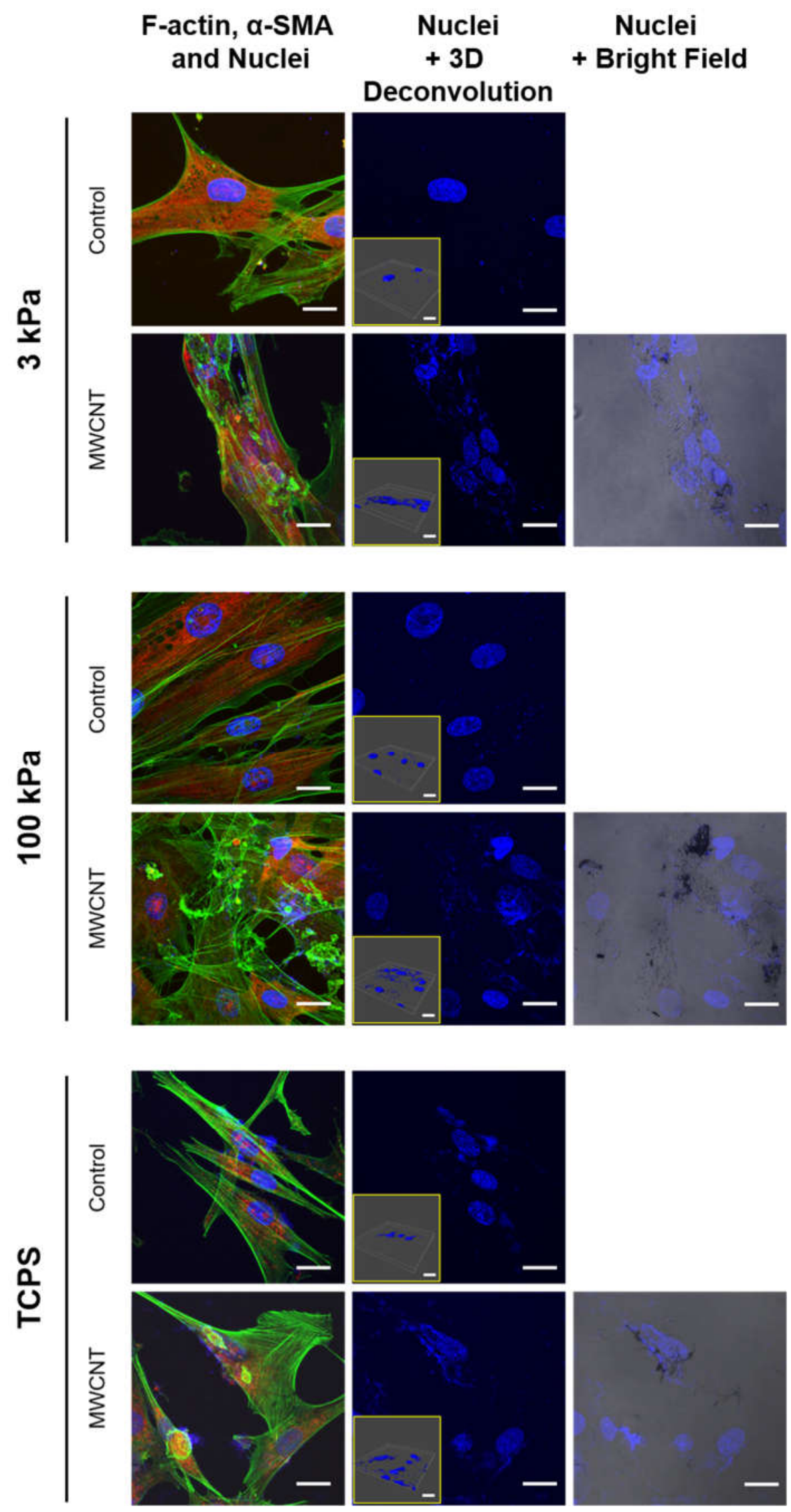
Figure 3-9: MWCNTs effects on nuclei. The first column shows the immunofluorescent staining of F-actin (green), $\alpha$-SMA (red) and nuclei (blue) of NHLFs on different substrates: $3 \mathrm{kPa}, 100$ $\mathrm{kPa}$ and TCPS. The second column shows the single channel of nuclei. The insets are the 3D deconvolution of nuclei. The last column on the right shows the overlay images of the nuclei and the bright field. The scale bars are $20 \mu \mathrm{m}$.

\section{Fibrogenesis response}

Cell Viability. Previous study has shown that increased cell proliferation is one of the hallmarks of lung fibrosis ${ }^{20}$ which was first investigated in the study to evaluate the fibrogenesis response of NHLFs to MWCNTs on substrates with different stiffness. The results of cell viability assay on $3 \mathrm{kPa}$ and $100 \mathrm{kPa}$ PAAm gel substrates as well as on TCPS with an MWCNTs dosage of $0.2 \mu \mathrm{g} / \mathrm{cm}^{2}$ were shown in Figure 3-10.

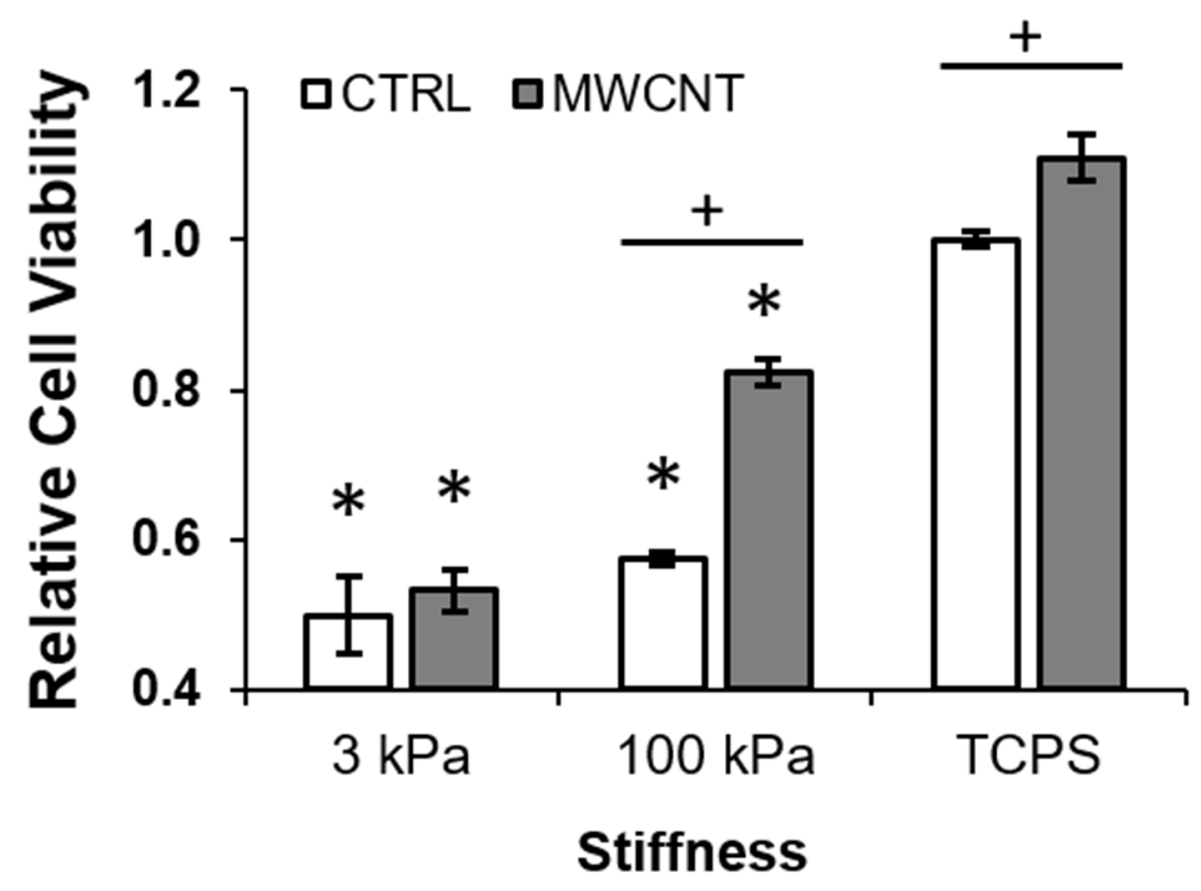


Figure 3-10: Cell viability of NHLFs on different PAAm gel substrates and TCPS control. The cells were treated with MWCNTs for $72 \mathrm{~h}$ (labeled as MWCNTs in the plot). Cells treated without MWCNTs were used as controls (labeled as CTRL in the plot). *: significant difference $(\mathrm{p}<0.05)$ from the TCPS controls; +: significant difference $(\mathrm{p}<0.05)$ between groups.

As shown in Figure 3-10, cell number increased when stiffness increased, indicating that on stiffer substrate, cell proliferation was more active than that on soft substrate. To compare the MWCNTs effects within group, there was no significant increase on soft substrate $(3 \mathrm{kPa})$ while on $100 \mathrm{kPa}$ gel substrate and TCPS, cell number was significantly increased, suggesting that MWCNTs could enhance proliferation in a stiffness-dependent manner. Moreover, according to the $p$-value from T-test, although on $100 \mathrm{kPa}$ and TCPS, cell proliferation both showed a significant increase, it increased much more on $100 \mathrm{kPa}(p=0.003)$ compared to that on TCPS $(p$ $=0.020)$. This phenomenon was agreed with a previous finding suggesting that soft substrate has a much lower membrane tension compared to the stiff substrate, where the high membrane tension of the cells on TCPS makes it hard for nanoparticles to enter, resulting in a higher cellular uptake of nanoparticles on the soft substrate. ${ }^{62}$ This could be a possible explanation for the difference in enhancement of CNTs on $100 \mathrm{kPa}$ and TCPS. However, our results showed that cell proliferation on the softest substrate $(3 \mathrm{kPa})$ did not result in a noticeable increase, which may seem contradictive to the previous theory. This could possibly result from the limited spreading area that cells remain on the soft substrate. Previous results showed a rounded morphology of fibroblasts that cultured on $3 \mathrm{kPa}$ PAAm gel, whereas cells cultured on $100 \mathrm{kPa}$ PAAm gel and TCPS substrates were more spread and elongated. It has been also studied that when the cell area was substantially decreased compared to the larger spreading area on two stiffer substrates, cellular uptake of nanoparticles resulted in a much lower total amount. ${ }^{62}$ 
Collagen I Expression. Western blotting was used to qualitatively and quantitatively measure the collagen I production with or without adding MWCNTs. Figure 3-11 here showed the western blot result of collagen I protein band and quantitative analysis.

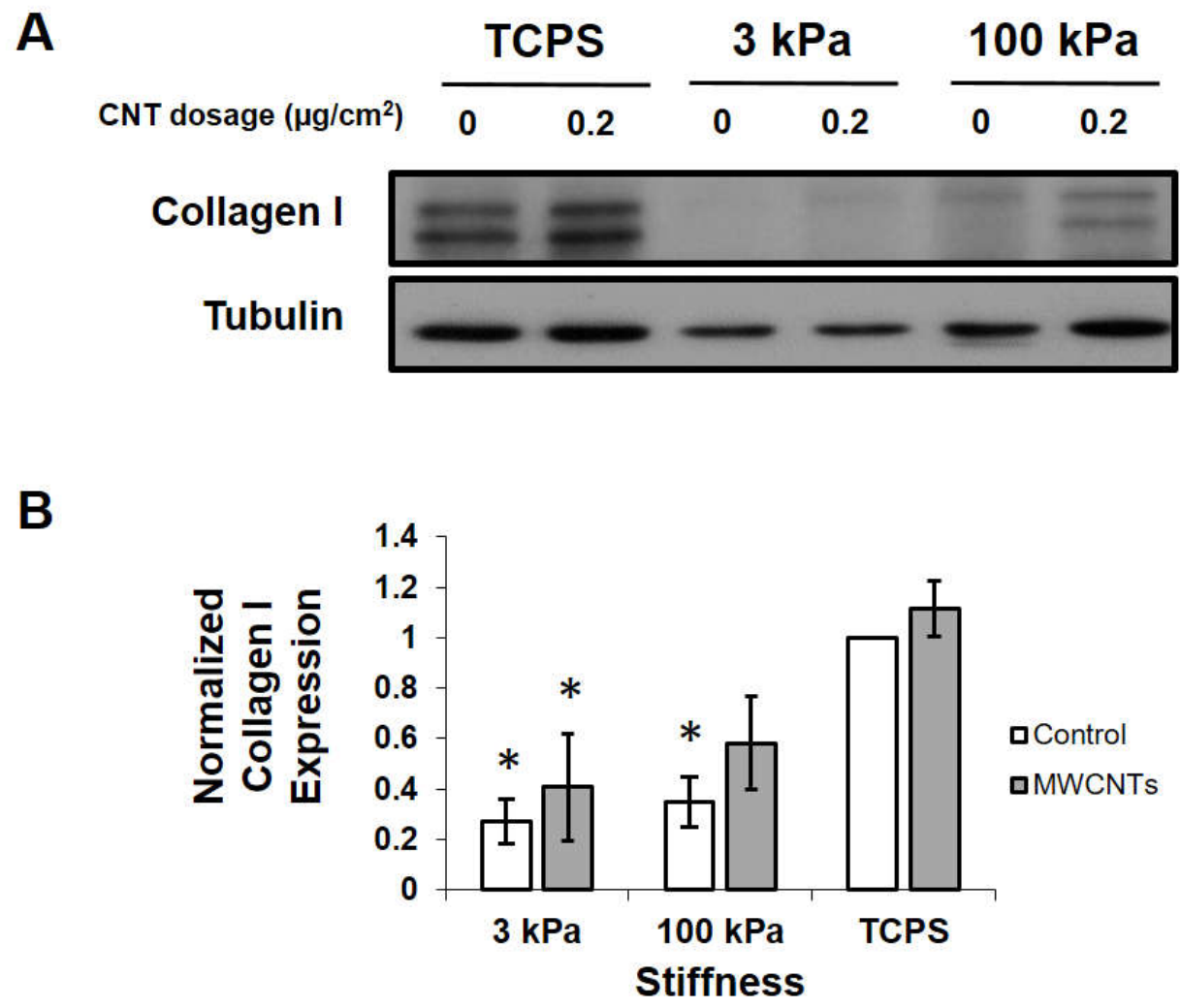

Figure 3-11: Collagen I expression of NHLFs treated with or without $0.2 \mu \mathrm{g} / \mathrm{cm}^{2}$ MWCNTs. (A) Immunoblotting of collagen I on $3 \mathrm{kPa}, 100 \mathrm{kPa}$ PAAm gel substrates as well as on TCPS. Tubulin was used as the loading control. Fibroblasts were treated with MWCNTs for $72 \mathrm{~h}$ in positive group (labeled as MWCNTs in the plot). Cells treated without MWCNTs were used as controls (labeled as CTRL in the plot). (B) Densitometric analysis of collagen I expression based on the results of immunoblotting in (A). *: significant difference $(\mathrm{p}<0.05)$ compared to the TCPS controls. 
The collagen I production of fibroblasts on $3 \mathrm{kPa}$ and $100 \mathrm{kPa}$ was much lower than that on TCPS, indicating that the expression of collagen depended on the stiffness of substrates. The expression on $3 \mathrm{kPa}$ substrates was significantly lower than TCPS with or without CNT treatment, while on $100 \mathrm{kPa}$ substrates it was less significant.

Other than cell proliferation, excessive deposition of collagen matrix was also considered as a hallmark in lung fibrosis. ${ }^{63}$ Previous study has shown that collagen I production could be significantly increased by dispersed SWCNT and MWCNT both in vivo and in vitro. ${ }^{64}$ From our results, collagen I production was enhanced on all substrates with the presence of MWCNTs but not significantly. It is speculated that this insignificant influence of MWCNTs was due to the competing effects between CNTs induced collagen I production and the disruption of cytoskeleton structure by CNTs. Previous studies have shown that CNT could induce lung fibroblasts differentiation to myofibroblasts both in vivo and in vitro. ${ }^{22,48,65}$ The presence of myofibroblast would result in synthesizing and secreting the ECM, which will increase the collagen I production. ${ }^{57,66}$ From another perspective, our previous observation of immunofluorescent staining in Figure 3-8 showed that the cytoskeleton structure seemed to disrupted when treated with CNTs, along with the decreasing of $\alpha$-SMA expression (red), which was a competitive effect compared to CNTs induced myofibroblast differentiation because $\alpha$-SMA was a commonly used molecular marker indicating the formation of myofibroblast. The collagen I production under this circumstance was expected to decrease. In the view of these two contradictory effects, the significant of CNTs induced collagen production was compromised. However, this was not a conclusive result where more solid evidence regarding the cytoskeleton organization was needed to consolidate our finding. 
ROS Generation. Previous studies have shown that oxidative stress was associated with the toxicity of the nanoparticles, hence played an important role in nanomaterial-induced fibrogenesis. ${ }^{48,67,68}$ Lung tissue is generally exposed to more oxygen, which potentially leads it to a more vulnerable condition of experiencing oxidative stress. ${ }^{69}$ MWCNTs could enter lung interstitial via inhalation, where the deposition of nanoparticles could have the potential to generate oxidative stress, thus triggering fibrogenic response. Therefore, the influence of substrate stiffness on ROS generation in response to MWCNTs has been examined.

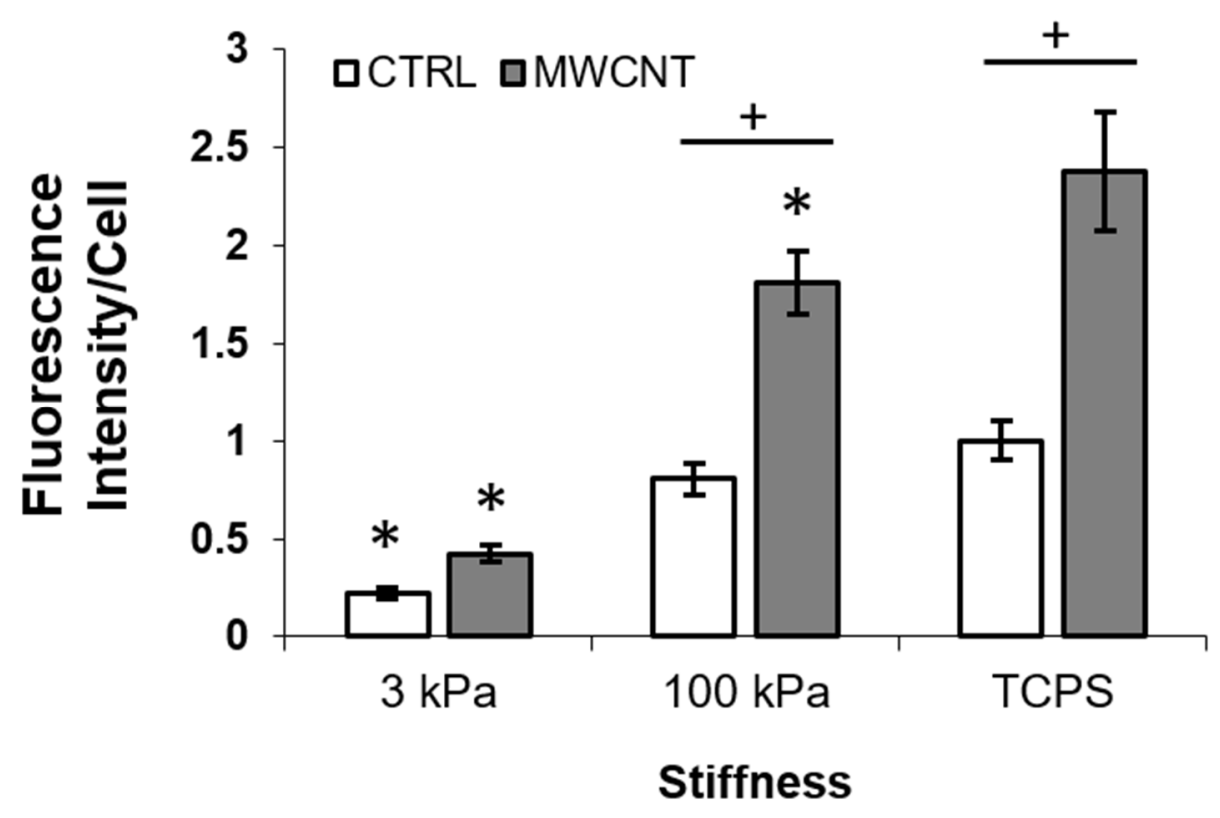

Figure 3-12: The influence of ROS generation of NHLFs on substrate stiffness in response to MWCNTs. The NHLFs were treated with MWCNT for $16 \mathrm{~h}$ (labeled as MWCNTs in the plot). Cells treated without MWCNTs were used as controls (labeled as CTRL in the plot). ROS was stained with DCF-DA and nuclei were stained with DAPI. Quantitative ROS image analysis was obtained from at least ten separate fields. *: significant difference $(\mathrm{p}<0.05)$ compared to the TCPS controls. + : significant difference $(\mathrm{p}<0.05)$ between groups. 
As shown in Figure 3-12, the quantitative analysis of ROS generation suggested that as the stiffness increased, the ROS generation increased with or without CNTs exposure, suggesting that substrate stiffness could regulate ROS generation of NHLFs. The effects of MWCNTs treatment resulted in enhanced ROS generation on all substrates. The level of increase was different between these three substrates, which was correlated with the previous cell proliferation results. The increase was not obvious and no significance on the soft substrate $(3 \mathrm{kPa})$ whereas significant increases were both observed on $100 \mathrm{kPa}$ PAAm substrate and TCPS.

Although extensive studies have been done that suggested the CNTs induced substantial ROS production, less effort has been made to explore the stiffness mediated ROS generation when exposed to CNTs. One studies used MSCs as a model cell to investigated the stiffness affected ROS generation by using PAAm gel substrate in kilopascal range compared to the fibronectincoated glass surface in gigapascal range, which revealed that ROS generation on the soft substrate was increased by a 2-4 fold when remained noncytotoxic. ${ }^{70}$ The result was not agreed with our findings possibly due to the difference in cell model and the different in vivo condition. Our result indicating that fibroblasts endured more oxidative stress when cultured on stiffer substrates (100 $\mathrm{kPa}$ ), which represented the fibrotic lung tissue. On the contrary, on soft substrate ( $3 \mathrm{kPa})$, normal lung tissue was under lower oxidative stress. This result highlighted the importance of incorporating stiffness cue to build a physiologically relevant model to investigate cell behavior for disease model.

\section{Mechanosensing}

Influence of stiffness on focal adhesion kinase (FAK) and phosphorylated tyrosine397 FAK (pFAK). FAs are dynamic protein molecules that regulate signals reflecting how cells 
respond to ECM, serving as a link between cytoskeleton and ECM. ${ }^{71,72,73}$ FAK is a key signaling kinase in FAs which could respond to substrate stiffness, thus mediate mechanotransduction. ${ }^{74}$ Western blotting was performed to examine the total and activated FAK levels by using antibodies specific for FAK and pFAK.

A

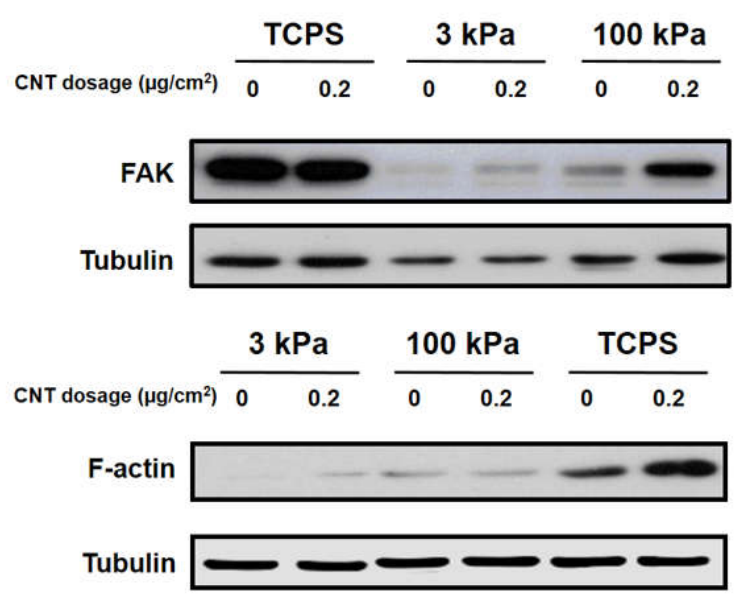

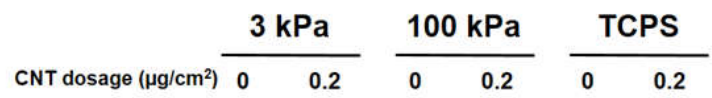

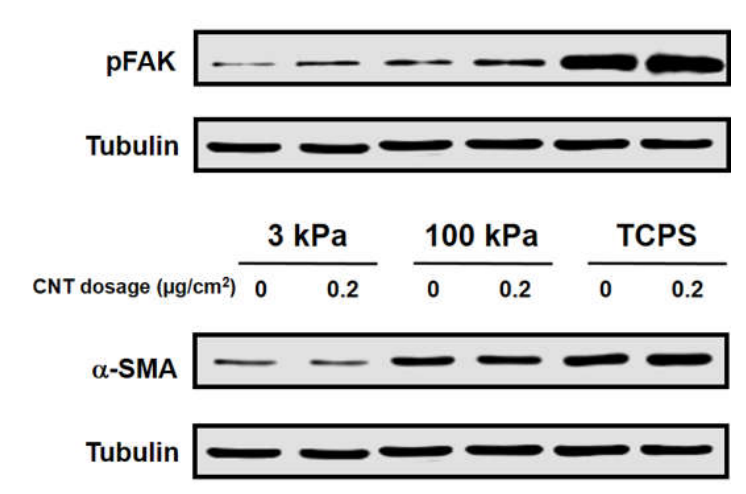

B

FAK

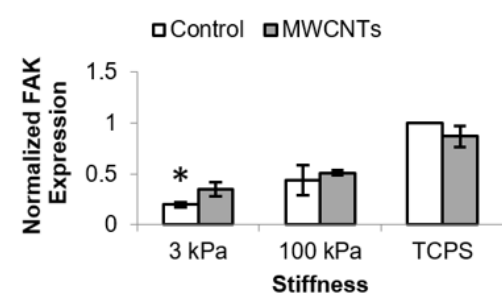

F-actin

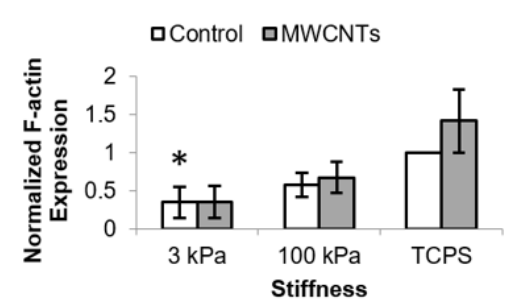

pFAK

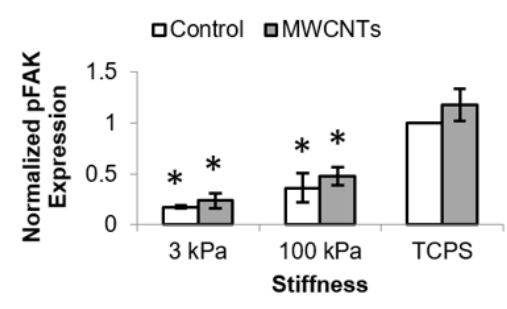

a-SMA

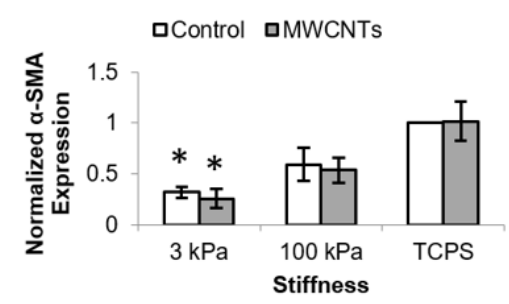

Figure 3-13: Protein expression of NHLFs treated with or without $0.2 \mu \mathrm{g} / \mathrm{cm}^{2}$ MWCNTs. (A) Immunoblotting of F-actin, $\alpha$-SMA, FAK and pFAK on $3 \mathrm{kPa}, 100 \mathrm{kPa}$ PAAm gel substrates as well as on TCPS. Tubulin was used as the loading control. Fibroblasts were treated with MWCNTs 
for $72 \mathrm{~h}$ in positive group. (labeled as MWCNTs in the plot). Cells treated without MWCNTs were used as controls (labeled as CTRL in the plot). (B) Densitometric analysis of the protein level of F-actin, $\alpha$-SMA, FAK and pFAK based on the immunoblotting results of (A). *: significant difference $(\mathrm{p}<0.05)$ compared to the TCPS controls.

Generally speaking, the stiffness effects of all four proteins were significant on $3 \mathrm{kPa}$ PAAm gel while the CNTs effects on the protein expression didn't show significant influence. From the immunoblotting in Figure 3-13A, both FAK and pFAK showed a similar trend of increased level when increasing the substrate stiffness. Quantitative analysis of the protein bands in Figure 3-13B showed that compared to TCPS controls, both the protein level of FAK and pFAK showed significantly decreased expression on soft substrate $(3 \mathrm{kPa})$ regardless of whether under CNTs treatment. The effects of CNTs on the expression of FAK was highly stiffness-dependent. On soft substrate $(3 \mathrm{kPa})$, the CNTs significantly increased the FAK expression, whereas on 100 kPa gel substrate and TCPS, FAK expression showed slightly increase and decrease, respectively. For pFAK, CNTs induced expression on all three substrates while none of which was significant.

Influence of stiffness on F-actin and $\alpha$-SMA. One of the important characters of lung fibrosis is the differentiation of lung fibroblasts into myofibroblasts which synthesize and secret the ECM. ${ }^{57,66}$ Fibroblasts in normal tissue exhibit little ECM production whereas in damaged tissue, they actively migrated towards the injured tissue and began to produce ECM. ${ }^{56,75}$ We thus investigated the F-actin expression and also $\alpha$-SMA expression, a molecular expressed by myofibroblasts to identify the influence of substrate stiffness affected cell sensing CNTs.

As shown in Figure 3-13A, cells on soft substrate $(3 \mathrm{kPa})$ generally expressed little F-actin as well as $\alpha$-SMA. The soft substrate is comparable to normal lung tissue stiffness in vivo. When 
the stiffness increase to $100 \mathrm{kPa}$ and as well as on TCPS, the expression of F-actin and $\alpha$-SMA were augmented. It has been suggested that fibroblasts could form contractile stress fibers when activated by stiffer substrate because matrix mechanical change caused constant change of ECM remodeling. from, whereas little to no stress fibers were formed on soft substrate. ${ }^{56,65,76}$ From the quantitative analysis shown in Figure 3-13B, the CNTs effects on F-actin formation was not clearly shown on softer substrate $(3 \mathrm{kPa}$ and $100 \mathrm{kPa})$. The increase on TCPS induced by CNTs was not significant, either. Moreover, it was observed that when treated with CNTs, $\alpha$-SMA expression was significantly decreased on softer substrate $(3 \mathrm{kPa}$ and $100 \mathrm{kPa})$ compared to the TCPS control.

\section{Effects of intracellular tension}

Effects of intracellular tension on TCPS. To further understand how cells respond to substrate stiffness in molecular level, we examined the effects of intracellular tension on fibroblasts by inhibition of the Rho-ROCK signally pathway. RhoA is one of the most studied that belongs to Rho family of GTPase, which is a family of small G proteins that involves in intracellular signal transduction. Extensive studies have shown that RhoA could regulate the remodeling of actin cytoskeleton, inducing stress fiber formation and upregulating the focal adhesion formation. ${ }^{77}$ It has been reported that higher intracellular tension was observed on stiff substrate, thus cells are more spreading and elongated, generating more stress fibers and where they adversely exerted augment traction force on the substrate. ${ }^{77,78,79,80}$ By inhibiting ROCK signally pathway, which is activated by RhoA, we could further investigated the mechanism of substrate stiffness modulated cellular response. Y27632, a pharmacological inhibitor of ROCK, was used inhibit the ROCK signally pathway. 
To determine the proper dosage for Y27632, we first conducted the experiment on TCPS by using several dosages of Y27632 and different administrative adding pattern (see Table 2). Cell morphologies were taken under bright field as a record (see Figure 3-14). 


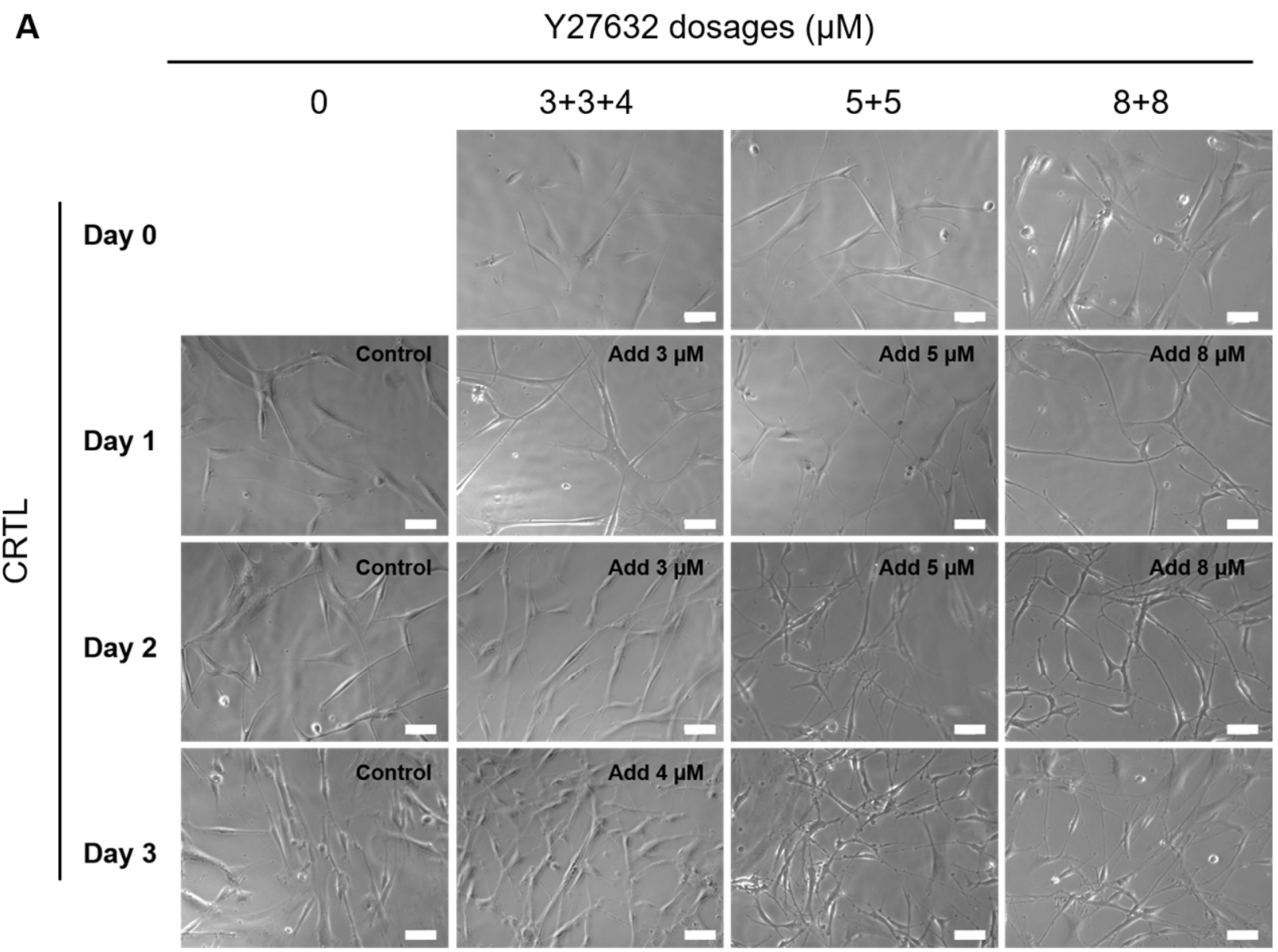

B

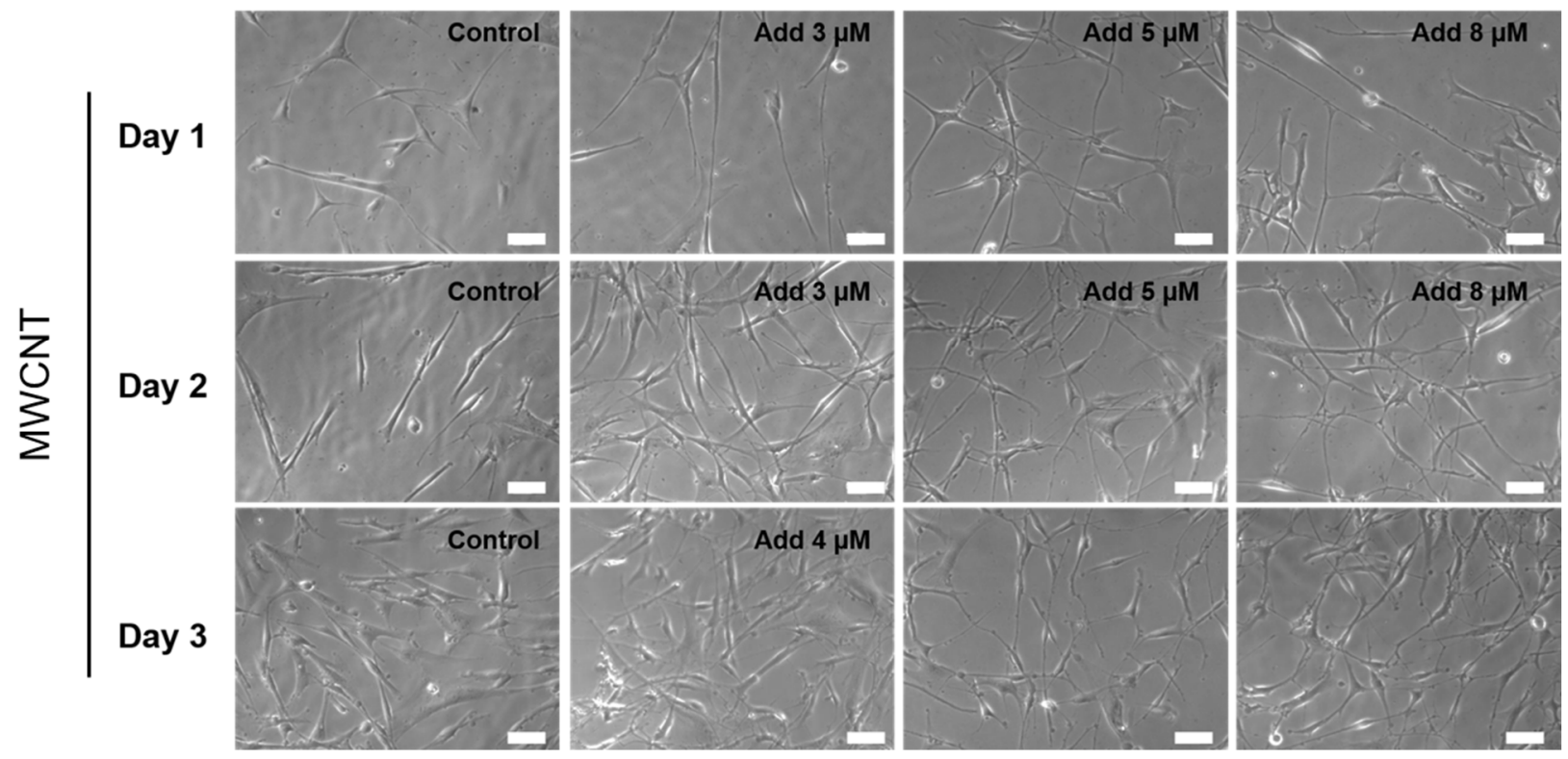


Figure 3-14: Bright field images of cells treated with different dosages of Y27632. NHLFs were seeded on day 0 . Y27632 was added from day 1 according to the predetermined dosages described in Table 3-2.

Since the most commonly used dosage used for $\mathrm{Y} 27632$ is $10 \mu \mathrm{M}^{54,81}$, we chose $10 \mu \mathrm{M}$ as the primary targeting dosage. We overserved that when adding a total dosage of $10 \mu \mathrm{M}$, cells experienced a distinct morphology change as they were being highly attenuated and elongated (see Figure 3-15). While when adding $5 \mu \mathrm{M}$ for each day for two days in a row, cells largely remained as their original morphologies. In this view, $(5+5) \mu \mathrm{M}$ was chosen for the following stiffness study. Moreover, fluorescent images showed that stress fibers were largely decreased when treated with Y27632, while there were clear stress fibers present in the control group (no Y27632 treatment). This result agreed with the previous theory that Rho-ROCK signally pathway is associated with stress fiber formation. 


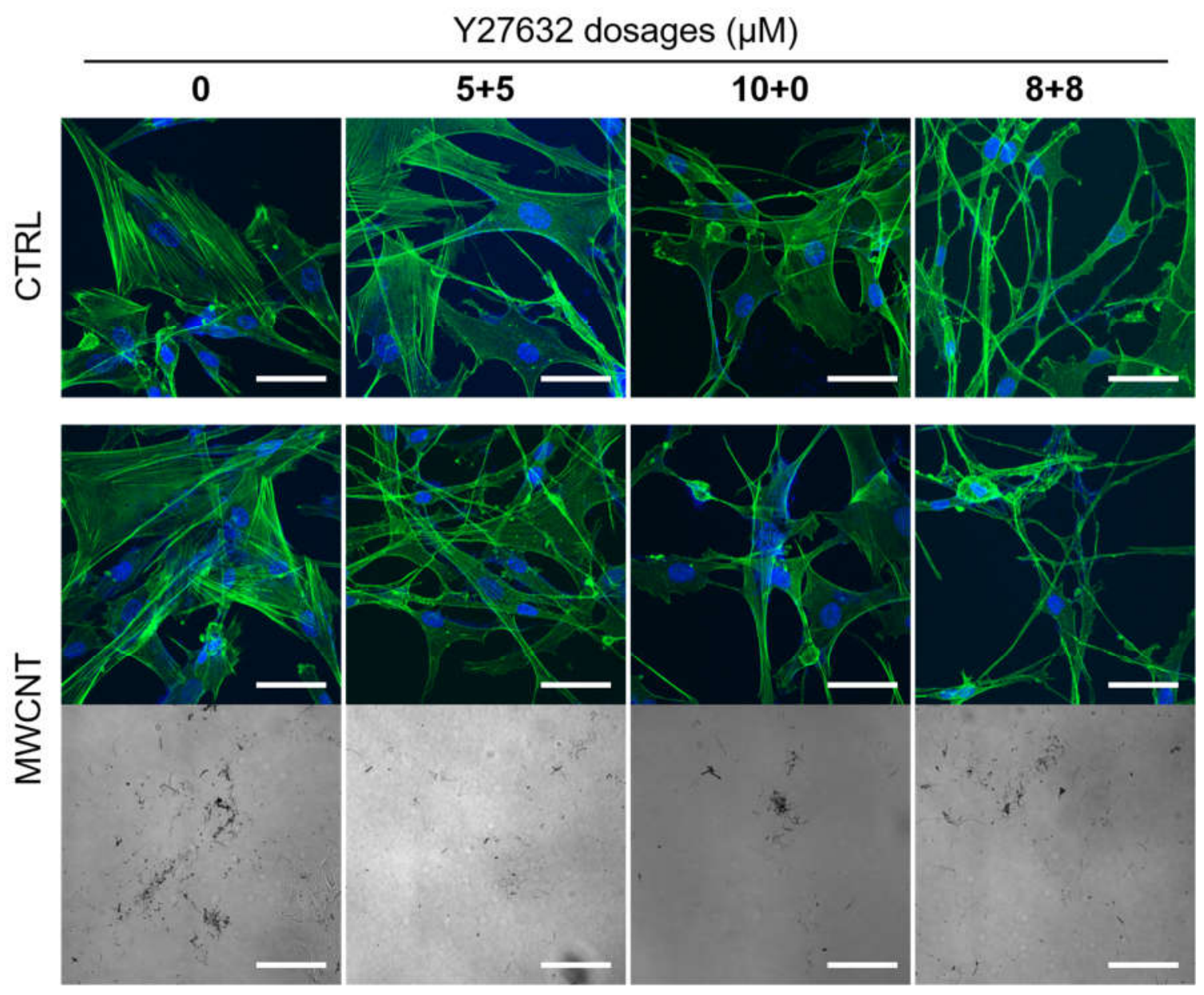

Figure 3-15: Images of NHLFs cell morphologies treated with different dosages of Y27632. Cells were cultured on TCPS. Fibroblasts were treated with MWCNTs for $72 \mathrm{~h}$ in positive group (labeled as MWCNT in the figure). Cells treated without MWCNTs were used as controls (labeled as CTRL). The F-actin (green) was immunostained with Alexa Fluor 488® phalloidin and the nuclei (blue) were stained with DAPI. The bright field images represent MWCNTs localized in the cells. The scale bars are $50 \mu \mathrm{m}$.

To further evaluate the effects of ROCK signaling in regard to different Y27632 dosages treatment, western blotting was performed to examine the collagen I expression under various Y27632 treatment. Figure 3-16 showed the immunoblotting and the quantitative analysis of 
collagen I expression, which indicated a downregulated mechanism of Y27632 to collagen I expression regardless of the dosage. However, statistical analysis did not reveal a significant decrease for either of the three dosages. Moreover, the treatment of MWCNTs didn't result in a significant increase in collagen expression. This observation was possibly related to the cell morphology change when adding Y27632 and decreased cell spreading area. It was observed that when treated with Y27632, cells were stretched and changed their morphologies in a dosedependent manner. When increased the dosage from $10 \mu \mathrm{M}$ total to a $(8+8) \mu \mathrm{M}$ total, the elongation and morphology change was increased, resulting in a decreased cell spreading area. For a total of $10 \mu \mathrm{M}$, adding in one day caused more morphology change than adding $5 \mu \mathrm{M}$ each day. The reduced cell area compared to control could result in a decrease in cellular uptake of the nanoparticle. However, inhibiting ROCK pathway by Y27632 would initially lower the intracellular tension, and previous reports showed a upregulated uptake of nanoparticle with lower membrane tension. ${ }^{62}$ According to Figure $3-16 \mathrm{~B}$, the collagen I production showed no significant change after adding CNTs, it was speculated that it was because of a neutralization of the two competing mechanisms. 


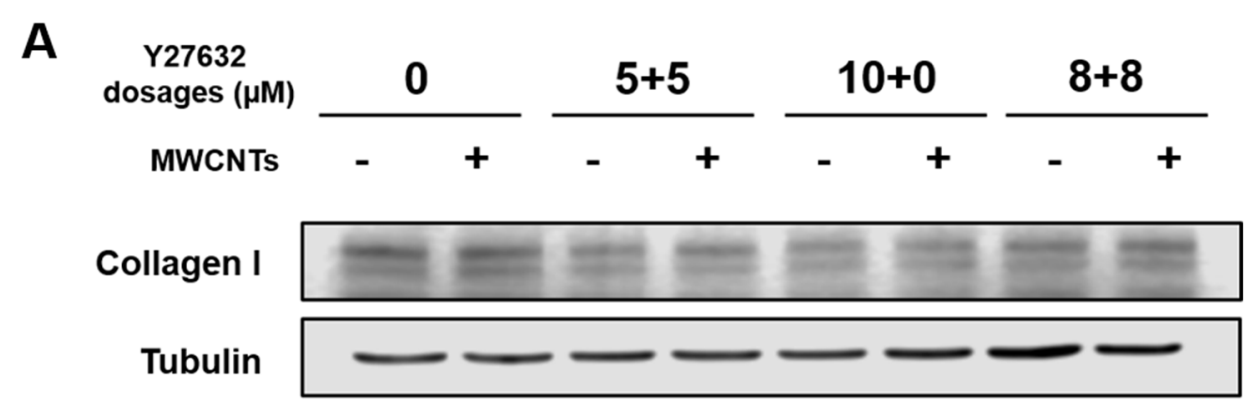

B

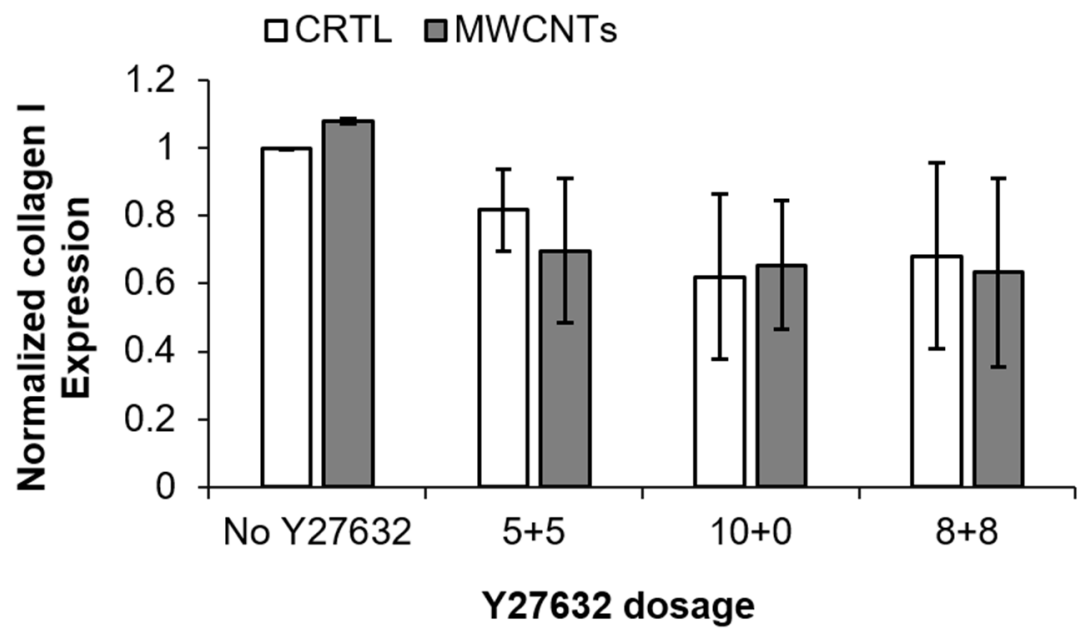

Figure 3-16: Collagen I expression of NHLFs exposed to $0.2 \mu \mathrm{g} / \mathrm{cm}^{2}$ MWCNTs when treated with different dosages of Y27632 on TCPS. (A) Immunoblotting of collagen I treated with different dosages of Y27632 TCPS. Tubulin was used as the loading control. Fibroblasts were treated with MWCNTs for $72 \mathrm{~h}$ in positive group (labeled as MWCNTs in the plot). Cells treated without MWCNTs were used as controls (labeled as CTRL in the plot). (B) Densitometric analysis of collagen I expression based on the results of immunoblotting in (A).

Effects of intracellular tension on $100 \mathrm{kPa}$ PAAm gel. Based on the immunofluorescent results and western blotting performed on TCPS, we chose $(5+5) \mu \mathrm{M}$ for the following study of intracellular tension effects on $100 \mathrm{kPa}$ PAAm gel. Western blotting also performed to show the collagen I expression when inhibiting ROCK on $100 \mathrm{kPa}$ PAAm gel (see Figure 3-17). In contrary 
to the results obtained from TCPS, Y27632 exhibited an upregulated mechanism when cultured on $100 \mathrm{kPa}$ PAAm gel. Although the detailed explanation of this phenomena remained unclear and needed to be further explored, we speculated that it might because culturing on soft gel (100 $\mathrm{kPa}$ compared to TCPS) lowered the membrane tension, which favored the cellular uptake of nanoparticles, ${ }^{62}$ thus increasing the collagen I production when treated with both Y27632 and MWCNTs. The preliminary condition of this explanation based on the similar spreading area that we observed before and after adding Y27632 on 100 kPa PAAm gel (see Figure 3-17B).

\section{A}

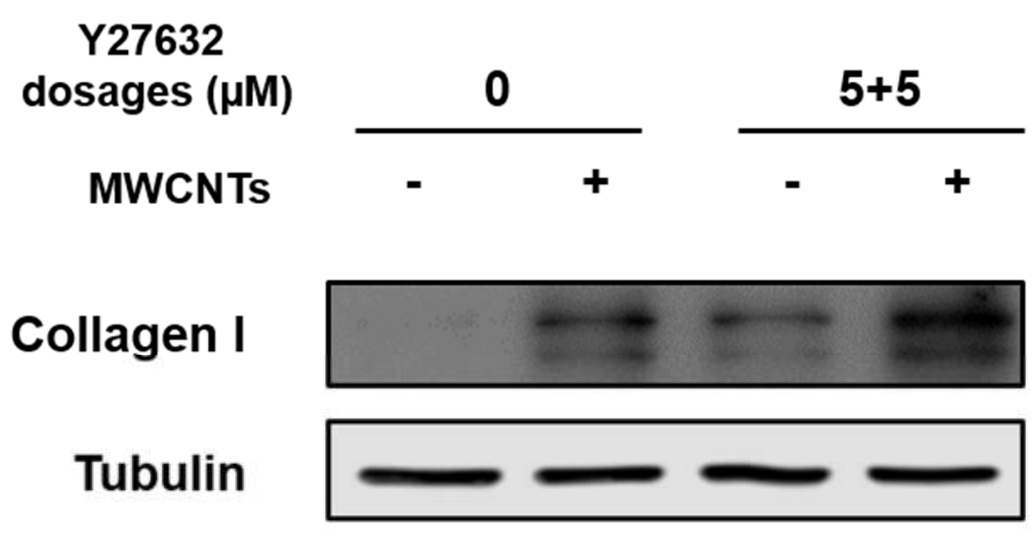

B
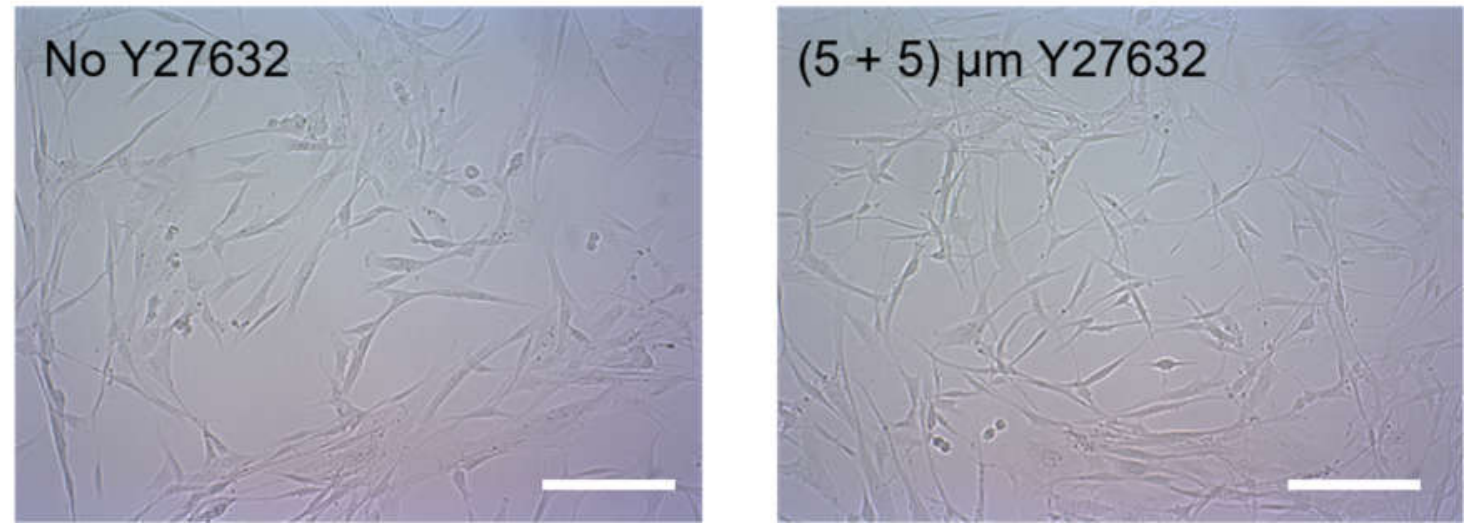

Figure 3-17: Collagen I expression of NHLFs exposed to $0.2 \mu \mathrm{g} / \mathrm{cm}^{2} \mathrm{MWCNTs}$ and $(5+5) \mu \mathrm{M}$ Y27632 on $100 \mathrm{kPa}$ PAAm gel substrates. (A) Immunoblotting of collagen I treated with $(5+5)$ 
$\mu \mathrm{M}$ Y27632. Tubulin was used as the loading control. Fibroblasts were treated with MWCNTs for $72 \mathrm{~h}$ in positive group (labeled as MWCNTs in the plot). Cells treated without MWCNTs were used as controls (labeled as CTRL in the plot). (B) Comparison of cell morphologies before and after adding Y27632. The scale bars are $200 \mu \mathrm{m}$.

We further conducted the same experiment by changing the substrate material to PDMS (see Figure 3-18) while remaining the same substrate stiffness. PDMS with a $100 \mathrm{kPa}$ stiffness was obtained by varying the ratio of the base material and curing agent (30:1) as well as controlling the curing condition. ${ }^{82,83,84}$ 
A

Y27632

dosages $(\mu \mathrm{M})$
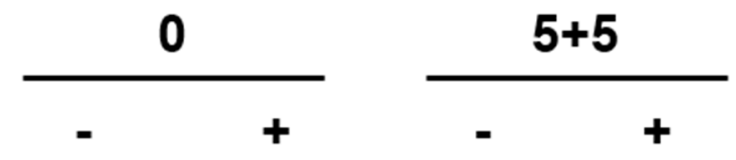

MWCNTs

Collagen I

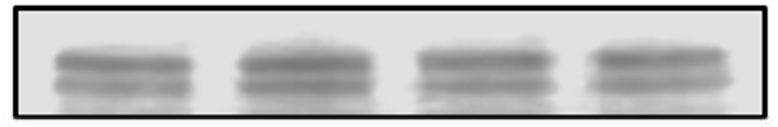

Tubulin

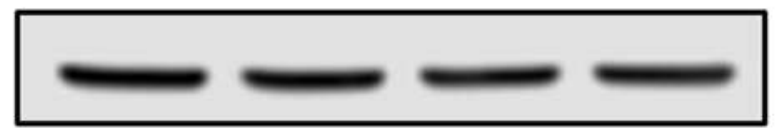

B

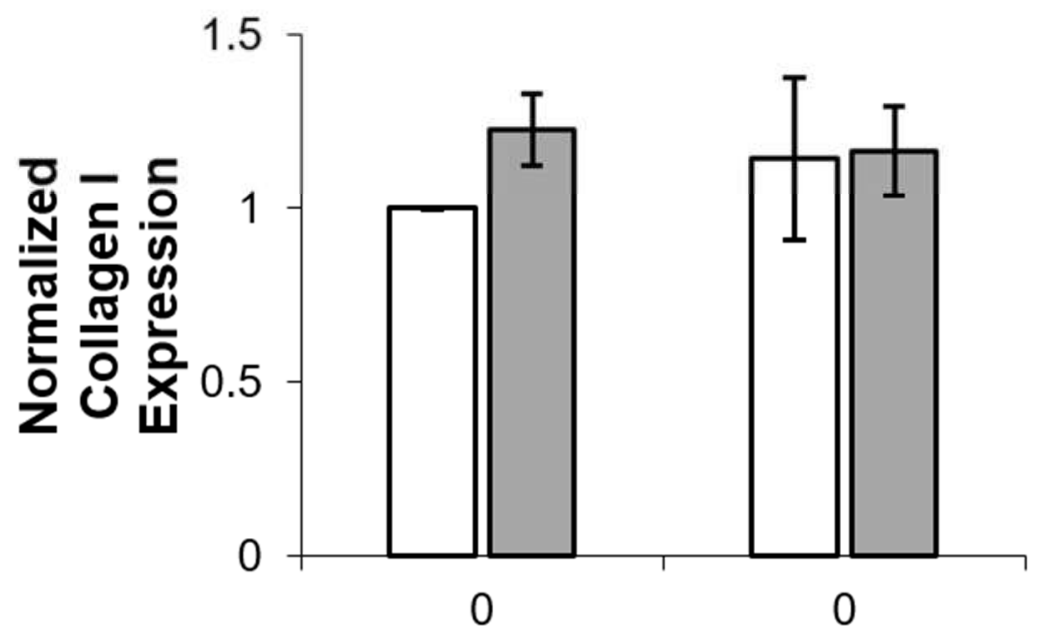

Figure 3-18: Collagen I expression of NHLFs exposed to $0.2 \mu \mathrm{g} / \mathrm{cm}^{2}$ MWCNTs and $(5+5) \mu \mathrm{M}$ Y27632 on $100 \mathrm{kPa}$ PDMS gel substrates. (A) Immunoblotting of collagen I treated with $(5+5)$ $\mu \mathrm{M}$ Y 27632. Tubulin was used as the loading control. Fibroblasts were treated with MWCNTs for $72 \mathrm{~h}$ in positive group (labeled as MWCNTs in the plot). Cells treated without MWCNTs were used as controls (labeled as CTRL in the plot). (B) Densitometric analysis of collagen I expression based on the results of immunoblotting in (A). 
From the immunoblotting, we could see that the collagen I expression under different condition showed no obvious change either treated with Y27632 or MWCNTs. The different result obtained from PDMS compared to previous PAAm result was possibly due to the structural difference between PDMS and PAAm, although they were designed for the same stiffness. One study has shown that cell responses to the substrate stiffness were not from the bulk stiffness but the coated ECM anchor point. ${ }^{85}$ The structure of PAAm is porous, where the pore size is associated with stiffness. Even under the same bulk stiffness, PDMS didn't have the porous structure, which might result in difference in cell behavior. 


\section{Conclusion}

There has been evolving and compelling evidence showed that substrate stiffness could have a profound influence on cell behavior including cell adhesion, cell spreading, cell migration, cell proliferation and cell migration. More and more studies have been done to realize the important roles that substrate stiffness played in regulating cell behavior. This study systematically investigated cellular responses to CNTs by incorporating stiffness cue to replicate the physiological condition of the human body. PAAm gel substrates were fabricated to represent normal human lung tissue and fibrotic lung tissue, respectively. NHLFs were cultured on PAAm substrates with different stiffness as well as on TCPS. Our findings indicated that substrate stiffness played a significant role in regulating cell phenotype and function, including cell adhesion, cell spreading, cell elongation and cell proliferation.

NHLFs on soft ( $3 \underline{\mathrm{kPa}})$ substrates were rounded without actin fibers, on the contrary, cells on stiffer $(100 \mathrm{kPa})$ substrates and TCPS were largely elongated with visible stress fibers. The fibrogenesis response of the cell to MWCNTs could also be mediated by substrate stiffness, including the increased collagen I expression, cell proliferation and ROS generation. Moreover, we found out that CNTs did induce the production of collagen I but not significant. The CNTs effects on cell proliferation and ROS generation were highly dependent on the substrate stiffness, where they didn't induce significant increase on soft substrates, but the increases in cell proliferation and ROS generation were both significant on $100 \underline{\mathrm{kPa}}$ substrates and TCPS. Furthermore, results of the mechanosensing showed similar trends on stiffness modulated the protein level expression of F-actin, $\alpha$-SMA, FAK expression. Finally, by inhibiting the Rho-ROCK signally pathway, we were trying to understand the substrate stiffness affected cellular responses to CNTs down to molecular level. We found out that ROCK pathway was associated with the 
collagen I synthesis and the CNTs induced collagen I effect was compromised by inhibiting ROCK. However, there are still needs to explore the mechanism of substrate stiffness effect.

This study provides a basic understanding of stiffness modulated cell behaviors and could potentially serve as an in vitro platform for disease modeling. While nanotechnology has been widely used in a diversity of different applications, the increasing concern of the toxicity of nanomaterials has been brought to attention. Efforts have been made to address the issues regarding the toxicity study of nanomaterials, while most of the established in vitro models were based on using stiff TCPS where the stiffness is far from most of the tissues existing in the human body. The novelty of our study was to build a physiologically relevant in vitro model by introducing stiffness cue to mimic the microenvironment of normal and fibrotic lung tissue for disease toxicology study of cellular response to MWCNTs, where there have been few reports on the idea of studying the toxicity by varying the substrate stiffness. We systematically investigated the substrate stiffness affected cell behaviors, as well as the fibrogenesis response of cellular responses to CNTs. Also, we targeted the cellular responses to CNTs through mechanosensing and intracellular tension, which helped further understanding the mechanism of substrate stiffness modulation of cell behaviors.

The stiffness cue could also be further applied to three-dimensional culture model to largely replicate the actual in vivo condition. Ultimately, the in vitro platform for disease modeling could be further optimized by introducing flow and shear stress to mimic the dynamic in vivo microenvironment into microfluidic devices. For example, simulating the breathing condition of the lung in the "lung-on-a-chip" could be potentially used as a reliable disease model for understanding and studying lung fibrosis. 


\section{References}

1. Di Lullo, G. A.; Sweeney, S. M.; Korkko, J.; Ala-Kokko, L.; San Antonio, J. D. Mapping the ligand-binding sites and disease-associated mutations on the most abundant protein in the human, type I collagen. Journal of Biological Chemistry 2002, 277 (6), 4223-31.

2. Rossert, J.; Terraz, C.; Dupont, S. Regulation of type I collagen genes expression. Nephrology Dialysis Transplantation 2000, 15 (Suppl 6), 66-8.

3. Mwenifumbo, S.; Stevens, M. M. ECM Interactions with Cells from the Macro- to Nanoscale. In Biomedical Nanostructures; John Wiley \& Sons, Inc., 2016, pp 223-260.

4. Michel, G.; Tonon, T.; Scornet, D.; Cock, J. M.; Kloareg, B. The cell wall polysaccharide metabolism of the brown alga Ectocarpus siliculosus. Insights into the evolution of extracellular matrix polysaccharides in Eukaryotes. The New Phytologist 2010, 188 (1), 82-97.

5. Kumar, V.; Abbas, A. K.; Aster, J. C. Robbins \& Cotran Pathologic Basis of Disease, $9 e$ (Robbins Pathology); Saunders2014. p 1408.

6. Discher, D. E.; Mooney, D. J.; Zandstra, P. W. Growth factors, matrices, and forces combine and control stem cells. Science (New York, N.Y.) 2009, 324 (5935), 1673-7.

7. Nemir, S.; West, J. L. Synthetic materials in the study of cell response to substrate rigidity. Annals of Biomedical Engineering 2010, 38 (1), 2-20.

8. Orr, A. W.; Helmke, B. P.; Blackman, B. R.; Schwartz, M. A. Mechanisms of mechanotransduction. Developmental Cell 2006, 10 (1), 11-20. 
9. Wozniak, M. A.; Chen, C. S. Mechanotransduction in development: a growing role for contractility. Nature Reviews Molecular Cell Biology 2009, 10 (1), 34-43.

10. Gilbert, P. M.; Havenstrite, K. L.; Magnusson, K. E.; Sacco, A.; Leonardi, N. A.; Kraft, P.; Nguyen, N. K.; Thrun, S.; Lutolf, M. P.; Blau, H. M. Substrate elasticity regulates skeletal muscle stem cell self-renewal in culture. Science (New York, N.Y.) 2010, 329 (5995), 1078-81.

11. Wells, R. G. The role of matrix stiffness in regulating cell behavior. Hepatology 2016, 47 (4), 1394-1400.

12. Dalby, M. J.; Gadegaard, N.; Tare, R.; Andar, A.; Riehle, M. O.; Herzyk, P.; Wilkinson, C. D. W.; Oreffo, R. O. C. The control of human mesenchymal cell differentiation using nanoscale symmetry and disorder. Nature Materials 2007, 6 (12), 997-1003.

13. Discher, D. E.; Janmey, P.; Wang, Y. L. Tissue cells feel and respond to the stiffness of their substrate. Science (New York, N.Y.) 2005, 310 (5751), 1139-43.

14. Rottner, K.; Hall, A.; Small, J. V. Interplay between Rac and Rho in the control of substrate contact dynamics. Current Biology 1999, 9 (12), 640-S1.

15. Lo, C. M.; Wang, H. B.; Dembo, M.; Wang, Y. L. Cell movement is guided by the rigidity of the substrate. Biophysical Journal 2000, 79 (1), 144-52.

16. Zaari, N.; Rajagopalan, P.; Kim, S. K.; Engler, A. J.; Wong, J. Y. Photopolymerization in microfluidic gradient generators: microscale control of substrate compliance to manipulate cell response. Advanced Materials 2004, 16 (23-24), 2133-2137. 
17. Engler, A.; Bacakova, L.; Newman, C.; Hategan, A.; Griffin, M.; Discher, D. Substrate compliance versus ligand density in cell on gel responses. Biophysical Journal 2004, 86 (1), 617 628.

18. Raffa, V.; Ciofani, G.; Vittorio, O.; Riggio, C.; Cuschieri, A. Physicochemical properties affecting cellular uptake of carbon nanotubes. Nanomedicine (London, England) 2010, 5 (1), 8997.

19. Vietti, G.; Lison, D.; van den Brule, S. Mechanisms of lung fibrosis induced by carbon nanotubes: towards an Adverse Outcome Pathway (AOP). Particle and Fibre Toxicology 2015, $13,11$.

20. Wang, L.; Mercer, R. R.; Rojanasakul, Y.; Qiu, A.; Lu, Y.; Scabilloni, J. F.; Wu, N.; Castranova, V. Direct fibrogenic effects of dispersed single-walled carbon nanotubes on human lung fibroblasts. Journal of Toxicology and Environmental Health, Part A 2010, 73 (5), 410-22.

21. Specks, U.; Nerlich, A.; Colby, T. V.; Wiest, I.; Timpl, R. Increased expression of type VI collagen in lung fibrosis. American Journal of Respiratory and Critical Care Medicine 1995, 151 (6), 1956-1964.

22. Ng, C. P.; Hinz, B.; Swartz, M. A. Interstitial fluid flow induces myofibroblast differentiation and collagen alignment in vitro. Journal of Cell Science 2005, 118 (Pt 20), 4731-9.

23. Warheit, D. B.; Laurence, B. R.; Reed, K. L.; Roach, D. H.; Reynolds, G. A.; Webb, T. R. Comparative pulmonary toxicity assessment of single-wall carbon nanotubes in rats. Toxicological Sciences 2004, 77 (1), 117-25. 
24. Shvedova, A. A.; Kisin, E. R.; Mercer, R.; Murray, A. R.; Johnson, V. J.; Potapovich, A. I.; Tyurina, Y. Y.; Gorelik, O.; Arepalli, S.; Schwegler-Berry, D.; Hubbs, A. F.; Antonini, J.; Evans, D. E.; Ku, B. K.; Ramsey, D.; Maynard, A.; Kagan, V. E.; Castranova, V.; Baron, P. Unusual inflammatory and fibrogenic pulmonary responses to single-walled carbon nanotubes in mice. American Journal of Physiology - Lung Cellular and Molecular Physiology 2005, 289 (5), L698-708.

25. Muller, J.; Huaux, F.; Moreau, N.; Misson, P.; Heilier, J. F.; Delos, M.; Arras, M.; Fonseca, A.; Nagy, J. B.; Lison, D. Respiratory toxicity of multi-wall carbon nanotubes. Toxicology and Applied Pharmacology 2005, 207 (3), 221-31.

26. Ding, L.; Stilwell, J.; Zhang, T.; Elboudwarej, O.; Jiang, H.; Selegue, J. P.; Cooke, P. A.; Gray, J. W.; Chen, F. F. Molecular characterization of the cytotoxic mechanism of multiwall carbon nanotubes and nano-onions on human skin fibroblast. Nano Letters 2005, 5 (12), 2448-64.

27. Plata, D. L.; Gschwend, P. M.; Reddy, C. M. Industrially synthesized single-walled carbon nanotubes: compositional data for users, environmental risk assessments, and source apportionment. Nanotechnology 2008, 19 (18), 185706.

28. Malur, A.; Barna, B. P.; Patel, J.; McPeek, M.; Wingard, C. J.; Dobbs, L.; Thomassen, M. J. Exposure to a mycobacterial antigen, esat-6, exacerbates granulomatous and fibrotic changes in a multiwall carbon nanotube model of chronic pulmonary disease. Journal of Nanomedicine \& Nanotechnology 2015, 6 (6), 340. 
29. Collin, O.; Tracqui, P.; Stephanou, A.; Usson, Y.; Clement-Lacroix, J.; Planus, E. Spatiotemporal dynamics of actin-rich adhesion microdomains: influence of substrate flexibility. Journal of Cell Science 2006, 119 (Pt 9), 1914-25.

30. Xie, J.; Zhang, Q.; Zhu, T.; Zhang, Y.; Liu, B.; Xu, J.; Zhao, H. Substrate stiffnessregulated matrix metalloproteinase output in myocardial cells and cardiac fibroblasts: implications for myocardial fibrosis. Acta Biomaterialia 2014, 10 (6), 2463-72.

31. Shi, Y.; Dong, Y.; Duan, Y.; Jiang, X.; Chen, C.; Deng, L. Substrate stiffness influences TGF-betal-induced differentiation of bronchial fibroblasts into myofibroblasts in airway remodeling. Molecular Medicine Reports 2013, 7 (2), 419-24.

32. Burgess, H. A.; Daugherty, L. E.; Thatcher, T. H.; Lakatos, H. F.; Ray, D. M.; Redonnet, M.; Phipps, R. P.; Sime, P. J. PPARgamma agonists inhibit TGF-beta induced pulmonary myofibroblast differentiation and collagen production: implications for therapy of lung fibrosis. American Journal of Physiology - Lung Cellular and Molecular Physiology 2005, 288 (6), L114653.

33. Tojkander, S.; Gateva, G.; Lappalainen, P. Actin stress fibers - assembly, dynamics and biological roles. Journal of Cell Science 2012, 125, 1855-1864.

34. Prager-Khoutorsky, M.; Lichtenstein, A.; Krishnan, R.; Rajendran, K.; Mayo, A.; Kam, Z.; Geiger, B.; Bershadsky, A. D. Fibroblast polarization is a matrix-rigidity-dependent process controlled by focal adhesion mechanosensing. Nature Cell Biology 2011, 13, 1457-1465. 
35. Liu, Z.; Tabakman, S.; Welsher, K.; Dai, H. Carbon nanotubes in biology and medicine: in vitro and in vivo detection, imaging and drug delivery. Nano Research 2009, 2 (2), 85-120.

36. Lam, C. W.; James, J. T.; McCluskey, R.; Hunter, R. L. Pulmonary toxicity of single-wall carbon nanotubes in mice 7 and 90 days after intratracheal instillation. Toxicological Sciences 2004, 77 (1), 126-34.

37. Ryman-Rasmussen, J. P.; Cesta, M. F.; Brody, A. R.; Shipley-Phillips, J. K.; Everitt, J. I.; Tewksbury, E. W.; Moss, O. R.; Wong, B. A.; Dodd, D. E.; Andersen, M. E.; Bonner, J. C. Inhaled carbon nanotubes reach the subpleural tissue in mice. Nature Nanotechnology 2009, 4 (11), 74751.

38. Hinz, B. Mechanical aspects of lung fibrosis: a spotlight on the myofibroblast. Proceedings of the American Thoracic Society 2012, 9 (3), 137-47.

39. Provenzano, P. P.; Keely, P. J. Mechanical signaling through the cytoskeleton regulates cell proliferation by coordinated focal adhesion and Rho GTPase signaling. Journal of Cell Science 2011, 124 (Pt 8), 1195-205.

40. Ng, M. R.; Besser, A.; Danuser, G.; Brugge, J. S. Substrate stiffness regulates cadherindependent collective migration through myosin-II contractility. Journal of Cell Biology 2012, 199 (3), 545-63.

41. Wang, Y. L.; Pelham, R. J., Jr. Preparation of a flexible, porous polyacrylamide substrate for mechanical studies of cultured cells. Methods in Enzymology 1998, 298, 489-96. 
42. Jerrell, R. J.; Parekh, A. Polyacrylamide gels for invadopodia and traction force assays on cancer cells. Journal of Visualized Experiments 2015, (95), 52343.

43. Cretu, A.; Castagnino, P.; Assoian, R. Studying the effects of matrix stiffness on cellular function using acrylamide-based hydrogels. Journal of Visualized Experiments 2010, 10 (42), 2089.

44. Fischer, R. S.; Myers, K. A.; Gardel, M. L.; Waterman, C. M. Stiffness-controlled threedimensional extracellular matrices for high-resolution imaging of cell behavior. Nature Protocol 2012, 7 (11), 2056-66.

45. Ali, M. Y.; Anand, S. V.; Tangella, K.; Ramkumar, D.; Saif, T. A. Isolation of primary human colon tumor cells from surgical tissues and culturing them directly on soft elastic substrates for traction cytometry. Journal of Visualized Experiments 2015, 4 (100), e52532.

46. Liu, F.; Mih, J. D.; Shea, B. S.; Kho, A. T.; Sharif, A. S.; Tager, A. M.; Tschumperlin, D. J. Feedback amplification of fibrosis through matrix stiffening and COX-2 suppression. The Journal of Cell Biology 2010, 190 (4), 693-706.

47. Liu, F.; Tschumperlin, D. J. Micro-mechanical characterization of lung tissue using atomic force microscopy. Journal of Visualized Experiments 2011, (54), e2911-e2911.

48. He, X.; Young, S. H.; Schwegler-Berry, D.; Chisholm, W. P.; Fernback, J. E.; Ma, Q. Multiwalled carbon nanotubes induce a fibrogenic response by stimulating reactive oxygen species production, activating NF-kappaB signaling, and promoting fibroblast-to-myofibroblast transformation. Chemical Research in Toxicology 2011, 24 (12), 2237-48. 
49. Luanpitpong, S.; Wang, L.; Manke, A.; Martin, K. H.; Ammer, A. G.; Castranova, V.; Yang, Y.; Rojansakul, Y. Induction of stemlike cells with fibrogenic properties by carbon nanotubes and its role in fibrogenesis. Nano Letters 2014, 14 (6), 3110-6.

50. Luanpitpong, S.; Wang, L.; Rojanasakul, Y. The effects of carbon nanotubes on lung and dermal cellular behaviors. Nanomedicine (London, England) 2014, 9 (6), 895-912.

51. Wynn, T. A. Integrating mechanisms of pulmonary fibrosis. The Journal of Experimental Medicine 2011, 208 (7), 1339-50.

52. Wang, K. Carbon nanotubes induced fibrogenesis on nanostructured substrates. Environmental Science: Nano 2017, 4 (3), 689-699.

53. Uehata, M.; Ishizaki, T.; Satoh, H.; Ono, T.; Kawahara, T.; Morishita, T.; Tamakawa, H.; Yamagami, K.; Inui, J.; Maekawa, M.; Narumiya, S. Calcium sensitization of smooth muscle mediated by a Rho-associated protein kinase in hypertension. Nature 1997, 389 (6654), 990-4.

54. Ugawa, Y.; Yamamoto, T.; Kawamura, M.; Yamashiro, K.; Shimoe, M.; Tomikawa, K.; Hongo, S.; Maeda, H.; Takashiba, S. Rho-kinase regulates extracellular matrix-mediated osteogenic differentiation of periodontal ligament cells. Cell Biology International 2017, 41 (6), $651-658$.

55. Phan, S. H. The myofibroblast in pulmonary fibrosis. Chest 2002, 122 (6 Suppl), 286s289s. 
56. Hinz, B.; Phan, S. H.; Thannickal, V. J.; Galli, A.; Bochaton-Piallat, M.-L.; Gabbiani, G. The myofibroblast: one function, multiple origins. The American Journal of Pathology 2007, 170 (6), 1807-1816.

57. Hu, M.; Che, P.; Han, X.; Cai, G. Q.; Liu, G.; Antony, V.; Luckhardt, T.; Siegal, G. P.; Zhou, Y.; Liu, R. M.; Desai, L. P.; O'Reilly, P. J.; Thannickal, V. J.; Ding, Q. Therapeutic targeting of SRC kinase in myofibroblast differentiation and pulmonary fibrosis. The Journal of Pharmacology and Experimental Therapeutics 2014, 351 (1), 87-95.

58. Reilly, R. M. Carbon nanotubes: potential benefits and risks of nanotechnology in nuclear medicine. Journal of Nuclear Medicine 2007, 48 (7), 1039-1042.

59. Kam, N. W. S.; Liu, Z.; Dai, H. Carbon nanotubes as intracellular transporters for proteins and DNA: an investigation of the uptake mechanism and pathway. Angewandte Chemie 2006, 118 (4), 591-595.

60. Pantarotto, D.; Briand, J. P.; Prato, M.; Bianco, A. Translocation of bioactive peptides across cell membranes by carbon nanotubes. Chemical Communications (Cambridge, England) 2004, (1), 16-7.

61. Pastorin, G.; Wu, W.; Wieckowski, S.; Briand, J.-P.; Kostarelos, K.; Prato, M.; Bianco, A. Double functionalisation of carbon nanotubes for multimodal drug delivery. Chemical Communications 2006, (11), 1182-1184.

62. Huang, C.; Butler, P. J.; Tong, S.; Muddana, H. S.; Bao, G.; Zhang, S. Substrate stiffness regulates cellular uptake of nanoparticles. Nano Letters 2013, 13 (4), 1611-5. 
63. Datta, A.; Scotton, C. J.; Chambers, R. C. Novel therapeutic approaches for pulmonary fibrosis. British Journal of Pharmacology 2011, 163 (1), 141-72.

64. Mishra, A.; Stueckle, T. A.; Mercer, R. R.; Derk, R.; Rojanasakul, Y.; Castranova, V.; Wang, L. Identification of TGF-beta receptor-1 as a key regulator of carbon nanotube-induced fibrogenesis. American Journal of Physiology - Lung Cellular and Molecular Physiology 2015, 309 (8), L821-33.

65. Tomasek, J. J.; Gabbiani, G.; Hinz, B.; Chaponnier, C.; Brown, R. A. Myofibroblasts and mechano-regulation of connective tissue remodelling. Nature Reviews Molecular Cell Biology 2002, $3(5), 349-63$.

66. Ni, J.; Dong, Z.; Han, W.; Kondrikov, D.; Su, Y. The role of RhoA and cytoskeleton in myofibroblast transformation in hyperoxic lung fibrosis. Free Radical Biology and Medicine 2013, 61, 26-39.

67. Avalos, A.; Haza, A. I.; Mateo, D.; Morales, P. Cytotoxicity and ROS production of manufactured silver nanoparticles of different sizes in hepatoma and leukemia cells. Journal of Applied Toxicology 2013, 34 (4), 413-23.

68. Bonner, J. C. Lung fibrotic responses to particle exposure. Toxicologic pathology 2007, 35 (1), 148-53.

69. Cheresh, P.; Kim, S. J.; Tulasiram, S.; Kamp, D. W. Oxidative stress and pulmonary fibrosis. Biochimica et Biophysica Acta 2013, 1832 (7), 1028-40. 
70. Yang, H.; Nguyen, K. T.; Leong, D. T.; Tan, N. S.; Tay, C. Y. Soft material approach to induce oxidative stress in mesenchymal stem cells for functional tissue repair. ACS Applied Materials \& Interfaces 2016, 8 (40), 26591-26599.

71. Chen, C. S.; Alonsob, J. L.; Ostunic, E.; Whitesidesc, G. M.; Ingberb, D. E. Cell shape provides global control of focal adhesion assembly. Biochemical and Biophysical Research Communications 2003, 307 (2), 355-361.

72. Geiger, B.; Bershadsky, A.; Pankov, R.; Yamada, K. M. Transmembrane crosstalk between the extracellular matrix - cytoskeleton crosstalk. Nature Reviews Molecular Cell Biology 2001, 2 (11), 793-805.

73. Provenzano, P. P.; Inman, D. R.; Eliceiri, K. W.; Keely, P. J. Matrix density-induced mechanoregulation of breast cell phenotype, signaling, and gene expression through a FAK-ERK linkage. Oncogene 2009, 28 (49), 4326-43.

74. Wang, H. B.; Dembo, M.; Hanks, S. K.; Wang, Y. Focal adhesion kinase is involved in mechanosensing during fibroblast migration. Proceedings of the National Academy of Sciences of the United States of America 2001, 98 (20), 11295-300.

75. Hinz, B. Formation and function of the myofibroblast during tissue repair. The Journal of Investigative Dermatology 2007, 127 (3), 526-37.

76. Hinz, B. Masters and servants of the force: the role of matrix adhesions in myofibroblast force perception and transmission. European Journal of Cell Biology 2006, 85 (3-4), 175-81. 
77. Hoon, J. L.; Tan, M. H.; Koh, C. G. The regulation of cellular responses to mechanical cues by Rho GTPases. Cells 2016, 5 (2).

78. $\quad$ Ghosh, K.; Pan, Z.; Guan, E.; Ge, S.; Liu, Y.; Nakamura, T.; Ren, X. D.; Rafailovich, M.; Clark, R. A. Cell adaptation to a physiologically relevant ECM mimic with different viscoelastic properties. Biomaterials 2006, 28 (4), 671-9.

79. Mih, J. D.; Marinkovic, A.; Liu, F.; Sharif, A. S.; Tschumperlin, D. J. Matrix stiffness reverses the effect of actomyosin tension on cell proliferation. Journal of Cell Science 2012, 125 (24), 5974-83.

80. Rhee, S.; Jiang, H.; Ho, C. H.; Grinnell, F. Microtubule function in fibroblast spreading is modulated according to the tension state of cell-matrix interactions. Proceedings of the National Academy of Sciences of the United States of America 2007, 104 (13), 5425-30.

81. Yokota, S.; Chosa, N.; Kyakumoto, S.; Kimura, H.; Ibi, M.; Kamo, M.; Satoh, K.; Ishisaki, A. ROCK/actin/MRTF signaling promotes the fibrogenic phenotype of fibroblast-like synoviocytes derived from the temporomandibular joint. International Journal of Molecular Medicine 1899, 39 (4), 799-808.

82. Gutierrez, E.; Groisman, A. Measurements of elastic moduli of silicone gel substrates with a microfluidic device. PLOS One 2011, 6 (9), e25534.

83. Xu, Q.; Li, C.; Kang, Y.; Zhang, Y. Long term effects of substrate stiffness on the development of hMSC mechanical properties. RSC Advances 2015, 5 (128), 105651-105660. 
84. Liu, M.; Chen, Q. Characterization study of bonded and unbonded polydimethylsiloxane aimed for bio-micro-electromechanical systems-related applications. MOEMS 2007, 6 (2), 023008-023008-6.

85. Trappmann, B.; Gautrot, J. E.; Connelly, J. T.; Strange, D. G.; Li, Y.; Oyen, M. L.; Cohen Stuart, M. A.; Boehm, H.; Li, B.; Vogel, V.; Spatz, J. P.; Watt, F. M.; Huck, W. T. Extracellularmatrix tethering regulates stem-cell fate. Nature Materials 2012, 11 (7), 642-9. 


\section{Chapter 4: Path Forward}

From the perspective of understanding the mechanism of the human disease and achieving ultimate treatment, it is of great significance to build in vitro disease model that could largely represent the actual in vivo condition. Although numerous experiments and researches have been done using animal models, there are still gaps existing between the results obtained from animal and human, causing the barrier to disease detection and drug development. In this dissertation, our work emphasized incorporating two biophysical cues, nanotopography cue and stiffness cue, into the process of disease detection and in vitro disease modeling, which had the potential to mimic the in vivo microenvironment. Both studies were basic research to understand the two biophysical cues, which eventually should be optimized and integrated into a platform for disease detection, diagnosis and treatment.

\section{Incorporating nanotopography into CTCs capture}

For nanotopography cue, we used adhesion preference on nanotopographies with various shapes and dimensions to capture tumor cells instead of culturing on flat substrate, which was inspired by the tremendous nanoscale structures inside human tissue. Our study provides useful information to optimize nanotopography to further improve tumor cells capture efficiency, which plays a major role in early cancer detection and diagnosis. Based on what we obtained from our results and the current research studies, there are multiple future aspects: optimization of shape and dimensions of nanotopographies, surface chemistry modification, surface biomarker conjugation, the use of artificial blood sample or patient blood sample and ultimately integration of nanotopography into a microfluidic device. 
Optimization of shape and dimensions. Motivated by the present work, the first path forward is going to be testing the different geometry and dimension of the nanotopography surface. In our study, we fabricated the representative nanopillars and nanogratings with specific dimensions to capture tumor cells. Results showed that the geometry did put an impact on the capture efficiency, which made the next step further be optimizing the nanotopography to further improve the cell adhesion, thus favored cell capture. Although nanogratings and nanopillars are representative ones, they are not the optimized ones. The optimization could focus on increasing cell-nanotopography interactions and facilitating focal adhesion formation. The previous reported RIE generated nanoroughened surface could achieve a capture efficiency up to $95 \%$ within 1 hour (see Figure 4-1). ${ }^{1}$ One of the reasons that such a high capture efficiency could be reached was the nanoroughened, chaotic structure that has been generated by RIE that largely enhanced the celltopographical interactions. Another reason might need to be taken into consideration was that the material they used was glass instead of PDMS in our study. PDMS is hydrophobic and typically inert to cell adhesion, whereas glass is more hydrophilic. The material that is used to perform the CTCs capture could also be carefully selected and modified. 

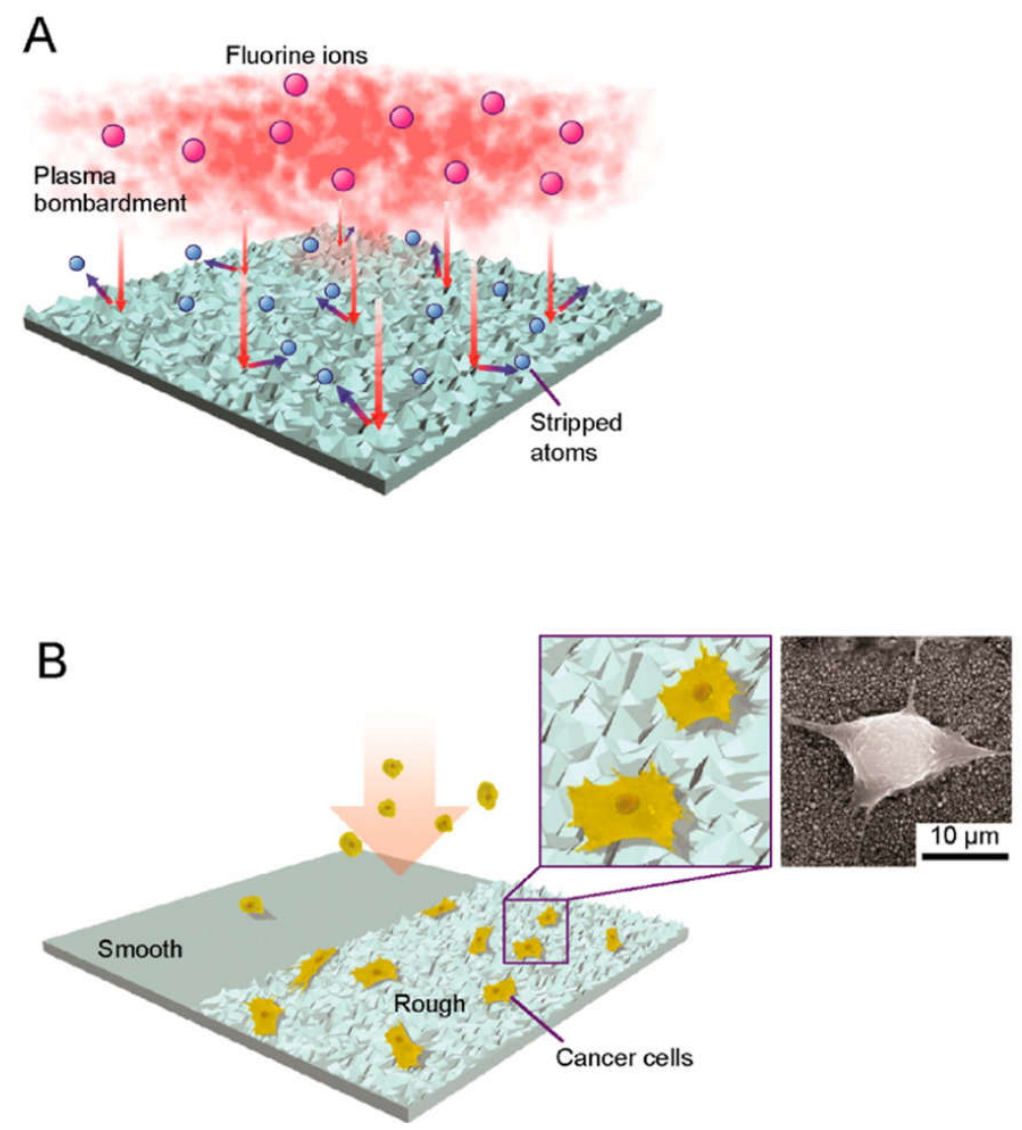

Figure 4-1: RIE generated nanoroughened surface for cancer cell capture. (A) The process of generating nanotopography on glass surface by RIE. (B) Schematic of nanotopography fabricated by RIE on glass surface compared to smooth surface and the cell capture performance on each substrate, respectively. Enlarged views show cell captured on the illustrated nanotopography (left) and SEM (right) micrographs of cancer cells captured on nanoroughened glass surfaces. (Reproduced with permission from Ref. [1])

Surface chemistry. As previously mentioned RIE generated nanoroughened surfaces, while it created a nanotopography surface to enhance the cell-topographical interaction, the RIE treatment could also chemically activate the surface, thus favoring cell adhesion (see Figure 4-1). 
Surface biomarker conjugation. The next future direction could focus on shortening the capture time by conjugating surface biomarkers on the nanotopography surfaces to capture specific tumor cells. As shown in our results, the capture time used was $4 \mathrm{~h}$, which was not fast enough to capture or detect CTCs. However, the importance of early diagnosis has a substantial influence on the disease treatment and patient survival. For example, statistics showed that the number of survived women who diagnosed with breast cancer at the earliest stage is 6-fold compared to that who diagnosed at the advanced stage. ${ }^{2}$ Based on our findings that 500-1x-150 nanogratings could enhance the adhesion of tumor cells, thus enhanced the capture efficiency, it is possible to shorten the capture time by chemically modifying the surface of the optimized nanogratings. Because, as previously mentioned in Chapter 2, the most widely used CTC capture techniques rely on positive selection based on surface biomarkers such as EpCAM expression on tumor cells. ${ }^{3}$ Besides EpCAM, there are various surface markers that expressed by different types of CTCs, which has been widely used for CTC isolation for cancer diagnosis. ${ }^{4}$ By identifying the specific biomarker that expressed on CTC to justify the proper antibody that could be conjugated to the surface, the capture efficiency is expected to be improved. By combining the topographical modulation and the chemical modification, the capture time could expect to be shortened and the capture efficiency is going to be further improved.

The use of artificial blood sample or patient blood sample and ultimately integration of nanotopography into a microfluidic device. The next step would be testing our system by using artificial blood sample, and ultimately, the optimized capture platform could be incorporated into the microfluidic system to largely mimic the dynamic blood flow. In real in vivo condition, CTCs are always circulating inside the bloodstream instead of static growing. The capture efficiency that obtained from static culturing was still substantially deviating the actual condition. 
The flow rate, shear stress in the dynamic culture condition would potentially change the outcome of the cancer cell capture and disease detection. Recently, a group reported a microfluidic CTC capture chip by using nanoroughened glass substrate and achieve a significantly high capture yield of CTCs from blood samples (see Figure 4-2). ${ }^{5}$

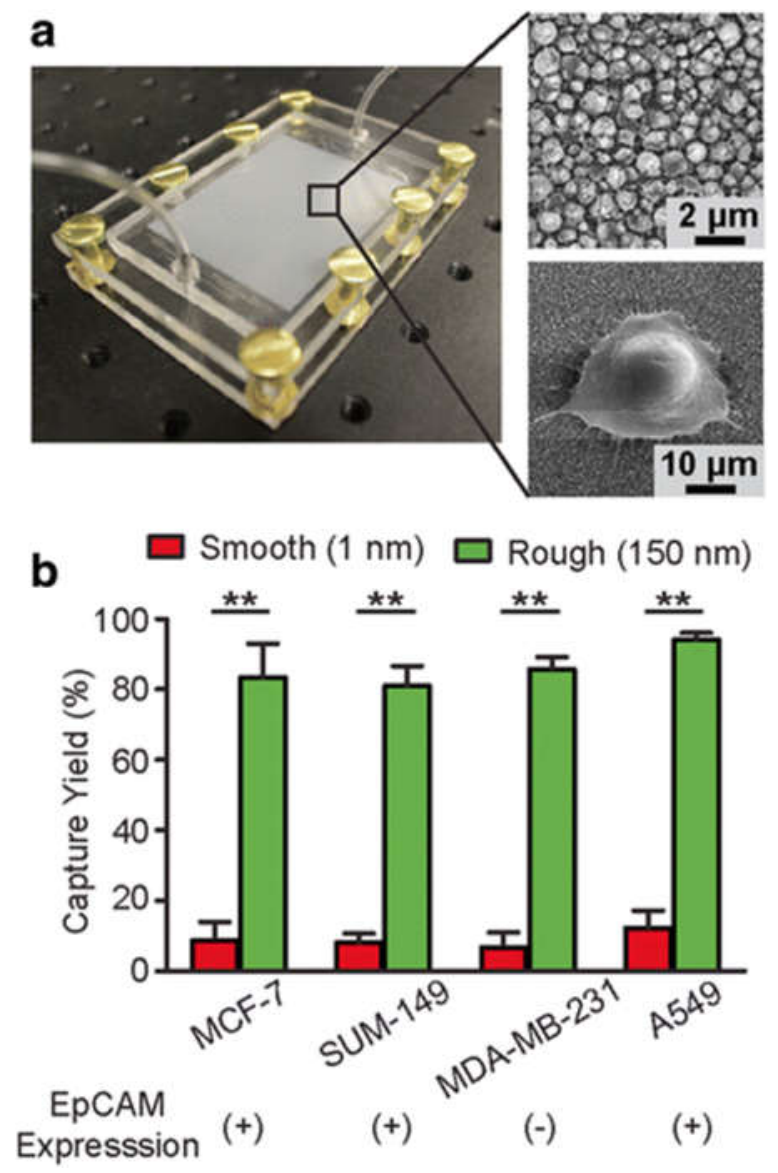

Figure 4-2: Nanoroughened surfaces incorporated microfluidic device for cancer cell capture. (a) Image for the cancer cell capture microfluidic device. The enlarged views show the SEM micrographs of the nanotopography surface (upper) and the cell captured on the nanotopography (lower). (b) Quantitative measurement of capture efficiency of cell captured on nanotopography compared with smooth substrates. The artificial blood sample was spiked with 1,000 cells for each 
cell type. $* *$ : significant difference $(\mathrm{p}<0.01)$ between groups. (Adapted with permission from Ref. [5])

\section{Incorporating stiffness into disease modeling}

For stiffness cue, we used both soft and stiff PAAm gel to represent normal and fibrotic lung tissue, respectively, to understand how the matrix stiffness affects cell sensing nanomaterials. Our findings suggested that substrate stiffness played an important role in modulating cell behaviors and function, including cell elongation, proliferation, fibrogenic response and mechanosensing, which established a basic understanding of how substrate stiffness affected cell behavior, leading the next step to land on incorporating stiffness cue into three-dimensional culture model, which advanced the current in vitro two-dimensional model and more closely mimic the in vivo condition. As in in vivo microenvironment, cells are embedded in multiple ECM components whereas in our model, cells were cultured on top of the substrate with various stiffness, which was essentially a two-dimensional model. Technically speaking, the identification of whether cells are cultured under two-dimensional or three-dimensional condition is based on how adhesion proteins are formed, where under two-dimensional they are formed on the top of the cells and around the cells from all 360 degrees under three-dimensional condition (see Figure 4-3). ${ }^{6}$ 
Collagen-coated glass (2D)

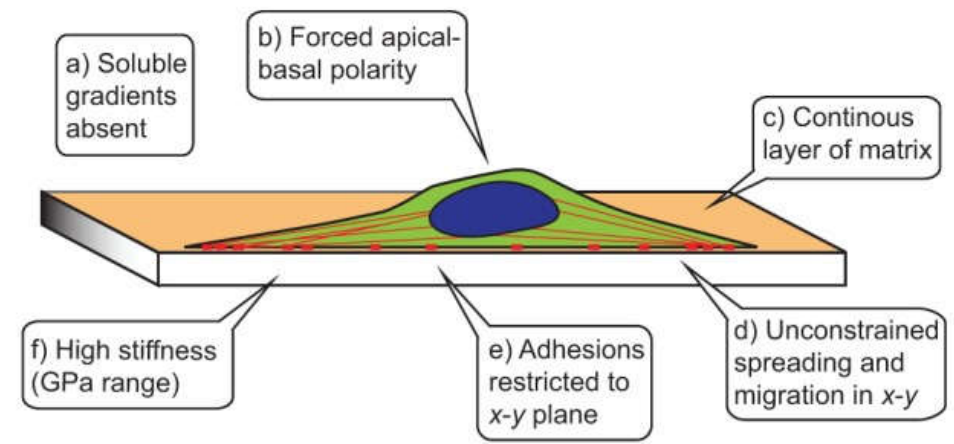

Collagen gel (3D)

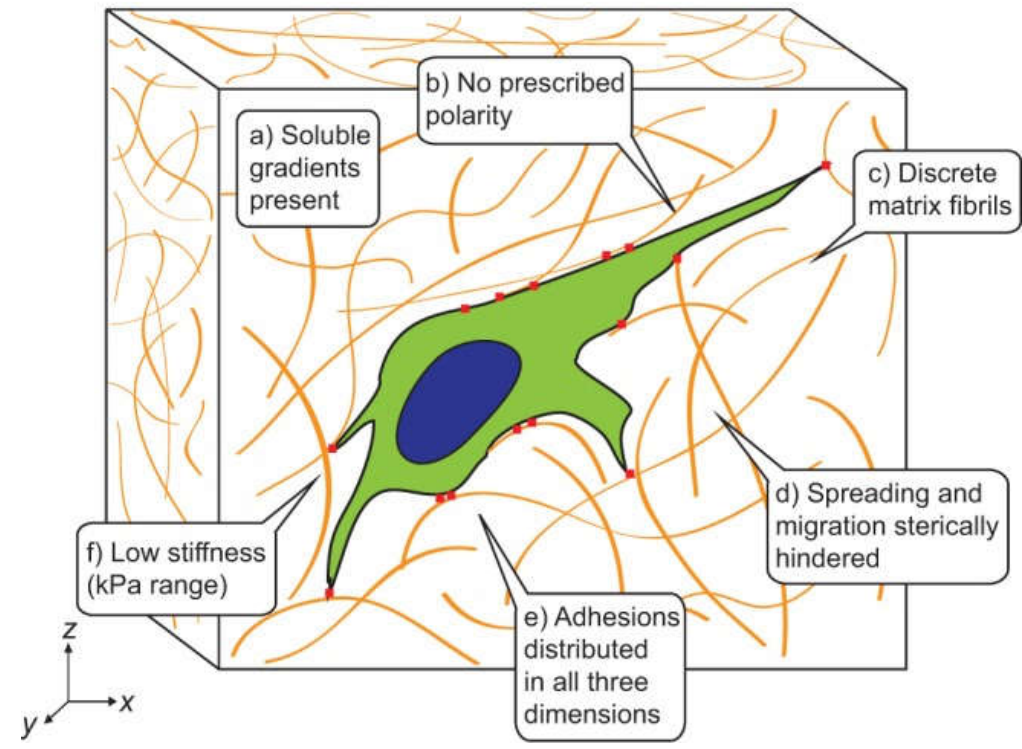

Figure 4-3: The difference between 2D culture (collagen-coated glass) and 3D culture (collagen gel) in regard to adhesion, polarity, spreading, matrix distribution and matrix stiffness. This illustration shows that the parameters cell are faced with under these two culture conditions are substantially different because of the dimensionality. (Adapted with permission from Ref. [6])

Currently, there have been more and more in vitro study that shifted their focus from traditional two-dimensional culture to three-dimensional culture to better understand how cell responses to the surrounding environment and the mechanical properties of the matrix. ${ }^{7}$ As cell behavior could possibly be altered by the variation of cultural environment. For example, as our 
study suggested that when cultured on PAAm gel, the increase in substrate stiffness could enhance cell elongation and spreading, where the results seemed counterintuitive while incorporating the system into three-dimensional culture. A studied has shown that valvular interstitial cells (VICs) encapsulated in soft gels expressed more actin fibers while in stiffened gels, there was no obvious exhibition of $\alpha$-SMA or F-actin fibers. ${ }^{7}$ This results confirmed what previously proposed that cell behaviors could be affected and changed by the alteration of culture dimensionality.

Moreover, the future model establishment may combine both nanotopographical cue and stiffness cue as they both serve important functions in the composition of the ECM. For example, one study that incorporated both nanotopography cue and stiffness cue by embedded Calu-3 and MDCK-II cells in Matrigel that was composed of important proteins existed in the ECM like laminins, collagen IV, and entactins. ${ }^{8}$ The cells were cultured on fabricated nanograss substrates. Results showed that this model could reflect the cell microenvironment as the cells formed tissuelike structures that were similar to their morphologies in vivo. ${ }^{9}$

Finally, the ultimate direction for our work would be the establishment of "organ-on-achip", which incorporates everything into microfluidics to conduct three-dimensional dynamic culturing. Although the current three-dimensional in vitro model has advanced applications in closely replicating the in vivo microenvironment for disease study, it still has the intrinsic limitation of being a static model. The ECM in the human body is a dynamic environment with numerous substance and signal exchanges that happen all the time. Cells that are embedded into three-dimensional culture model without external flow are normally lack of the mechanical cues including the shear stress, physical force, tension, ${ }^{10,11}$ which are crucial factors to the development of tissue and organ when analyzing the disease model. ${ }^{12}$ In the perspective of introducing fluid and to overcome the limitations of the current three-dimensional model, the recent development of 
microfluidic-based organ-on-a-chip attracts substantial interests across the biomedical field including disease detection and modeling as well as drug development, ${ }^{13}, 14$ including lung on a chip, ${ }^{15,16}$ kidney on a chip, $,{ }^{17}, 18$ liver on a chip, ${ }^{19,20}$ and body on a chip. ${ }^{21}$ Figure $4-4$ here listed several microfluidic chips that mimic the different organs in human body. ${ }^{22}$

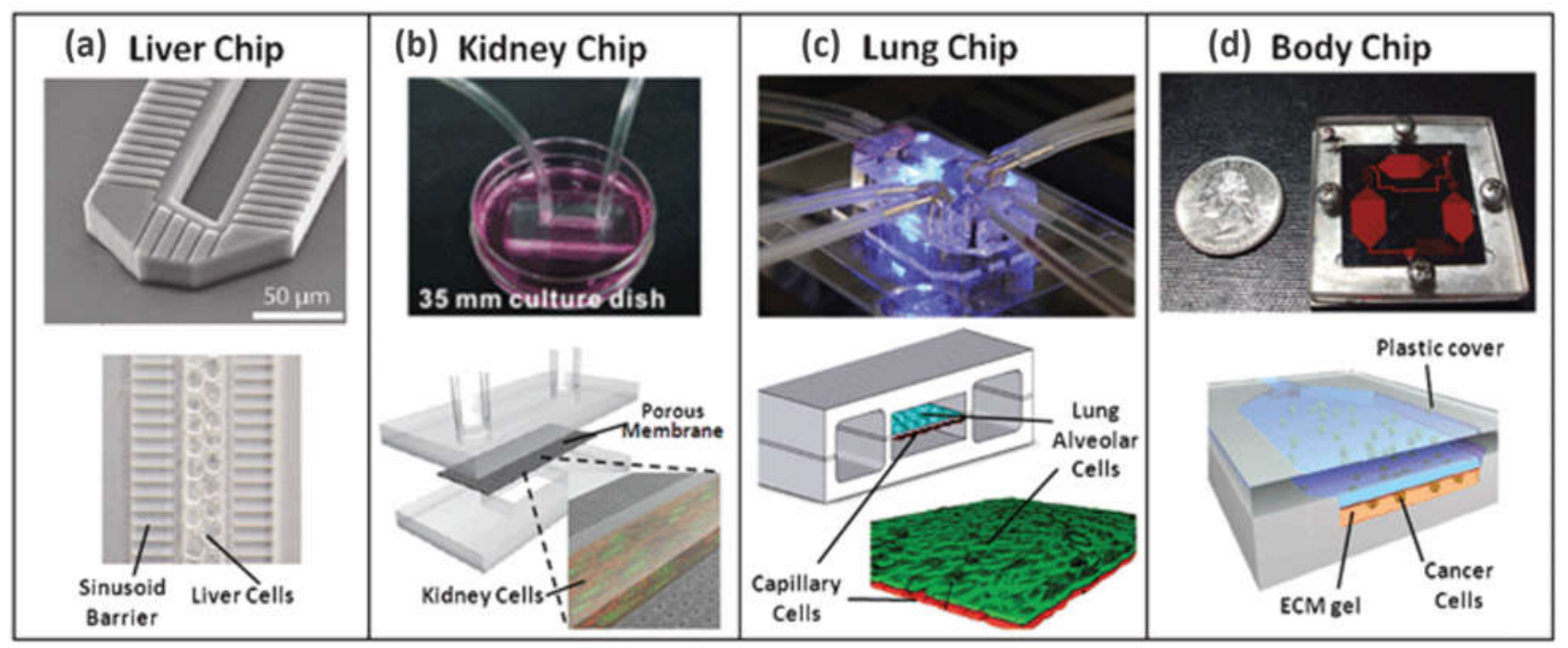

Figure 4-4: "Organ-on-a-chip" microfluidic devices that were fabricated to mimic tissue microenvironment for different disease models. (Reproduced with permission from Ref. [22]) (a) Liver Chip: The liver-on-a-chip microfluidics device was designed to mimic the hepatic cords structure in liver tissue. The cell culture area and the medium flow channel was divided by an endothelial-like barrier. This specific design made it possible that the rat primary hepatocytes formed a two line alignment which the formation of bile canaliculi along the hepatic cords-like structure could be largely facilitated. ${ }^{19}$ (b) Kidney Chip: The kidney-on-a-chip microfluidics device was designed to mimic the tubular microenvironment in vivo for primary rat inner medullary collecting duct (IMCD) cells. This particular multi-layer microfluidics design incorporated PDMS channel and a porous membrane which was able to introduce fluid flow for 5 hours. ${ }^{17}$ (c) Lung Chip: The lung-on-a-chip microfluidics device was designed to create a 
physiologically relevant model to mimic the alveolar system of human lung organ. The alveolarcapillary barrier was formed between two PDMS compartments on a porous membrane. This specific bioinspired microdevice also had the capability of mimicking the breathing movement, which had the potential application in nanotoxicity studies to test the lung inflammatory responses to silica nanoparticles. ${ }^{15}$ (d) Body Chip: The body-on-a-chip microfluidics device was designed to regenerate the in vivo microenvironment that reproduced organ-organ interactions. To achieve the desired purpose, different types of cell lines representing the liver, tumor, and marrow were embedded in the three-dimensional collagen hydrogel that was linked by the media flow of the microchannel that mimicked the blood flow. The specific type of the design had great potential by replicating organ-organ interactions, establishing a new platform for in vitro disease detection and modeling in a more realistic, in vivo-like microenvironment. ${ }^{21}$

This research direction of incorporating nanotopographical cue and substrate stiffness cue to build an organ-on-a-chip model should be based on optimizing the previous results for twodimensional study and three-dimensional static study, choosing the suitable conditions for threedimensional dynamic microfluidic study, which will ultimately provide great insight and useful reference for disease detection and modeling. The "organ-on-a-chip" microdevices that integrated biophysical cues could have the large potential of expanding the current cell culture in vitro models and providing the feasible alternatives to lower the cost of expensive in vivo animal models. ${ }^{15}$ 


\section{References}

1. Chen, W. Q.; Weng, S. N.; Zhang, F.; Allen, S.; Li, X.; Bao, L. W.; Lam, R. H. W.; Macoska, J. A.; Merajver, S. D.; Fu, J. P. Nanoroughened surfaces for efficient capture of circulating tumor cells without using capture antibodies. ACS Nano 2013, 7 (1), 566-575.

2. Cancer Research UK, Breast cancer survival statistics. http://www.cancerresearchuk.org/health-professional/cancer-statistics/statistics-by-cancertype/breast-cancer/survival (accessed 07/01/2017).

3. Armstrong, A.; Eck, S. L. EpCAM: a new therapeutic target for an old cancer antigen. Cancer Biology \& Therapy 2003, 2 (4), 320-6.

4. Kemmner, W. Currently used markers for CTC isolation-advantages, limitations and impact on cancer prognosis. Journal of Clinical \& Experimental Pathology 2011, 40.

5. Chen, W.; Allen, S. G.; Reka, A. K.; Qian, W.; Han, S.; Zhao, J.; Bao, L.; Keshamouni, V. G.; Merajver, S. D.; Fu, J. Nanoroughened adhesion-based capture of circulating tumor cells with heterogeneous expression and metastatic characteristics. BMC Cancer 2016, 16, 614.

6. Baker, B. M.; Chen, C. S. Deconstructing the third dimension - how 3D culture microenvironments alter cellular cues. Journal of Cell Science 2012, 125 (13), 3015-3024.

7. Caliari, S. R.; Vega, S. L.; Kwon, M.; Soulas, E. M.; Burdick, J. A. Dimensionality and spreading influence MSC YAP/TAZ signaling in hydrogel environments. Biomaterials 2016, 103, 314-323. 
8. Kleinman, H. K.; McGarvey, M. L.; Hassell, J. R.; Star, V. L.; Cannon, F. B.; Laurie, G. W.; Martin, G. R. Basement membrane complexes with biological activity. Biochemistry 1986, 25 (2), 312-8.

9. Shen, Y.; Hou, Y.; Yao, S.; Huang, P.; Yobas, L. In vitro epithelial organoid generation induced by substrate nanotopography. Scientific Reports 2015, 5, 9293.

10. Mammoto, T.; Mammoto, A.; Ingber, D. E. Mechanobiology and developmental control. Annual Review of Cell and Developmental Biology 2013, 29, 27-61.

11. Ingber, D. E. Mechanobiology and diseases of mechanotransduction. Annals of Medicine 2004, 35 (8), 564-77.

12. Bhatia, S. N.; Ingber, D. E. Microfluidic organs-on-chips. Nature Biotechnology 2014, 32 (8), 760-772.

13. Benam, K. H.; Dauth, S.; Hassell, B.; Herland, A.; Jain, A.; Jang, K. J.; Karalis, K.; Kim, H. J.; MacQueen, L.; Mahmoodian, R.; Musah, S.; Torisawa, Y. S.; van der Meer, A. D.; Villenave, R.; Yadid, M.; Parker, K. K.; Ingber, D. E. Engineered in vitro disease models. Annual Review of Pathology 2015, 10, 195-262.

14. Huh, D.; Kim, H. J.; Fraser, J. P.; Shea, D. E.; Khan, M.; Bahinski, A.; Hamilton, G. A.; Ingber, D. E. Microfabrication of human organs-on-chips. Nature Protocols 2013, 8 (11), 21352157. 
15. Huh, D.; Matthews, B. D.; Mammoto, A.; Montoya-Zavala, M.; Hsin, H. Y.; Ingber, D. E. Reconstituting organ-level lung functions on a chip. Science (New York, N.Y.) 2010, 328 (5986), $1662-1668$.

16. Huh, D.; Leslie, D. C.; Matthews, B. D.; Fraser, J. P.; Jurek, S.; Hamilton, G. A.; Thorneloe, K. S.; McAlexander, M. A.; Ingber, D. E. A human disease model of drug toxicityinduced pulmonary edema in a lung-on-a-chip microdevice. Science Translational Medicine 2012, 4 (159), 159 ra147.

17. Jang, K. J.; Mehr, A. P.; Hamilton, G. A.; McPartlin, L. A.; Chung, S.; Suh, K. Y.; Ingber, D. E. Human kidney proximal tubule-on-a-chip for drug transport and nephrotoxicity assessment. Integrative Biology 2013, 5 (9), 1119-29.

18. Wei, Z.; Amponsah, P. K.; Al-Shatti, M.; Nie, Z.; Bandyopadhyay, B. C. Engineering of polarized tubular structures in a microfluidic device to study calcium phosphate stone formation. Lab on a Chip 2012, 12 (20), 4037-40.

19. Nakao, Y.; Kimura, H.; Sakai, Y.; Fujii, T. Bile canaliculi formation by aligning rat primary hepatocytes in a microfluidic device. Biomicrofluidics 2011, 5 (2), 22212.

20. Knowlton, S.; Tasoglu, S. A bioprinted liver-on-a-chip for drug screening applications. Trends in Biotechnology 34 (9), 681-682.

21. Sung, J. H.; Shuler, M. L. A micro cell culture analog (microCCA) with 3-D hydrogel culture of multiple cell lines to assess metabolism-dependent cytotoxicity of anti-cancer drugs. Lab on a Chip 2009, 9 (10), 1385-94. 
22. Huh, D.; Torisawa, Y. S.; Hamilton, G. A.; Kim, H. J.; Ingber, D. E. Microengineered physiological biomimicry: organs-on-chips. Lab on a Chip 2012, 12 (12), 2156-64. 